Portland State University

PDXScholar

$5-1973$

\title{
Personality correlates of interpersonal perception in a residential treatment center for adolescent girls
}

\author{
Raymond Paul Micciche \\ Portland State University \\ Terrell Lynn Eheler \\ Portland State University
}

Follow this and additional works at: https://pdxscholar.library.pdx.edu/open_access_etds

Part of the Social Control, Law, Crime, and Deviance Commons, Social Psychology Commons, and the Social Psychology and Interaction Commons

Let us know how access to this document benefits you.

\section{Recommended Citation}

Micciche, Raymond Paul and Eheler, Terrell Lynn, "Personality correlates of interpersonal perception in a residential treatment center for adolescent girls" (1973). Dissertations and Theses. Paper 1728.

https://doi.org/10.15760/etd.1727

This Thesis is brought to you for free and open access. It has been accepted for inclusion in Dissertations and Theses by an authorized administrator of PDXScholar. Please contact us if we can make this document more accessible: pdxscholar@pdx.edu. 
PERSONALITY CORRELATES OF INTERPERSONAI PETCEDTION

IN A RESIDENTIAL TREATMENT CENTER FOR

ADOLESCENT GIRIS

by

RAYMOND PAUI MICCICHE

and

TERRELI LYNN EHELER

A practicum submitted in partial fulfillment of the requirements for the degree of

MASTER OF

SOCIAL WORK

Fortland State University

1973 


\section{This Practicum for the \\ Master of Social Work. Degree}

by

Raymond Yclul Micciche

and

Terreli Lynn Eheler

has been approved

May, 1973

Chairman, Practicum Committee

Committee Menber

Dean, Graduate School of Socia]. Work 
TABLE OF CONTENTS

Page

IIST OF TABLES • . . . . . . . . . . . . . V v

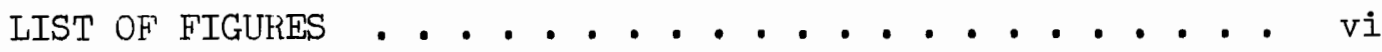

CHAPTER

I. INTRODUGTION . . . . . . . . . . . . . 1

The Etiology and 'Treatment of the Delinquent: An

Emerging Philosophy .. . . . . . . . . 3

The Role and Function of Residential Treatment • 5

Rational for the Study . . . . . . . . 9

Development of Focus . . . . . . . 10

Research Methods . . . . . . . . 12

Overview of Study .......... 13

II. REVIEW OF THE LITERATURE • . . . . . . • . 17

Interpersonal Perception: Interaction Between the

Self and Social Group . . . . . . . . . 17

Theoretical Orientation . . . . . . . 17

The Genesis of the Self . . . . . . 20

Interpersonal Perception . . . . . . 25

The Significance of the Self-Concept and Reference

Group in a General Theory of Delinquency . . . 36

The Self-Concept and Delinquency . . . . . 38

The Reference Group and Delinquency . . . . . 44

III. METHODOLOGY . . . . . . . . . . . . 56

Measurement of the Self-Concept . . . . . . 56 
CHAPTER Page

Interpersonal Perception ........ 64 Relational Analysis . . . . . . . 65 Sociometric Matrix Analysis . . . . . . 66 Interpersonal Perception as a Function of SelfConcept ................... 67

Administration of Data Gathering Instruments . . 69 IV. FINDINGS . . . . . . . . . . 71

Self-Concept, Ideal Self and Degree of SelfRejection ............... 72 Interpersonal Perception . . . . . . . 81 The Self-Concept and Interpersonal Perception . 87 Pathological Implications of Certain Self-Concept Types . . . . . . . . . . . 101 V. SUMMARY AND IMPLICATIONS . . . . . . . . 108 BIBLIOGRAPHY . . . . . . . . . . . . 117 APPENDICES . . . . . . . . . . . . . . 126 


\section{LIST OF TABLES}

Table

Page

1. Frequency Distribution of Self and Ideal Self-Concepts by Four Diagnostic Types . . . . . . . . . 76

2. Mean Self-Rejection Score by Four Types of Self-Concept with Computed T Values . . . . . . . . . . 77

3. Product-Moment Correlations Between Length of Stay and the Major Axes of Self and Ideal Self-Concepts . . . 80

4. Number of Affective Choices Given and Perceived as Given by the Residential Population in Response to Two Sociometric Questions . . . . . . . . 83

5. Mean Number of Affective Choices Given and Received by Type of Self-Concept . . . . . . . . . . .

6. T Values of Mean Differences Among Affective Choices Given and Received by Types of Self-Concept . . . . 91

7. Mean Number of Affective Choices Perceived as Given and Received by Type of Self-Concept . . . . . . . 95

8. T Values of Mean Differences Among Affective Choices Perceived as Given and Received by Type of SelfConcept .....................

9. Product-Moment Correlations Between Length of Institutional Stay and Two Components of Interpersonal

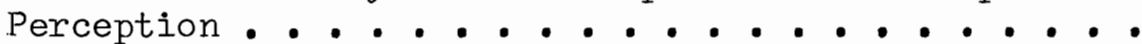

10. Role-Taking Accuracy: Mean Differences Between the Predicted and Actual. Number of Affective Responses Received From Others by Type of Self-Concept . . . . 103 


\section{LIST OF FIGURES}

Figure

1. Summary point diagnosis of self and ideal selfconcepts by descriptive octant . . . . . . . 58

2. Summary point diagnosis of self and ideal selfconcepts by major axes and descriptive quadrant . . 62

3. Mean summary point profiles of the residential population by self and ideal self-concepts . . . . 73

4. Manipulative orientations by four diagnostic types of self and ideal self-concepts . . . . . . 74 


\section{CHAPTER I}

\section{INTRODUCRION}

It has become too easy to see that the luckless men of the past lived by mistaken, even absurd beliefs; so we may fail in a decent respect for them and forget that the historians of the future will point, out that we too lived by myths.

\section{--Herbert J. Muller ${ }^{1}$}

While men do indeed construct self-validating and often peculiar interpretations of the realities of their world the simple fact that these views become consensually shared doctrines of experience does not protect them from the revisionism of historical scrutiny. These perceptions of the world become retrospectively altered as developing bodies of knowledge reject them as being clearly deceptive or anachronistic. The concept of psychopathology, distinguished historically under many mbrics, has not been immune to these same processes of modification, nor has it ever been free of the diverse irrationalities which men of all ages have constructed to explain the etiology and treatment of deviant behavior. Historically, consideration of atypical behavior all reflect attempts to explain dysfunction utilizing existing systems of belief and knowledge. For example, primitive and ancient societies advanced quasi-theoretical frameworks that stressed either external causation (e.g. spirit intervention, sorcery, demonic possession, lunacy, bewitchment) or personal 
causation (e.g. loss of soul, breach of taboo, object intrusion, brain disease).2

Of course, retrospective evaluation of these explanatory devices have found them to be woefully impoverished. With the advent of science these archaic beliefs were found to be incompatible with a rational view of the world where all events had logical and determinable causes. Moreover, with the development of the medical model of disease, aberrant behavior, of a functional nature, could be explained and treated in the same systematic manner as that which had an organic basis. While the "new view" still distinguished between external and internal causation of psychopathology, it radically redefined explanatory concepts and apparently located dynamics of the disease process within the individual. The classic psychiatric/psychological approach has (and continues to) stressed the description and classification of pathological signs and symptoms and when etiology was considered, illness was accounted for more often than not by such intrapsychic factors as anxiety, stress, breakdown of defense mechanisms and ego strength.

Current theories of psychopathology have not been quite as' oblivious to the effects of the individual's environment in the production and maintenance of both functional and organic illness. Nor can they be, for the last two decades have witnessed a growing awareness of the purely sociological aspects of pathological processes--processes which had hitherto been assigned only to individual defects. Research in the social epidemology of mental 
illness has established the importance of numerous sociological variables including ecological and socioeconomic status factors, 3 personal and social characteristics, 4 and culture-specific factors. 5 It is now commonly recognized that the environment of the individual plays a crucial role in determining the characteristics and course of pathological processes.

\section{THE ETIOLOGY AND TREATMENT OF THE DELINQUENT:} AN EMERGING PHILOSOPHY

Despite the implications of the foregoing research, the assumption that pathology is, in a terminal sense, related to an individual imperfection is a pervasive one. This assumption is clearly manifested in prevailing treatment technologies which often neglect viewing deviant behavior as a product of the larger social system and particularly the network of interpersonal relationships within which the individual is inextricably embedded. That is to say, the individual is frequently "treated" as an isolated agent, seperate from the larger system of social relationships that have developed and maintained behavioral processes.

As is the case with the larger concept of deviant behavior, the understanding of etiology and treatment of delinquent pathology continues to suffer from an overemphasis upon intrapsychic antecedents. Again, although there exists clear evidence regarding the social/environmental precipitants of delinquency ${ }^{6}$ the preeminence of the medical model and the related Freudian orientation reflect and focus upon individual causation: "from the study of neurosis and their emotional manifestations, it was, 
then, but a short jump to the viewing of delinquent behavior as a symptom of some underlying emotional conflict."? By contrast, a thoroughly sociological interpretation of delinquent behavior seriously questions "the emphasis placed on personality development - . as the major immediate causative factor in delinquent behavior." 8

Despite the prevalence of the psychiatric or individualistic conception of delinquency, research implicating the role of the environment has led to a reformulation of theory regarding etiologic and treatment dynamics. It seems clear that one cannot logically assert the role of one's environment in the etiology of pathology and continue to direct treatment effort primarily within the psychological realm. On the other hand, an exclusive interpretation of delinquency based only on sociological premises neglects the very real contribution of individual psychological factors in the same process. In this regard Cohen notes, that while the literature on delinquency theory consists substantially of arguments between competing "psychological" and "sociolog⿳亠丷厂ıcal" positions, each considered separately, oversimplifies the complex interactive nature of the phenomenon:

Any act--delinquent or otherwise depends on 'something about the actor,' that is, something about his goals, his interests, his tempermant, or, speaking inclusively, his personality, and it depends also on 'something about the situation' (i.e. environment) in which he finds himself.9

It is precisely because of the impossibility of separating the sociological from the psychological that a combined sociopsychological theory of delinquency has emerged. The foundation of this 
approach is predicated upon the notion that personality is generated through interaction and consists of self-other systems. It stresses the fact that interaction with other persons provides the individual with definitions of himself (i.e. his self concept) and other objects in his environment. These definitions guide and direct behavioral expression:

Each person's orientation toward his human environment is formed and sustained in social interaction; his sentiments toward himself as well as other people are organized while he is learning to cope with specific people.10

Many of the significant studies based on this sociopsychological orientation have stressed the role of group processes involving the interaction of self and the setting of group activity in the production and inhibition of delinquent behavior. A more detailed discussion of this process will be taken up in a subsequent chapter. Suffice it to say here, that a sociopsychological theory of delinquent behavior provides a most illuminating, though frequently neglected rational for the existence of residential centers.

The Role and Function of Residential Treatment

Within this broad interactionist theory of delinquency lies the nucleus of some of the more contemporary and innovative correctional programs directly concerned with child welfare. If deviant behavior is conceived as the product of some complex interactive process involving the personality of the individual and his environment (particularly his wider network of significant social relationships) then treatment must, necessarily, include 
the manipulation of both factors simultaneously. This orientation represents the guiding rational which has inspired not only community involvement in the rehabilitation of delinquent youth but also the implimentation of broad scale community mental health programs. Here, removal of the deviant from the community--his environment as it were--is not seen as therapeutic, simply because the deviant is the community: his deviance is implicated in a more extensive system of social structures and relationships from which he cannot be detached.

The same theoretical orientation characterizes those correctional programs which elect to temporarily remove the delinquent from his immediate environment in order to restructure or create an environment that is uniquely therapeutic. Typically conceived as group oriented programs, ${ }^{11}$ these residential treatment centers were established on the premise that with intensive group methods rehabilitation could be accomplished in less than one year. Programming is simple and designed to emphasize the problem solving, the decision making, and the control effects of the group.

A major assumption for treatment intervention is to make the delinquent group the target for change; that is, attempt to change shared standards, points of view, rewards and punishments. In its most popularized form this process amounts to a creation of a "therapeutic milieu" wherein individual growth and change are inextricably linked to a number of environmental factors peculiar to a given institutional setting. For an individual, a milieu includes the totality of social structures and interpersonal 
systems directly or indirectly impinging upon him. Significant transactional factors in the manipulation of personality and environment include: the social structure of the residential institution including roles, status, and communication networks among staff and residents; an operative value system; routines, rituals, regulations and the impact of group process. 12

This is certainly an oversimplified version of specifically what milieu treatment is; however, it is not our task to define the concept further nor is it to delineate "how" milieu therapy works. The important point to note in this discussion, and one that is crucial to the research focus of this paper, is that a technology of intervention in residential settings depends on some complex jnteraction betweer the unique individual (personality) and the social system and structures (environment) created within the setting.

Research in Residential Settings. The foregoing socicpsychological corceptualization of treatment indicates the greater concern with the fossibility of treating problematic persons through the planned management of the structure and processes of the situations in which they live. There exists, however, a paucity of empirical investigation of the residential unit. In part, this dilemma reflects the fact that each residential unit is a unique entity creating a similarly unique milieu within which treatment proceeds. Investigation of one unit and results thereby derived do not necessarily lend themselves to valid generalizations. A more significant impediment to research, however, derives 
from the complexity of the milieu concept in theory and practice:

Milieu therapy means many things to many people. It is reasonably safe to assume that the bulk of prograins presently in operation or proposed ror financial support that are alleged to be milieu therapy are little more than ad hoc tinkering with a naively perceived 'environment' or forlorn attempts to make institutional life fit the model of individual clinical treatment. Too many people are ready to assume that because they are experts in the complexities of the human organism or its intrapsychic dynamics, they are equally perceptive and skilled in conceptualization and analysis of what takes place at interpersonal, organizational, and cultural levels. Authorities in clinical fields who insist upon sophisticated conceptualizations and methods in their own areas of competence frequently appear quite ready to rely on shoddy and naive thinking and bumbling, if well-intentioned activity when it comes to dealing with the interactive processes of the institutional community. 13

Beyond the conceptual deficits outlined above, productive research in such settings is often limited by an ill-conceived set of research objectives. We maintain that at least three interrelated questions must be articulated prior to or in the course of the research design. The first concerns the appropriate levels of intervention. What are the most significant milieu variables for study? Does one focus on the communication system of the unit, staff and resident value orientations, or some other variable(s)? Secondly, once the level of intervention is specified, which research methods are most appropriate? Should they be confined to participant-observation or should one attempt to construct rigorous quantitative models? Finally, recalling that the milieu concept considers both psychological and environmental factors, can one demonstrate associations between the two given a particular level of intervention and methodology? These are broad, but essential considerations of research focus--consider- 
ations which should ultimately lead, directly or indirectly, to the illumination of treatment design, function, and goals.

\section{RATIONAL FOR THE STUDY}

Although the term milieu therapy has been referred to in our discussion we make no assertion that Villa Saint Rose is or is not directly concerned with milieu therapy. As Redl clearly indicates, the elasticity of the concept and its ad hoc invocation by clinicians often renders it meaningless:

The cry for the therapelitic milieu as a general slogan is futile and in this wide formulation doesn't mean a thing. - . Ever a concept of (total milieu therapy) does not imply that all aspects of a given milieu, are equally relevant in all moments of clinical life. 14

Despite the ambiquity associated with the term, we maintain that Villa Saint Rose has, as do all institutional settings, a milieu. That is to say, an adolescent girl placed in this setting is not unaffected by the wider and often more covert environmental systems that would include her own peer group, staff relationships, implicit and explicit value orientations, and the existing treatment structure. It is precisely the lack of control over and failure to systematically understand the nature of these miliel variables that ultimately distinguish between the simple existence of a milieu and one that is therapeutic. The nature of a substantive research effort is not to explicate the total range of milieu phenomena characteristic of a particular setting nor is it to define whether the milieu is or is not a therapeutic one. Rather, it is to explain, and hopefully understand thoroughly a 
given milieu phenomenon.

\section{Development of Focus}

Recalling that the individual cannot be seen as :eparate from other environmental systems we have chosen to articulate the relationship between a psychological or individual variable and one that is clearly the product of the milieu at Villa Saint, Rose. At the milieu level we have confined our attention to the nature of the peer culture within the institution and, more specifically, to those aspects of the interpersonal choice process that develop, maintain, and perpetuate a peer culture. We take as a point of departure the realization that the peer social system is a most significant environmental influence on the individual. Polsky has demonstrated the crucial importance of understanding this social system as a precondition to any effective therapeutic intervention:

- . it is possible for at least a significant segment of the residential population . . . to maintain and transmit a separate deviant subculture that supports values and a social system that are counter to those of the institution itself. . . For notwithstanding his intrapsychic characteristics . . residents find it necessary to adopt the values and patterns of the deviant subculture and to function in the role imposed on him by the group without regard to what occurs in the rest of the institution including clinical therapeutic sessions. 15

Although confining our attention to the peer social system at Villa Saint Rose we further delimit our focus in attempting to understand the phenomenon of interpersonal perception as it is manifest in a group setting. That is, by assuming the importance of interpersonal relationships among the residents per se, it becomes necessary to examine the conditions for the existence of 
such relationships. The structure of these conditions is fully explained in Chapter III.

At the individual or psychological level of analysis we are principally concerned with gaining a broader understanding of the personality structure of the resident and how this factor is associated with certain aspects of the perceptual processes within the peer social system. Again, where Folsky emphasized the impact of the peer culture upon the individual, Redl emphasizes the equal importance of the personality characteristics of the individual that tend to exploit the existing peer culture. It is worth examining in some detail Redl's understanding of these interrelated processes. Discussing the affinity toward gang formation and mob psychology in a residential setting he states:

With the science of group psychology as undeveloped as it is, we sometimes feel full of envy when we observe some of our youngsters developing a nearly uncanny instinct for sizing up group situations for the delinquency support they might render. Such children will naturally drift. into the type of group atmosphere which is clearly that of a gang structure, or they will skillfully produce, or at least exploit, the phenomenon of 'mob psychology'. There are . . rich possibilities which specific group atmospheres offer the delinquent child. Especially does the sudden breakdown of inhibitions, reality appraisal, personal affectional ties which even otherwise well functioning groups suffer under the impact of excitement or group psychological intoxication, lend itself to a masterful pickup by the delinquert manipulator. He is able to get others and himself into more delinquent activity under those conditions than even he would dare or would be able to devise under other circumstances. This phenomenon is intensified when a number of children with delinquent egos live together in a group to begin with and when they have a chance to solidify their individual delinquent defenses into something like an officially recognized 'group code'. It is as though those youngsters knew that submergence into a delinquent group code would be the best antidote against the remainders of their individual superego demands, which might hamper their guilt-free enjoyment of delinquent fun. 16 
Clearly then, a psychological as well as an environmental analysis must accompany any attempt to explicate a given milieu phenomenon for they are mutually interdependent. At the psychological level then, we have chosen to examine the resident's ego attitudes or self-concept. Note here that a purely psychological. analysis is valuable only insofar as it permits us to understand the personality composition of the total residential group. However, it does not allow us to explain group phenomenon unless we can isolate the group factor for analysis and demonstrate interrelationships between the two levels. This we have attempted to do by examining certain aspects of the residents perceptual. system and treating it as a function of the individual's self-concept.

\section{$\underline{\text { Research Methods }}$}

There is little agreement regarding specifically what constitutes "appropriate" research methods in residential settings. Existing paradigms range from the participant-observation technique, best exemplified by Polsky's Cottage Six, wherein the researcher is required to achieve intimate contact with the residential community, to more elaborate quantitative designs such as the now-classic sociometric studies of Moreno, Jennings, and Lundberg and Lawsing. 17 Despite the limitations of quantitative statistical designs a number of considerations influenced our decision to utilize quantitative methods.

The exploratory nature of this study, although not designed to test any a priori hypothesis, does seek to provide a foundation for further research into the peer social system at Villa Saint 
Rose. With respect to an analysis of this system we have utilized a. sociometric technique which is well suited to collect large amounts of numerical data regarding aspects of interpersonal perception. Quantification at this level permits a more useful description of the phenomenon at hand than less rigorous methods do. Furthermore, the use of a personality inventory to measure self-concept is itself given to quantitative as well as descriptive formulation. This same inventory is currently used by staff at Villa Saint Rose for a clinical assessment of the individual girl; however, there is little knowledge regarding its empirical and predjctive significance. By demonstrating its quantitative utility in this study we hope to provide some validation for its continued use.

\section{Overview of the Study}

Any research effort must reflect a theoretical base, however vague, which directly or indirectly validates a given interventive strategy. Since this study is largely concerned with the selfconcept and peer group phenomena, the review of the literature is intended to illuminate their collective significance ins 1) a general theory of the self and interpersonal perception and 2) a specific understanding of adolescence and delinquency.

Our methodology reflects an attempt to answer three related questions: 1) what is the nature of the self-concept as manifested in this residential population; 2) how are the theoretical components of interpersonal perception operationalized within the interactive network of the residential peer group and 3) how does 
the self-concept influence defined aspects of interpersonal perception?

The section on methodology, apart from its broader intent to construct a design to test the above questions, is quite useful in assessing the application of large scale data collection devices in a residential setting. Finally, we believe that this research has provided a useful foundation with which to continue exploration of the residential treatment unit at Villa Saint Rose. 
CHAPTER NOIES

1. Herbert J. Muller, Freedom in the Western World: From the Dark Ages to the Rise of Democracy (New York, 1963), pp. 40-41.

2. James D. Page, Psychopathology: The Science of Understanding Deviance (New York, 1971), Chapter 4.

3. See for example: Robert E. Faris, Social Disorganization (New York, 1948); Warren H. Dunham, "The Ecology of the Functional Psychosis in Chicago," American Sociological Review, 2(No. 4, 1937); August B. Hollingshead and Frederick C. Redlich, "Social Stratification and Psychiatric Disorders," American Sociological Review, 18 (No. 2, 1953); Bert Kaplan, Robert B. Reed, and Richard Wyman, "A Comparison of the Incidence of Hospitalized and Non-Hospitalized Cases of Psychosis in Two Ccmmunities, "American Sociological Revjew, 21 (No. 4, 1956).

4. See: Bertram H. Roberts and Jerome K. Myers, "Religion, National Origin, Immigration and Mental Illness," American Journal of Psychiatry, 110 (No. 5, 1954); Evelyn Ellis, "Social Psychological Correlates of Upward Social Mobility Among Unmarried Career Women," American Sociological Review, 19 (No. 5, 1952).

5. See: H.B. Murphy et-al., "A Cross-Cultural Survey of Schizophrenic Symptomatology," International Journal of Social Psychiatry, 9 (No. 4, 1963); John B. Enright and Walter R. Jaeckle, "Psychiatric Symptoms and Diagnosis in Two Subcultures," International Journal of Social Psychiatry, 9 (No. 1, 1963).

6. A number of environmental determinants such as socioeconomic status, social class, and familial factors have been associated with delinquent behavior. See for example: F. Ivan Nye, James F. Short Jr., and Virgin J. Olson, "Socioeconomic Status and Delinquent Behavior," American Journal of Sociology, 63 (January, 1958); Albert J. Reiss Jr., and Albert I. Rhodes, "Status Deprivation and Delinquent Behavior," The Sociological Quarterly, 4 (Spring, 1963); John P. Clark and Eugene P. Wenninger, "Socioeconomic Class and Area as Correlates of Illegal Behavior Among Juveniles," American Sociological

Review, 27 (December, 1962); Albert J. Reiss Jr., and Albert L. Rhodes, "The Distribution of Juvenile Delinquency in the Social Class Structure," American Sociological Review, 26 (No. 1, 1961); and Thomas P. Monahan, "Family Status and the Delinquent 
Child: A Reappraisal and Some New Findings," Social Forces, 65 (No. 3, 1957)。

7. Warrer H. Dunham, "The Juvenile Court: Contradictory Orientations in Processing Offenders," in Readings in Juvenile Delinquency, ed. Ruth Cavan (Philadelphia, 1964), p. 344.

8. Youth and Delinquency (Summary Report on Regional Hearings and Statewide Conference) (New York, 1956), p. 78. An excellent critique of the individlialistic orientation can be found in Michael Hakeem, "A Critique of the Psychiatric Approach to the Prevention of Juvenile Delinquency," Social Problems, 5 (No. 3, 1958).

9. Albert J. Cohen and James F. Short, "A Survey of Delinquency Theories," in Faces of Delinquency, eds. John P. Reed and Fuad Baali (New Jersey, 1972), p. 215.

10. Tamotsu Shibutani, Society and Personality (New Jersey, 1961), p. 556 .

11. Lamar T. Empey, "Contemporary Programs for Convicted Juvenile Offenders: Problems of Theory, Practice and Research," in Crime and Violence: A Staff Report on the Courses and Prevention of Violence (Washington D.C.: U.S. Government Printing Office, 1969), Vol. 13, pp. 1383-86, 1393-97, 1399-1404, 1407$1409,1412-14,1418-19$.

12. Fritz Redl, "The Concept of a Therapeutic Milieu," American Journal of Orthopsychiatry, 29 (No. 4, 1959).

13. Leonard S. Cottrell Jr., "Forward," in Howard W. Polsky, Cottage Six (New York, 1962), pp. 5-6.

14. Fritz Redl, "The Concept of a Therapeutic Milieu," pp. 722-723.

15. Cottrell, p. 6 .

16. Fritz Redl and David Wineman, Children Who Hate (New York, 1951), p. 186 .

17. Jacob L. Moreno, Who Shall Survive? A New Approach to the Problem of Human Interrelationships (Washington D.C., 1934); Helen H. Jennings, "Individual Differences in the Social Atom," Sociometry, 4 (No. 2, 1941); George A. Lundberg and Margaret Lawsing, "The Sociography of Some Community Relations," American Sociological Review, 2 (No. 3, 1937). 


\title{
CHAPTER II
}

\author{
REVIEW OF THE IITERATURE
}

\section{INTERPERSONAL PERCEPTION: INTERACTION BETWEEN THE SELF AND SOCIAL GROJP}

\section{Theoretical Orientation}

Perhaps no other area of personality theory has received more attention or been the object of as much controversy as that of the self. Conventionally referred to as the ego, this concept has acquired considerable prominence in the psychological literature. ${ }^{1}$ Although this literature includes a diversity of theoretical orientations, considered collectively they all reflect certain philosophical dispositions that have, historically, plagued all theoretical frameworks regarding the self. Philosophically, attempts to understand the nature of consciousness, particularly self-consciousness, have raised four competing perspectives. Essentially, these perspectives question whether or not the concept of self should be considered as 1) an existent fact or simply a convenient hypothetical construct, 2) the subject ("I") or the object ("me") of conscious experience, 3) structural in character or reflective process and 4) singular (self) or multiple (selves) in character. A complete discussion of these different perspectives is beyond the scope of this paper. The reader should be aware of them however, for they serve to indicate that identity 
is definitely not a simple matter of theoretical consensus. Our task here is to outline a theory of the self that is consistent with, and supports, the use of group treatment methods in residential settings.

The social/psychological orientation that influences our discussion of the self is known as symbolic interaction. 2 An interactionist theory of the self addresses itself to two major problems. The first is that of socialization: how does the individual acquire the ways of behaving, the values, norms, and attitudes of the social group(s) of which he is a part? The second problem concerns the basis for the organization of persistent behavior patterns. The directive intent of interactionist theory is to explain these questions in terms of an interaction between the self and other significant social relationships of the individual.

At least four assumptions characterize this position. First, interactionism is dogmatically anti-reductionist. It argues that valid principles of human social/psychological behavior cannot be derived from, or inferred from, the study of non-human forms, nor can they be reduced to and explained by the existence of a "psychic apparatus." Thus, interactionism is distinguished from the respective behaviorist and Freudjan orientations regarding the nature of the self. Second, any explanation of human behavior must be concurrent with the explanation of the social group: "the basic unit of observation is interaction and from interaction both society and the individual derive." 3 Third, human development is 
not simply given genetically or environmentally. The human infant is asocial in character, amorphous and plastic; it awaits organization through interaction with others. Finally, the human being is considered to be both actor and reactor; he simultaneously affects and is affected by others through interaction.

The major integrating concept within this theory is the principle human emergent of language behavior. Blumer succinctly summarizes the pivotal significance of language in social interaction:

- - symbolic interaction, refers of course, to the peculiar and distinctive character of interaction as it takes place between human beings. The peculiarity consists in the fact that human beings interpret or 'define' each others' actions. Their 'response' is not made directly to the actions of one another but instead is based on the meaning which they attach to such actions. Thus human interaction is mediated by the use of symbols, by interpretation, or by ascertaining the meaning of one anothers actions. This mediation is equivalent to inserting a process of interpretation petween stimulus and response in the case of human behavior. 4

In Blumer's view the most significant conclusion to be derived from this account of the human "act" of interpretation is that human beings have a self. However defined, self refers to activity, to reflexive activity, and not to an object, thing or essence. It is the product of the interaction of the individual within a wider matrix of social relationships. It is similarly amenable to modification within the same system of social relationships.

Although the concept of self is crucial to an interactionist theory of personality, it is one that is used cautiously:

The necessity of using the concept of self does not confer the privilege of misusing it. As we use concepts in our thinking they tend to get firmer and harder. Thought about 
fluid events tends to curdle and form solid clots. Before long we begin to think of the self as if it were a lump in the personality. It becomes a region, an institution, an entity. . . In the end the self is standing like a solid boulder of granite in the midst of personality and one's thinking about it is as flexible as granite. 5

\section{The Genesis of the Self}

It should be apparent that an interactionist conception of self does not begin with an analysis of the individual qua individual. Rather, it begins with an explanation of how cooperative group life is sustained. Any attempt to explain properties of the self (how it is generated, developed, and maintained) within this framework must specify the necessary conditions for the existence of cooperative social activity.

Unlike the biologically determined cooperative behavior characteristic of infrahuman social organization, sustained human interaction can occur only through a process wherein: 1) each acting individual ascertains the intention of others and then 2) makes his response on the basis of that intention. Human interaction, Meltzer states, "is not a matter of responding directly to the activities of others. Instead, it involves responding to the future, intended behavior of others . . not merely to their present actions." 6 some kind of mechanism, therefore, must exist which permits each acting individual to understand the "meaning" of others actions and guide his own behavior to fit in with the intended meaning.

The interpretation of the meaning of any given act is essentially a function of the role taking process. To understand the 
meaning of anothers act (e.g. a clenched fist means anger), the Individual must have learned to put himself in the position of the other person, must identify with him. Cooperative social interaction is based on the developed ability of human beings to respond symbolically to their own acts via the role-taking process.

This ability (role-taking) enables different human beings to respond in the same way to the same act, thereby sharing one anothers experience. . . Behavior is viewed as 'social' not simply when it is a response to others, but rather when it has incorporated in $1 t$ the behavior of others. The human being responds to himself as other person's respond to $\mathrm{him}$, and in so doing he imaginatively shares the conduct of others. That is, in imagining their response he shares that response.?

The development of the self is concurrent with the development of the ability to take roles. Simply stated, the possession of a self implies that an individual may act socially toward himself just as toward others. The role-taking process is most dramatically illustrated by considering what Piaget has termed the "egocentric" character of childish thought. 8 The entire intellectual development of the child from the time at which he can speak with relative adequacy to the point at which he acquires an approximately adult view of himself and the world, is described as a gradual process of overcoming this initial egocentric attitude. We shall see in a subsequent section that fallure in process represents an important basis of pathological adjustment.

The child is at first enclosed in his own point of view and sees all things from within 1t. His perceptions and judgements tend to be absolute or egocentric because he is unaware of any other points of view and perceptions. Because the child does not 
at first gxasp the role of others he tends to act in terms of short range egocentric goals. Learning to grasp other points of view, learning to become non-egocentric, is the crucial process in the genesis of the self. To the extent that a person is able to take the role of others, he can respond to himself from their perspective and hence, become an object to himself. With respect to the interactionist conception of self this role-taking process may be subsumed under two broad developmental stages: 1) play and games and 2) the generalized other.

In the play and game stage the actual playing of roles occur. In play, the child takes on a set of dual roles, his own and that of some other person (e.g. mother, teacher, mailman, etc.). Such activity gives the child an opportunity to explore the attitudes held by others toward himself. However, during play the young child's configuration of roles is unstable; he passes from one role to another in an unorganized and inconsistent fashion. At this early stage of development a person's self is constituted by an organization of the particular attitudes held by other persons toward himself and toward one another, in the contexts of those social acts he has explored in his play.

The game by contrast, is an example of "organized" social interaction. In it the child must have the attitudes of all the others involved in the game. The attitudes of the other players which the participant assumes, organize into a sort of unit, and it is that organization which controls the response of the individual: ". - each of his own acts is determined by his assumption 
of the action of others." 9 Thus, in the game the child goes beyond the particular attitudes of specific others. In the game, the other is an organization of the attitudes of those engaged in the same process or activity. The use of the term "game stage" is not intended to suggest that the development of the self occurs only through the agency of game playing. Rather, the game is a model of organized social activity in which the ability of an individual to function depends upon his knowledge of the complex role relationships among the participants.

The game stage is, in a sense, the completing stage of the self. In time, the child finds himself in situations wherein he must take a number of roles simultaneously. He must respond to the expectations of several people at the same time. The child can accomplish this task only by abstracting a "composit" role out of the concrete roles of particular persons.

In the course of his associations with others through play and games the child builds up a generalized other, a generalized role or perspective from which he views himself and his behavior. Through this process the child eventually learns the generalized attitudes of the community (group) of which he is a part. In effect, during the second stage in the development of the self, the individual experiences his social group as an organized community of attitudes, norms, values, and goals, which regulate his behavior and the behavior of others. The attitudes of the group become incorporated into the structure of the self, just as did the attitudes of particular others. Thus: 
- . It is in the form of the generalized other that the social process influences the behavior of the individuals involved in it. . . for it is in this form that the social process or comminity enters as a determining factor into the individuals thinking (i.e. self).10

Once the role taking process is firmly underway the reflexive character of the self is established. Society is, in effect, internalized. As a consequence of this process we note Mead's familiar distinction between "I" and the "me" as constituent elements of the self.

As a result of the internalization of the social act, the 'inner forum' comes into being. The organism rehearses internally various types of possible social relations. Mead denotes the internalized role of the other towards the beginnings of a response the 'me' . . . the 'me' is the other person's reaction, implanted within the organism towards the initial stages of the given organism's developmental actions. It is in this manner that it is possible for other people to influence permanently our lives. A person who is important to us is internalized in the form of a 'me' which modifies the course of our ongoing behavior. The altered or adjusted response of the organism to the imported reactions of the other is termed by Mead the 'I'-the ' $I$ ' is the response of the organism to the attitudes of others; the 'me' is the organized set of attitudes of others which one himself assumes. - . Personality is the resultant of the interaction between the ' $I$ ' and the 'me.'11

A number of major implications for selfhood in human behavior follow from an interactionist formulation. First, the possession of a self makes the individual a society in miniature. That is, he may engage in interaction with himself just as two or more different individuals might. In the course of this interaction, he can come to view himself in a new way, thereby bringing about changes in himself. Secondly, the ability to act toward oneself makes possible an inner experience which need not be overtly expressed. The individual by virtue of having a self is thereby 
endowed with the possibility of having a mental life. Finally, the individual with a self is enabled to direct and control his behavior. Instead of being subject to all impulses and stimuli directly playing upon him, the individual can check, guide, and organize his behavior.

\section{Interpersonal Perception}

The foregoing presentation delineates the nucleus of a theoretical approach which elucidates the importance of the social group to the development of the self. In fact, the self exists only in and through interaction with others. The social group(s) (family, peers, etc.), in effect, define for the individual the nature of the self; the interaction between the individual and social group circumscribes, validates and alters the self. As a result of the role-taking process the individual's perception of himself and others is concretely dependent upon continuous interaction with members of his human social group. Hare, Borgatta, and Bales summarize the crucial role of perception in this process:

Each of us intuitively understands the perspective of the individual in a social situation, since it is the same perspective from which each of us views his own world . . consequently, we are all concerned with the accuracy of our perception--that it should report the world to us now as we shall find it later. ${ }^{12}$ (itallos our's)

Thus, the perceptual processes that maintain the bond between self and others assumes some degree of importance in understanding the basis of social interaction. Indeed, the self is interaction.

With respect to a theoretical clarification of these concepts, Kinch $^{13}$ has systematically stated the relationship between the self 
and perceptual processes. The formalized theory is stated simply: the individual's self-concept emerges from social interaction and in turn, guides and influences the behavior of that individual. The relationship between the self and interpersonal perception are predicated lxpon the following assertions: 1) the self-concept is based on the individual's perception of the way others are responding to him, 2) the self-concept functions to direct behavior and 3) the perception of others' responses reflect the actual responses of these others.

The theoretical relationship between the self and perception yields several highly useful hypothesis. 14 First, the manner in which the individual perceives the responses. in intentions of others toward him will influence his behavior. Secondly, the manner in which others respond to the jndividual (actual responses) not only will affect his behavior but will also determine the way he sees himself (self-concept). Finally, the behavior that the individual emits will influence the way others respond to him.

At the outset it should be said that there have been no studies which independently or in combination totally validate all elements of the formalized theory. The partial support that does exist has been derived from two broad sources: 1) empirical/theoretical research efforts directed toward the explication of sociometric choice processes as a function of self-concept and 2) investigation of the perceptual basis of "adjustment" and its implications for understanding pathological conditions.

\section{Effects and Conditions of Interpersona.I Perception. Kuhn's} study, 15 utilizing one of the now classic measures of the self 
(The Twenty Statements Test), 16 attemipted to investigate the notion that the self represents a series of attitudes or plans of action the person holdss toward himself as a social object. That is, the self represents the internalized responses of others which the individual now holds toward himself. This study suggests that as an individual moves through the life cycle of alternative status-role relationships (and hence a different series of responses by others toward him), his self-conceptions change to reflect these different social relationships. Kuhn's study supports the interactionist hypothesis that the self-concept reflects the social relationships and activities that the individual is currently engaged in.

Miyamoto and Dornbush ${ }^{17}$ undertook a much more intensive analysis of the self as a correlate of interpersonal perception. These investigators isolate three key elements of the formalized theory for analysis: 1) that self-conception is the resultant of the responses of others in shaping self-definitions; 2) the significance of the response of the other in the definition cf the self and 3) the role of the gereralized other (e.g. peer group) in shaping self-definitions.

Subjects were instructed to rate their self-concept along the dimensions of intelligence, attractiveness, and likeableness. Having made these ratings, subjects then rated their significant others' (collectively and individually) conception of them along the same dimensions, and significant others made the same ratings on the subjects. This paradigm permits an assessment of the 
degree of accuracy with which subjects perceive (predict) the nature of the other's response (self-concept ratings). Moreover, it permits the investigation of the degree of congruence between how one sees himself and how others see him.

Partial confirmation was obtained for the hypothesis that there is greater agreement between one's own conception of self and one's perception or prediction of others' evaluations of them than between one's own conception and the actual attitudes of others'. This finding indicates that the self-concept is largely a function of one's own perceptual hypothesis concerning the attitudes of others toward him and does not reflect the real attitudes of others. Although this design permitted the investigators to measure the extent of self-other agreement on the self-concept, no effort was made to determine whether the others who made the ratings were significant to the subject.

This investigation was extended and replicated by Quarantelli and Cooper 18 and again confirmation was found for the general hypothesis. However, this study was far superior to that of either Kuhn or Miyamoto and Dornbush for an attempt is made here to measure the self with the same subjects over a period of time. In addition, role-specific significant others were asked to rate the focal subjects on the same self-concept dimensions. In consequence, a more direct effort at measuring the impact of the other was achieved since the investigators attempted to deduce the total possible range of others that might influence the subject (e.g. faculty, classmates, parents, wives, etc.). This is a necessary 
inclusion, for not all others' in one's life are equally significant in moulding the self-concept. Quarantelli and Cooper observe that, over a period of time, the subjects conception of self is more closely associated with "how he thinks" (perception) the other feels about him, than to how the other actually regards him.

Taken together, these three investigations lend support to the interactionist hypothesis concerning the existence of a relationship between the self-concept, the social group, and interpersonal perception. Still other research, extending the paradigms of these studies have atterpted to utilize the postulated relationship between the self and others 19 as a predictive tool; that is, as a source of intra-individual and/or behavioral change. Recall that one of the major implications of the theory is that the individual's self-concept has the function of directing or influencing the way he will behave. Such an emphasis is of obvious importance, for if variations in self-conceptions could not be used successfully to explain and predict differential conduct they would be of limited value in the behavioral sciences. Much of the research cited above has not adequately dealt with this issue. Instead, they have been concerned only with the validation of a rather broad interactionist hypothesis: that the individual's conception of himself is based on his perception of the way others are responding to him. This focus lacks the systematic specification of antecedent conditions that affect interpersonal perception. 
Kinch 20 expands the basic hypothesis so that variable relationships are made more explicit. For Kinch, the basic question seems to be as follows: under what conditions do the perceptions of others' responses have an effect on the individual's selfconcept? Taking the "response" of the other as the critical variable, he postulates that the nature of the self-concept, and self-concept change, will be a function of: 1) the frequency of responses in the course of interpersonal contacts; 2) the perceived importance of the contacts; 3 ) the temporal proximity of the contacts and 4) the consistency of those responses resulting from the contacts. These postulates take the form of four basic hypotheses, most of which have been confirmed, to one degree or another, in collateral research (see corresponding citations). First, the more frequently the individual perceives others as responding toward him in a particular way, the more likely he is to align his self-concept with the perceived responses. 21 Second, the more important the individual perceives the contact between himself and the others to be, the more likely it is that the individual's perception of the responses of others will be used in defining his self image. Here, research indicates that "significant others," are necessary but specifically who they must be is not entirely clear. 22 Third, the individual's concept of himself is a function of: the earliest evaluations he receives on a particular attribute and the most immediate evaluations. Much of the research concerned with the validation of this hypothesis has utilized sociometric choice methods wherein some attempt is 
made to establish a correspondence between the self-concept and the choice process (i.e. like and dislike choices) within group settings. 23 Self-concept is closely bound to the nature of interpersonal choice. Kinch states that ". . once an individual developes a conception of himself, he will interact as much as possible with others who will reinforce this conception for him," and that those most immediate contacts (e.g. peers in a residential setting) "are important in understanding the individual's self-concept at any given time."24 Finally, the more the individual perceives a consistent pattern in the responses of others, the more likely he is to let this affect his self-concept.

The systematic statement of these four hypotheses, buttressed by collateral research, only represent partial confirmation of the interactionist theory of interpersonal perception. They are intended to yield a much more definitive understanding of conceptual relationships. An equally significant area of research rests upon the pragmatic utility of these hypotheses: do they account for abnormal, 25 as well as normal, aspects of human behavior?

\section{Pathology and Interpersonal Perception. The perceptual} basis of pathology is derivative of the interactionist notion that individuals act on the basis of their inferences about the probable behavior of others toward them and that the self-concept is mediated by how we think others feel about us. Rosenberg illustrates the functional unity of this process in examining the basis of common friendship choice: 
'. friendship is the purest illustration of picking
one's propaganda. For it is characteristic of a friend
that not only do we like him, but he likes us. To some
extent at least, it is probable that we like him because
he likes us. Indeed, it is well nigh impossible to be
friends with someone who hates us, not only because we
would have no taste for such a friendship, but because he
would not allow the friendship to exist. The upshot of
friendship selection is thus to expose people to implicit
and explicit interpersonal perceptions which reflect well
on themselves, whereas they hear mich less from people
who dislike them. All friendship then, is at least to
some extent a 'mutual admiration society,' whereby each
partner helps to sustain the desired self-image of the
other. 26

In its most salient form the friendship process, or as we shall refer to it, the interpersonal choice process, illustrates the crucial importance of role-taking for validation of the self. It is axiomatic in interactionist theory that there are functional relationships between: 1) how we see ourselves; 2) how we see others and 3) how we think others see us. Such interrelationships have important consequences in overt behavior and are also the essential ingredients of interpersonal perception. An understanding of pathology rests on a disturbance in these functional relationships. Accurate role-taking is seen as an essential precondition for adequate interpersonal adjustment (absence of gross forms of pathology). Note that adjustment is synonymous with adaptation, both terms referring to a process whereby one alters the course of his behavior and/or perceptions in terms of the demands of the social situation. 27 These social situations are always constructed and defined interpersonally.

Stryker formulated the relationship between role-taking and adjustment as an hypothesis: "the adjustment of the individual is 
a function of the accuracy with which he can take the role of others implicated with him in some social situation."28 Roletaking was conceived as the anticipation of the responses of others and operationally defined as the correct prediction of the responses of others. The reader should note the definitional components of role-taking for it provides an important, though partial explanation of the choice process within this residential setting.

The use of this definition did permit the author, in a subsequent study, 29 to specify more clearly the structural properties of role-taking. (Note, parenthetically, their application to our study). Stryker describes four general propositions concerning role-taking: 1) social activjties (interpersonal choice) are embedded in a structure of roles; 2) to engage in social activities (interpersonal choice), a person must take the role of others (have the ability to anticipate or predict their responses); 3) a significant segment of the role of the other which one must take consists of attitudes (choices of like and dislike) and 4) ability to take the role or attitude of the other (an accurate prediction of the others anticipated choice) is predicated upon a common universe of discourse (a shared system of meanings).

The role-taking accuracy model and its implications for the adjustive functions of the individual has been directly extended by Rosengren to an analysis of the self in the emotionally disturbed. 30 Rosengren's study represents one of the few serious attempts to link an interactionist theory of the self to pathological conditions. 
Taking as a point of departure the postulated relationships in self functions (how we see ourselves, how we see others, and how we think others see us), Rosengren noted that it is necessary to take temporal changes into account in order to demonstrate empirically functional relationships among the self-processes. The rational for this focus arises from Rosengren's observation that:
- . ideally, changes in the self would occur over a relatively long period of time during which the individual moves sequentially through the stages of the play, the game, and the generalized other. Moreover, once having developed to that stage of socialization, most persons maintain a rather stable and continuing set of relation- ships among the functions of the self.. . the behavior of persons becomes relatively stable and predictable inso- far as there is some convergence between how they see them- selves, how they see others, and how they think others see
them.

Utilizing a small group of institutionalized boys, Rosengren demonstrated that a major disruption of role-taking functions existed prior to treatment and were subsequently improved in the course of treatment (temporal changes). Initially, subjects tended to define themselves (self-concept) dissimilar to the ways in which they thought (predicted) others would define them. On sociometric ratings of liked-disliked others, both liked and disliked persons tended to impute to the subjects qualities of self dissimilar to those which the subject expected would be imputed to them. That is, the subjects were rather inaccurate in predicting the responses of these others. The more disparate the relationship between the way the subject saw himself and the way others saw him the more severely diminished were his role-taking 
capacities--defined again, as the ability to correctly predict the response of the other.

The theoretical position outlined earlier combined with the foregoing research lead us to affirm an essential thesis of our research: that the self-concept cannot be viewed independently of a larger system of relationships that have played no small role in shaping, maintaining, and changing self definitions. We have seen that the self-concept is inextricably woven with one's social group, the latter composed of significant others whose responses directed to the individual are crucial in structuring attitudes toward the self. Moreover, we have seen that selfconception and social group, apart from being mutually dependent phenomena, are also two aspects of a larger and most significant process called interpersonal perception. The perceptions that one has of himself (self-concept), of his beliefs of what others think of him, are related in a complex, interactive, and reciprocal manner. The direct application of this knowledge base to the study of the peer social system at Villa Saint Rose is based on two fundamental assumptions: 1) that the self-concept is an important determinant of interpersonal perception and pathology and 2) that an understanding of the responses of significant others is a critical dimension of the interaction of self and social group. However, before we articulate a methodology for the study of these phenomena it would be well to present the existing evidence that implicates them in delinquency. 
II. THE SIGNIEICANCE OF THE SEIF-CONCEFT AND REFERENCE GROUP IN A GENERAL THEORY OF DELINQUFNCY

A great deal of theoretical attertion has been given to the explanation of causal factors in delinquency. Delinquency has been attributed to innate characteristics, mental deficiencies, personality maladjustments, glandular malfunctions, and physical inadequacies. These theories, as Cohen and Short indicate, 32 represent purely psychological interpretations. Their main deficiency lies in advancing limited conceptual schemes; they deal with only one level of inquiry while ignoring other levels or making implicit assumptions about them. By contrast, sociological explanations of delinquency attribute the phenomenon to such factors as the family, peer group, neighborhood, school, and urban conditions. Many sociologists argue that most delinquency is culturally determined, and that the central focus of sociological investigation should be the human social group. As is the case with psychological interpretations, there are no "settled" sociological issues regarding delinquency causation.

Those psychological orientations which postulate a disturbance in personality function often take as a point of departure the psychoanalytic notion of the major developmental task of adolescence, identity resolution. The process, normally considered a crucible of adulthood, is frequently exacerbated by the general turmoil characteristic of contemporary social life. Major sources of disruption occurring within the nuclear family, the adolescent subculture, and value systems, serve to obstruct any 
simple resolution of this crucial psychological task.33 In fact, resolutions are often not forthcoming. In its place we see, as Klapp so cogently put it, "a rebellion with no place to go" 34 -rebellions that are distinguished by, if not symptomatic of, the pervasive social malaise that runs rampant throughout the social system. Faulty adaptive modes of functioning thrive under these conditions; so too are delinquent identities forged in the process. However appealing the concept of identity resolution may be, it is only a partial aid to understanding the abortive coping mechanisms of the delinquent child; failure to resolve the crisis of identity is only part of the total etiologic process. Trends in juvenile delinquency indicate that the phenomenon cannot be explained simply by postulating some psychological deficit, particularly such an all-inclusive one as identity resolution. Delinquency, as do all pathologic processes, has a dual etiologic basis. There are psychogenic as well as sociogenic factors operable.35 Psychogenic factors, while including the broader issue of identity formation, are increasingly pointing to the more specific quality of the adolescent's self-concept as a major precipitant of delinquent adjustment. On the other hand, sociogenic factors implicate the adolescent's most significant reference group (his peers), especially the needs for peer status and recognition and acceptance within the group as primary contributors to the process. The self-concept and reference group are, as we shall point out, not unrelated. 
The Self-Concept and Delinquency

Evidence substantiating the general theoretical concern with the self-concept as a determinant of delinquency adjustment has been derived from two sources: 1) a body of empirical research largely dominated by the pioneerine work of Reckless et al. and 2) contemporary treatment programs. With respect to the former, early research designed to explain gang delinquency inspired further exploration into the quality of the self-concept. Here, it was noted that the "culture of the gang" 36 is such that individuals with damaged or otherwise distorted self-concepts often find a supportive and collectively reinforcing milieu within which attitudes toward the self can be assuaged.

Observations of this kind provided an important research impetus for exploring the extent of association between the selfconcept and delinquent adjustment. In this regard the work of Reckless et al. is particularly noteworthy since it approaches delinquency and the self-concept from a social/psychological perspective. Delinquency is viewed as a product of the interaction between society and the self, with the quality of the self-concept being a key differentiating variable in the explanation of delinquency as well as non-delinquency.

Essentially the Reckless studies consist of four parts. The first is a study of 125 white, sixth grade boys having been chosen or nominated by their teachers as unlikely to experience any court contacts in the course of their development. 37 Each of these "good" boys was administered the delinquency proneness (DE) and the 
social responsibility ( $\mathrm{RE}$ ) scales of the California Personality Inventory (CPI), and asked about his concept of self, his family, and his interpersonal relations. The boys' mothers were interviewed also. Based on the scale scores and favorable perceptions of family the authors conclude that "insulation against delinquency is an ongoing process reflecting internalization of nondelinquent values and conformity to the expectations of significant others."

A follow-up study 38 of these "good" boys four years later ( 16 years old) located 103 of the original group and f'ound that 99 of them were still in school. Moreover, teachers nominated 95 of the 99 boys as "good" boys again. The boys and their mothers were once again interviewed and the boys completed the $\mathrm{DE}$ and $\mathrm{RE}$ scales once more. The responses on the tests were consistent with their earlier performances: favorable family interaction patterns existed and only four of the re-nominated "good" boys had had any police contact. Apparently these boys were "insulated" against delinquency over the four year period.

A similar longitudinal study was conducted with a group of 101 "bad" boys who were nominated by their teachers as likely to experience police and juvenile court contacts. Testing and interviews were conducted in the same manner as the "good" boy procedure. Of these 101 "bad" 12 year-old boys, 24 were already on record for previous offenses. Tests and interviews were once again admin- • istered. The results were as follows. The "bad" boy scores were significantly higher on the $\mathrm{DE}$ and lower on the RE scales than those made by the 'good' boys of the first 
study. Indeed, this mean delinquency vulnerability score was higher than that achieved by any of the non-delinquents and non-disciplinary sample subjects treated in other studies. Similarly, the mean social responsibility score was lower than those recorded in other studies for all but prisoners, delinquents and school disciplinary cases. These scores seem to validate the judgements of the teachers in selecting these boys as ones who would get into future difficulties with the law. Not only do these scales appear to differentiate between the potentially delinquent and non-delinquent, but even more importantly they were found to discriminate within the sample of nominated delinquests between those boys who had not experienced previous court contact. 39

A follow-up study of these "bad" boys took the same form as the "good" boys" study. 40 Thirty-nine percent had experienced serious and frequent court contacts. Their mean scores on the DE and RE scales had not changed and were still worse than the "good" boys" scores. The "bad" boys, then, seem to be more vulnerable to delinquency, and on the basis of the scale scores and the interview data, Reckless and his associates conclude that the discriminating factor is quality of "self-concept." The "bad" boys see themselves (self-concept) as likely to get into trouble in the future; their mothers and teachers agree. The "good" boys see themselves as unlikely to get into trouble; their mothers and teachers agree.

These studies are by no means conclusive evidence that a defective self-concept causes delinquency. The primary significance of this research lies in its attempt to interpret delinquency from the interactionist perspective which we outlined earlier. Recall that the interactionist theory suggests that the self-concept is developed through interaction with significant others and largely consists of the internalized responses of these 
significant others. Behavior is a function of this self-concept. In this regard, we note that a major assumption in the Reckless studies is that mothers and teachers represent the significant others in the lives of these young boys and that they incorporate their evaluations into their self-concepts. In a sense, the delinquent or non-delinquent adjustment of these boys is a "selffulfilling prophecy" to the extent that their significant others provide them with a self-concept that is or is not dysfunctional. The findings and assumptions underlying these studies have been the subject of several critiques.

Swartz 41 has critically examined the major assumptions contained in the Reckless studies. Although he confirms the notion that two such nominated groups do have different qualities of self-concept, he questions the importance of teachers and mothers evaluations in formulating differential self-concept of these subjects. This and other critiques 42 of the Reckless studies all converge on some basic conclusions regarding the postulated association between delinquency and the self-concept: 1) there is a certain amount of agreement between teachers and parents regarding the likelihood of certain individual adolescents getting into trouble, but no demonstration of an agreement between this consensus and present or future actual experience; 2) although adolescents are aware of the judgements their elders make of them there has been no unequivocal demonstration that they accept and hence incorporate them as their own and 3) the latter case is true of "good" as well as "bad" nominated individuals. 
While it is true that the empirical research does not unequivocally substantiate a self-concept theory of delinquency there is a great deal of collateral, though less rigorous support for this position in various institutional studies. Findings such as Dorn's 43 indicating that institutionalized delinquents are less likely to be socially anchored in society, more likely to be alienated and anxious and more apt to make self-derogating statements about their self-concepts than non-delinquent adolescent's tend to support the research focus on the self-concept.

Some authors have noted that change in self-concept often accompanies institutional treatment, implying some initial deficit prior to engagement in treatment. Joplin, 44 for example, argues that since the self-concept of an individual appears to be a contributing factor in delinquency, residential treatment programs might be structured in the direction of improving the self-concept. Utilizing a self-report personality inventory he notes significant improvement of the self-concept, in terms of greater certainty ano. clarity of self-perception as a function of treatment. 45

Many of the studies implicating the self-concept in the production and treatment of delinquency, have utilized young male populations. There seems to be an absolute paucity of research dealing specifically with the self-concept of the female. Of course, there is little theoretical justification for considering as uniquely different the delinquency of females vis a vis males. However, the position that women occupy in the general system of human relationships does influence, to some degree, the quality of 
her self-concept. In this regard, Knopka ${ }^{46}$ sumnarizes some major findings in the research dealing with the delinquent girl. She notes that: 1) the delinquent girl is an adolescent girl and therefore shares all the characteristics of adolescents; 2) she shares with all girls the problems of a deeply seated cultural change in the position of females and 3) she is an especially lonely person, significantly alienated from society. Knopka argues that this excessive lonliness generates dysfunctional behavior and also tends to exacerbate an already low self-image. The most significant implication for treatment, in her view, is that any kind of intervention must be directed toward the reorganization of the self-concept.

While the evidence is not uniformly clear, it does appear that the quality of an adolescent's self-concept may precipitate, or at least contribute significantly to, delinquent adjustment. In any case, the concept has found an important source of application in the treatment of delinquents and one that we believe is essential to the understanding of the resident and his interaction within the institution.

Although the self-concept may indeed by associated with delinquency it is by no means the only factor. We noted earlier in our introduction that one cannot understand pathological outcomes only by reference to the personality of the individual. Such parochial explanations serve only to contribute to simplistic and misleading conceptualizations of a most complex phenomenon. This complexity derives from the fact that pathological adjust- 
ments such as delinquency involve the interaction of personality variables within the setting of group activity. We have discussed only one side of the coin, as it were. The other side recognizes, as we pointed out in our theoretical discussion, that the selfconcept is defined and maintained through group interaction with significant others.

\section{The Reference Group and Delinquency}

Apart from the role that personality variables (i.e. selfconcept) are presumed to play. in delinquency, there has been an equally impressive body of research suggesting that delinquency is a peer group phenomenon. The history of this focus began with the pioneering work of Clifford R. Shaw and Henry McKay 47 whose data taken from Chicago courts indicated a heavy predominance of delinquent incidents involving more than one youngster. This, and related studies emphasizing the role of the gang in delinquency, 48 seemed to point to the peer group as the major single associative factor in delinquency. This type of research, as Klein 49 points out, although correct in its emphasis upon the group related nature of delinquency, often, confuses peer groups with gangs. This ambiguity is most unfortunate because it suggests that delinquency is only a group phenomenon and one need not make any interpretive reference to the role of personality variables. A more useful approach, and one that incorporates the dual significance of the peer group and individual personality, has been to consider the generic importance of the reference group concept in delinquency. As a developmental phenomenon group formation among adoles- 
cents is a general occurrence and is well documented in the literature. 50 As a generic concept it avoids the ambiguity associated with its more specialized referent, the gang. The term "gang," applied to group formation, reflects an important social class bias inasmuch as it typically refers to intimate groups in lower-class settings. By contrast, less stigmatic referents such as "cliques" and "friendship circles" are applied to the same type of group formation in middle and upper class settings. A less emotionally tinged term applied to group formation, irrespective of class setting, is reference group.

Originally developed by Hyman 51 the concept of reference group has assumed at least three distinct meanings. One common usage designates that group(s) which serves as a point of "reference" in making comparisons or contrasts. Thus reference groups can be represented by those groups whereby one compares and evaluates one's own status. A second meaning of the term designates that group(s) to which the individual aspires to gain or maintain acceptance. 52

The third application of the concept, and one that theoretically "binds" the self-concept to the group, denotes those groups whose perspectives constitute and frame the perceptions of the individual (i.e. perceptions of self, others, and world.) 53 This perspective on the function of reference groups unites the interactionist concept of the "generalized other" with the developrnent of the self. Recall that the generalized other represents the means whereby the child learns the generalized attitudes of the 
group of which he is a part and incorporates those attitudes, along with those of specific significant others, into the structure of his self-concept. Reference groups then, are a "generalized other" whose norms are used as anchoring points in structuring the perceptual field. Thus, a reference group represents any group with which a person psychologically identifies himself or in relation to which he thinks of himself. These groups establish the individual's basis for ordering his experiences, perceptions, and self-concept. Sherif states the matter as follows:

The individual's directive attitudes, namely egoattitudes, which define and regulate his behavior to other persons, other groups, and to an important extent even to himself, are formed in relation to values and norms of his reference groups. They constitute an important basis of his self-identity, of his sense of belongingness, of the core of his social ties. 54

Through direct or vicarious participation in a group one comes to perceive the world from its standpoint. The concept of reference group points more to a psychological phenomenon than to an objectively existing group of people; it refers to an organization of the individual's experience; it is a structuring of his perceptual activity •

With respect to the nature of adolescent reference groups, composed of peers, they, like any other group are characterized by: 1) a structure or organization of interaction among members which function to define the statuses and roles of members in various respects, and thereby define the proper attitudes of the members toward each other and toward members of other groups, and 
2) a set of values or group norms shared by group members over and above those values they have in common with others in their setting and the society of which they are a part. The crucial significance of adolescent reference groups derives from the fact that the adolescent is personally concerned with remaining a part of it; his self-concept, his very identity, is dependent upon his reference group which is composed of significant others in the form of peers. "In fact," Sherif concludes,

the individual's concerns over acceptance or rejection, his experiences of personal achievement or failure, that is, the directive components of his warmly experienced ego, in no small part consists of stuff of this sort. 55

The adolescent's peer group then, is clearly an important source of self and behavioral construction.56 It assumes an even more important position when we realize how closely bound is the self-concept of the individual to his peer group. The shift towards a more intense identification with peers during adolescence provides the basis for understanding some crucial dimensions of delinquency.

At a psychological level of analysis the relationship between the individual and the peer group links the problem of group membership to the process of reformation that must take place in the individual's self-concept if he is to transcend his status of child and nove forward into adulthood. The ease of this transition is closely related to whether or not the adolescent gains the acceptance of his peers. To appreciate the singular importance of these peer relationships the intensive interview study of delinquent girls i.s helpful.57 Repeatedly her report shows the painful 
uncertainty of not being securely anchored in a social context, the almost desperate search for "companionship," the feeling of closeness to others "in the same boat" and the defiance of official rulings not to associate with them, for no other reason than that "one has to have someone."

This orientation illustrates the impossibility of understanding delinquency in terms of either the self-concept or the peer group if we continue to consider them as separate and unrelated. Because the peer group acquires positive value in the eyes of the adolescent, he is resistant to restrictions as well as positive actions by adults that interfere with or prevent the pursuit of satisfaction he finds in the peer group. Indeed,

the intensity of the adolescent's identification with his particular reference group of other adolescents . . . increases perhaps proportionately to the shakiness of his ties with adults and their sponsored programs and institutions. 58

This fact explains the observation of many treatment staff involved in residential facilities that even when compliance with a therapeutic residential program is required, the residents remain relatively impervious as they pursue the relationships and plans generated within the peer group--relationships that are "real" to them because their identities and conceptions of self are linked to their peer group through the process of interpersonal perception and collective interaction.

The evidence implicating the self-concept and peer group as crucial and reciprocal factors in adolescence and delinquency clearly illustrates the need for research into the residential 
social system:

- - the occurrence of delinquent deeds frequently is associated with the processes of groups and with collective interaction. In order to understand these events, groups and collective processes inust be studied relative to the settings in which they occur and in which members have developed.

- - practical attempts to 'rechannel' groups without reference to the limitations of their immediate settings or to public images of fast success will run into obstacles. 59

To reiterate an earlier contention: we cannot understand the basis for pathology nor can we hope to treat it, without reference to personality as well as group factors. With respect to residential treatment we can amplify this assertion and maintain that at all times the personality of the individual is nanifest through, and affected by, group interaction, interaction which: 1) often functions to maintain a delinquent culture within the institution and effectively deflect the best treatment intervention; 2) is potentially useful in organizing constructive change through selfconcept modification and 3) is predicated upon the processes of interpersonal perception wherein the responses of significant others are crucial in shaping self-concepts. Until we understand the dynamics of these processes, treatment programs must necessarily remain little more than custodial in nature. The remainder of this paper is devoted to a more thorough understanding of the selfconcept and interpersonal perception as they are manifest through interaction within the residential group at Villa Saint Rose. 
CHAPI'ER NOTES

1. See for example: Gordon W. Allport, "The Ego in Contempurary" Psychology," Psychological Review, 50 (No. 5, 1943); I. Chein, "The Awareness of Self and Structure of the Ego," Psychological Review, 51 (No. 5, 1944); P. A. Bertocci, "The Psychological Self, the Ego, and Personality," Psychological Review, 52 (No. 2, 1945); Muzarf Sherif and H. Cantril, The Psychology of Ego Involvements (New York, 1947); E. R. Hilgard, "Human Motives and the Concept of Self," American Psychologist, 4 (No. 9, 1949); M. Brewster, Smith, "The Phenomenological Approach in Personality Theory: Some Critical Remarks," Journal of Abnormal and Social Psychology, 45 (No. 3, 1950). An excellent summary and critique of literature dealing with the concept of self up to 1960 can be found in Ruth C. Wylie, The Self Concept (Nebraska, 1961).

2. The interactionist position is a developing one. There have been few systematic statements of the theory. The following are statements of the theory. The following are recommended materials which incorporate, to varying degrees, the general theory: Herbert Blumer, Symbolic Interactionism: Perspective and Method (Englewood Cliffs, 1969); Alfred R. Lindesmith and Anseim L. Strauss (eds.), Readings in Social Psychology (New York, 1969); Peter McHugh, Defining the Situation: The Organization of Meaning in Social Interaction (Indianapolis, 1965); Tamotsu Shibutani (ed.), Human Nature and Collective Behavior: Papers in Honor of Herbert Blumer (Englewood Cliffs, 1970); Gregory P. Stone and Harvey A. Farberman (eds.), Social Psychology Through Symbolic Interaction (Waltham, 1970); Jerome G. Manis and Bernard N. Meltzer, eds.) Symbolic Interaction (Boston, 1972).

3. Sheldon Stryker, "Symbolic Interaction as an Approach to Family Research," in Symbolic Interaction, (eds.) Jerome G. Manis and Bernard N. Meltzer, p. 436.

4. Herbert Blumer, "Society as Symbolic Interaction," in Symbolic Interaction, (eds.) Jerome G. Manis and Bernard N. Meltzer, p. 145 .

5. Robert W. White, The Abnormal Personality (New York, 1948), p. 140 .

6. Bernard N. Meltzer, "Mead's Social Psychology," in Symbolic' Interaction, (eds.) Jerome G. Manis and Bernard N. Meltzer, p. 6 . 
7. Meltzer, "Mead's Social Psychology," p. 8.

8. See the following. works by Jean Piaget: The Moral Judgment of the Child (New York, 1948); The Child's Conception of the World (New York, 1951); The Language and Thought of the Child (New York, 1952); The Child's Conception of Physical Causality (New Jersey, 1960).

9. George Herbert Mead, Mind, Self, and Society (Chicago, 1934), p. 155 .

10. Ibid., p. 155. The reader should note here that this process assumes some degree of importance in establishing the social bond between the individual and the group. This one factor, as we shall later point out, accounts for the large amount of theoretical preoccupation with delinquency as a group phenomenon.

11. William H. Desmonde, "The Position of George Herbert Mead," in Psychoanalysis and the Future, (ed.) B. Nelson (New York, $1957)$, p. 35. This process of internalization and differentiation appears to be closely related to the Freudian id, ego, and superego. However, Meltzer points out that "the resemblance is, for the most part, more apparent than real. While the superego is held to be harshly frustrating and repressive of the instinctual, libidinous, and aggressive id, the 'me' is held to provide necessary direction--often of a gratifying nature--to the otherwise undirected impulses constituting the 'I' . . Freud views the id and superego locked in combat upon the battleground of the ego; Mead sees the 'I' and 'me' engaged in close collaboration. This difference in perspective may derive from different pre-occupations: Freud was primarily concerned with tension, anxiety, and 'abnormal' behavior; Mead was primarily concerned with behavior generically." Meltzer, "Mead 's Social Psychology," p. 11 (see footnote \#3).

12. A. Paul Hare, Edgar F. Borgatta, and Robert F. Bales, (eds.) Small Groups (New York, 1965), Introduction, Chapter Four.

13. John W. Kinch, "A Formalized Theory of the Self Concept," American Journal of Sociology, 68 (No. 4, 1963).

14. Ibid., pp. 482-483.

15. Manford H. Kuhn, "Self-Attitudes by Age, Sex, and Professional Training, Sociological Quarterly, 1 (No. 2, 1960).

16. Manford H. Kuhn and Thomas S. McPartland, "An Empirical Investigation of Self-Attitudes," American Sociological Review, 19 (No. 1, 1954). 
17. S. Frank Miyamoto and Sanford M. Dornbush, "A Test of the Interactionist Hypothesis of Self-Conception," American Journal of Sociology, 61 (No. 5, 1956).

18. E. L. Quarantelli and Joseph Cooper, "Self-Conceptions and Others: A Further Test of Meadian Hypothesis," Sociological Quarterly, ? (No. 3, 1966).

19. There is a plethora of confirming evidence for this postulated relationship though too extensive to be dealt with adequately in this paper. For a representative sampling see: Carl Couch, "Self-Attitude and Degree of Agreement with Immediate Others," American Journal of Sociology, 63 (March, 1958); Leo G. Reeder. George Donahue, and Arturo Biblarz, "Conceptions of Self and Others," American Journal of Sociology, 66 (September, 1960); M. Maehr, J. Mensing, and S. Nafager, "Concept of Self and the Reactions of Others," Sociometry, 25 (No. 4, 1962); John J. Sherwood, "Self-Identity and Referent Others," Sociometry, 28 (March, 1965).

20. John W. Kinch, "Experiments on Factors Related to Self Concept Change," Journal of Social Psychology, 74 (April, 1968).

21. Richard Videbeck, "Self Conceptions and the Reaction of Others," Sociometry, 23 (December, 1960); A. Bergin, "The Effect of Dissonant Persuasive Communication Upon Changes in a SelfReferring Attitude," Journal of Personality, 30 (No. 3, 1962); M. Maehr, J. Mensing, and S. Nafager, "Concept of Self and the Reactions of Others;" H. I. Haas and M. Maehr, "Two Experiments on the Concept of Self and the Reacting of Others," Journal of Personality and Social Psychology, 1 (No. 1, 1965).

22. O. J. Harvey, H. H. Kelley, and M. M. Shapiro, "Reactions to Unfavorable Evaluations of the Self made by Other Persons," Journal of Personality, 25 (No. 4, 1957); J. L. Kennedy and H. D. Lasswell, "A Cross-Culture Test of Self-Image," Human Organization, 17 (No. 1, 1958); A. Bergin, "The Effect of Dissonant Persuasive Communication."

23. C. W. Backman and P. F. Secord, "The Effect of Perceived Iriking on Interpersonal Attraction," Human Relations, 12 (No. 4, 1959); G. E. Dittes, "Attractiveness of Group as a Function of SelfEsteem and Acceptance by Group," Journal of Abnormal and Social Psychology, 59 (No. e, 1959); H. W. Reese, "Relationships Between Self-Acceptance and Sociometric Choices," Journal of Abnormal and Social Psychology, 62 (No. 2, 1961); C. W. Backman, "Liking, Selective Interaction, and Misperception in Congruent Interpersonal Relations," Sociometry, 25 (December, 1962).

24. Kinch, "Experiments on Factors Related to Self Concept Change," p. 253. 
25. We use the term "abnormal" in a generic sense. Delinquency would fall within this discussion.

26. Morris Rosenberg, "Psychological Selectivity in Self-Esteem Formation," in Attitudes, Ego-Involvement and Change, (eds.) Carolyn W. Sherif and Muzarf Sherif (New York, 1967), p. 29.

27. Mead, Mind, Self, and Society, pp. 155-159.

28. Sheldon Stryker, "Role-Taking Accuracy and Adjustment," Sociometry, 20 (December, 1957).

29. Sheldon Stryker, "Conditions of Accurate Role-Taking: A Test of Mead's Theory," in Human Behavior and Social Processes, (ed.) Arnold Rose (Boston, 1962).

30. William R. Rosengren, "The Self in the Emotionally Disturbed," American Journal of Sociology, 66 (March, 1961).

31. Ibid., p. 455 .

32. Albert K. Cohen and James F. Short, Jr., "A Survey of Delinquency Theories," in Faces of Delinquency, (eds.) John P. Reed and Fuad Baali (New Jersey, 1972), pp. 215-228.

33. William A. Schonfeld, "The Twentieth Century Adolescent: Adolescent Turmoil and the Search for Identity," American Journal of Psychoanalysis, 31 (No. 1, 1971).

34. Orrin E. Klapp, Collective Search for Identity (New York, 1969), pp. 57-62.

35. Salvatore V. Didato, "Some Recent Trends in Juvenile Delinquency," Mental Hygiene, 53 (No. 4, 1969). See also, Richard D. Knudten, "Social-Psychological Causes of Crime," in Crime in a Complex Society, (ed.) Richard D. Knudten (Illinois, 1970).

36. Albert $K$. Cohen, Delinquent Boys: The Culture of the Gang (Illinois, 1956).

37. Walter C. Reckless, Simon Dinitz and Ellen Murray, "Self Concept as an Insulator Against Delinquency," American Sociological Review, 21 (No. 6, 1956).

38. Frank R. Scarpitt1, Ellen Murray, Simon Dinitz and Walter C. Reckless, "The 'Good' Boys in a High Delinquency Area: Four Years Later," American Sociological Review, 25 (No. 2, 1960).

39. Simon Dinitz, Walter C. Reckless and Barbara Kay, "A Self Gradient Among Potential Delinquents," Journal of Criminal Law, Criminology and Police Science, 49 (No. 35,1958 ), p. 231.。 
40. Simon Dinitz, Frank R. Scarpitti, and Walter C. Reckless, "Delinquency Vulnerability: A Cross Group and Longitudinal Analysis," American Sociological Review, 27 (No. 4, 1962).

41. Michael Schwartz, "A Note on the Self Concept as an Insulator Against Delinquency," American Sociological Review, 35 (December, 1963).

42. For a good review see: Sandra S. Tangri and Michael Schwartz, "Delinquency Research and the Self Concept Variable," Journal of Criminal Law, Criminology and Police Science, 58 (No. 2, 1967).

43. Dean S. Dorn, "Self-Concept, Alienation and Anxiety in a. Contraculture and Subculture," Journal of Criminal Law, Criminology and Police Science, 59 (No. 4, 1968).

44. Glenn H. Joplin, "Self-Concept and the Highfields Program," Correctional Psychologist, 3 (No. 5, 1968).

45. In a similar study, Rubin confirms the positive effects of treatment but found that the degree of change in self-concept was inversely related to the length of institutional stay. Jerome Rubin, "Change in Self Concept During Institutional Confinement," Dissertation Abstracts International (Ann Arbor Michigan). Self-concept change has been shown to be an important variable, not only in treatment of the delinquent, but also more severe forms of adolescent pathology. See for example, Wayne C. Richard, Catherine G. Mates, and Laura Whitten, "Personality Traits and Attitudes of Adolescent Girls wi.th Behavior Disorders," Corrective Psychiatry and Journal of Social Therapy, 15 (No. 2, 1969); Peter 0. Peretti, "Identification and Reidentification: A Change in the Self Concept," International Journal of Child Psychiatry, 37 (No. 11, 1971).

46. Gisela Knopka, "The Rehabilitation of the Delinquent Girl," Adolescence, 2 (No. 5, 1967).

47. Clifford R. Shaw and Henry D. McKay, "Social Factors in Juvenile Delinquency," Report on the Causes of Crime (Washington D.C., 1931).

48. See for example: 'Edwin H. Sutherland, Principles of Criminology (New York, 1955); Albert K. Cohen, Delinquent Boys (New York, 1.955); Richard A. Cloward and Lloyd E. Ohlin, Delinquency and Opportunity: A Theory of Delinquent Gangs (New York, 1.960); Frederick M. Thrasher, The Gang: A Study of 1,313 Gangs in Chicago (Chicago, 1963).

49. Malcolm W. Kiein, "Or the Group Context of Dèlinquency," Sociology and Social Research, 54 (October, 1969). 
50. Harold E. Jones, Development in Adolescence (New York, 1943); John E. Horrocks, The Psychology of Adolescence (Boston, 1951); James S. Coleman, The Adolescent Society (New York, 1961).

51. Herbert Hyman, "The Psychology of Status," Archives of Psychology, 269 (No. e, 1942).

52. Robert K. Merton and A. Kitt, "Contributions to the Theory of Reference Group Behavior," in Studies in the Scope and Method of the American Soldier, (eds.) Robert $\mathrm{K}$. Merton and Paul F. Lazarsfeld (Illinois, 1950).

53. Tamotsu Shibutani, "Reference Groups as Perspectives," American Journal of Sociology, 60 (No. 2, 1955).

54. Muzarf Sherif, Group Relations at the Crossroads (New York, 1953), p. 214.

55. Muzarf Sherif and Carolyn W. Sherif, "Social Settings and Reference Groups," in Reference Groups, (eds.) Muzarf Sherif and Carolyn W. Sherif (New York, 1964), p. 250.

56. We do not suggest that the peer group is the only reference group for the adolescent. The family is, as Haskell points out, also a significant personal reference group of the child as well as a normative reference group. We maintain, however, that the peer group is a comparatively more significant reference group during this developmental stage. Martin R. Haskell, "Toward a Reference Group Theory of Juvenile Delinquency,". Social Problems, 8 (Winter, 1961).

57. Gisela Knopka, The Adolescent Girl in Conflict (New Jersey, 1966).

58. Muzarf Sherif and Carolyn W. Sherif, "Group Processes and Collective Interaction in Delinquent Activities," Journal of Research in Crime and Delinquency, 4 (January, 1967), p. 50 .

59. Sherif, "Group Processes and Collective Interaction in Delinquent Activities," p. 53. 
CHAPTER III

METHODOLOGY

Our proposed research intervention within this institutional setting reflects a methodology designed to explore the directive focus of this paper: the resident's self-concept as it becomes manifest in group interaction through interpersonal perception. As an exploratory intervention, our primary intent was to increase the understanding of the phenomenon and hopefully provide a foundation for more precise future research. In doing so, we articulated three interrelated levels of methodological intervention: 1) assessment of the self-concept profiles of the total residential population; ancillary foci include an assessment of the ideal self-concepts and the degree of self rejection among the residents; 2) an exploration of interpersonal perception based on certain sociometric choice procedures and 3) an analysis of the impact that the resident's self-concept has upon the various aspects of interpersonal perception.

\section{MEASUREMENT OF I'HE SELF-CONCEPT}

The essential thrust of the interactionist theory of person.ality is that an individual has a "self" and that this self is constructed largely by the responses and attitudes of others. Measurement of the self-concept within our methodological framework is not directly concerned with the validation of this postu- 
late. That is, we have not chosen or designed a measuring device explicitly purporting to determine which, and to what extent, responses of others have been internalized and hence form an enduring part of the resident's self-concept. However we assume: 1) the crucial importance of understanding the self-concept within this framework and 2) maintain that data derived from any measuring device can be interpreted to reflect this position. More importantly, we are primarily concerned with an objective assessment of self-concept as it characterizes this residential population in this institution. In doing so, we have utilized a rigorous quantitative instrument known as the Interpersonal Check List (ICL). The ICI, was developed by a team of psychologists at the Kaiser Foundation Hospital in Oakland, California, for clinical and research purposes. ${ }^{1}$ The major underlying assumption influencing the construction of this inventory, and one that is consistent with the focus of this paper, is that personality is an interpersonal phenomenon. The interpersonal nature of the inventory derives from the fact that one can rate his perception of his own and/or other individual personalities and others can rate their perception of the individual's personality.

The ICL contains 128 descriptive adjectives or short phrases about qualities of personality (see Appendix A). These items are designed to measure sixteen variables of personality centering around two major axes: dominance-passiveness and friendlinesshostility. In addition to the major axes, all sixteen variables of personality are arranged on a circular continuum so that the 
correlation between any two is a decreasing function of their separation on the perimeter of the circle. The computational basis of the instrument rests on intensity scores of the major axes. We have, therefore, interpreted all scores in terms of these two axes.

Figure 1 depicts the organizational scheme within which all scores derived from the ICI (self and ideal) are statistically defined.

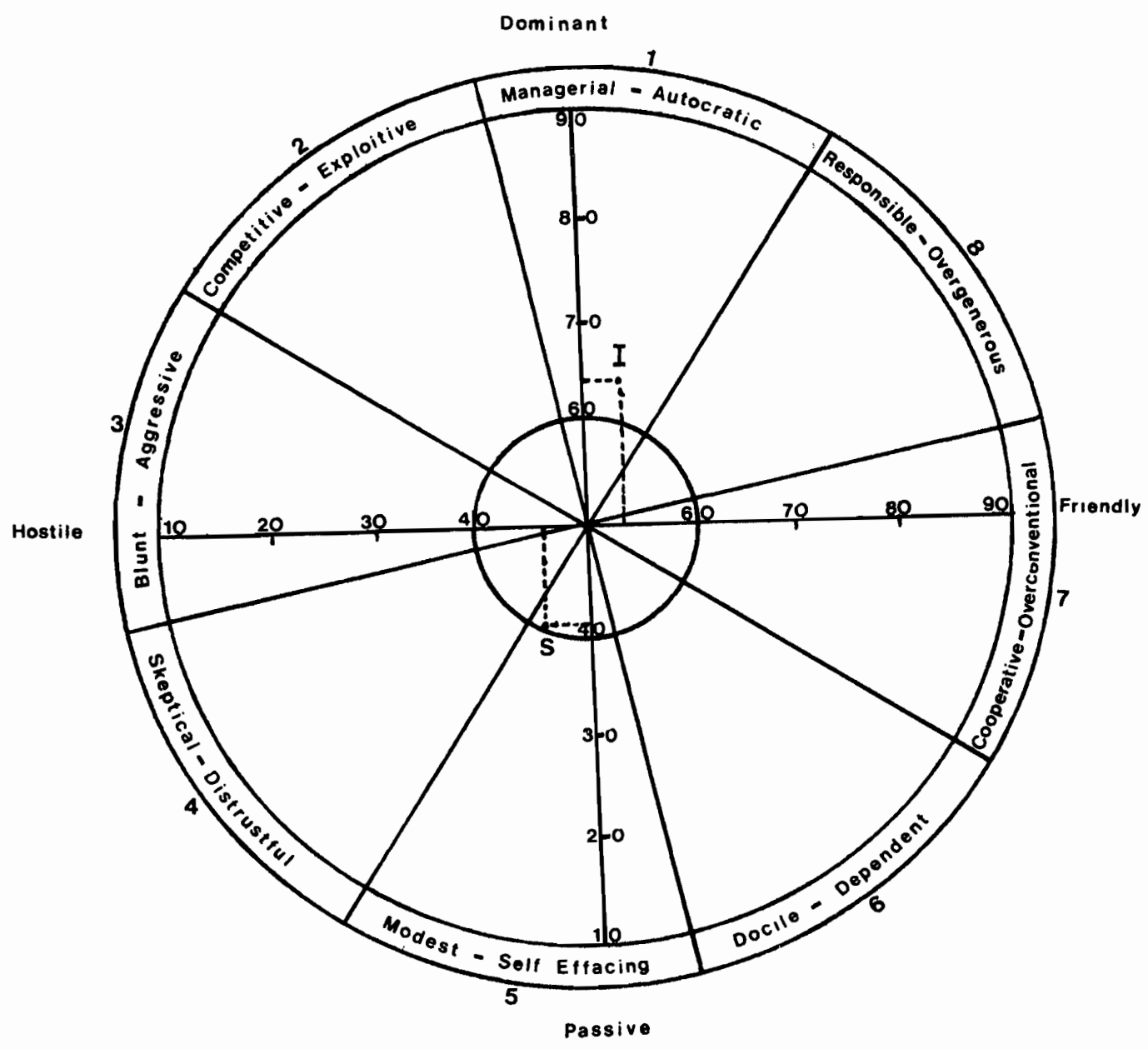

Figure 1. Summary point diagnosis of self and ideal self concepts by descriptive octant 
The reader should note first that the circle is divided vertically into a dominance axis (dominance-passiveness) and horizontally into a frierdliness axis (friendliness-hostility). Each axis is calibrated by intensity, the intersection of both axis (50) representing the mean of a normative, non-psychiatrically ill population. The small circle intersects both axes at one standard deviation; the circle is further divided into eight octants which are designated numerjcally and correspond to a descriptive diagnostic label. The first term of the label refers to an adaptive or moderate personality trait while the second designates a maladaptive or extreme personality trait. Thus, managerial is a moderate diagnosis for octant one while autocratic is an extreme diagnosis for the same octant.

An octant diagnosis depends upon the intensity scores of both axes and is arrived at in the following manner. Performance on each of the self and ideal self-concept questionaires is determined by tabulating the number of check marks for each of the eight rows of descriptive adjectives and phrases of the ICL. This data is converted, by formula, into a raw score and converted again, by ICL norms, into a standard score. These standard scores represent the intensity values of both axes and permit comparisons between scores. Standard scores (intensity scores) are calculated for both self and ideal questionaires and yield two scores for each: an intensity score for the dominance axis and one for the friendly axis. The intersection of these two points is referred to as a summary point. The octant that this summary point falls 
in represents the diagnosis for either the self or ideal concept. Raw scores, standard scores, and octant diagnosis by summary point for the entire population are located in Appendix C.

As an example of this process refer to Appendix $C$ and locate the standard scores for subject $A_{1}$ on both self and ideal performances. For the self-concept we obtain dominance and friendliness standard scores of forty and forty-five respectively. For the ideal self-concept we obtain dominance and friendliness scores of sixty-four and fifty-five respectively. The summary points designating the intersection of these scores is presented in Figure 1 and are labeled "S" (self-concept) and "I" (ideal self-concept). The summary point for $S$ falls within the inner circle and also within octant five. We conclude that this individual's selfconcept falls within the normal range and can be described as exhibiting a modest and adaptive personality trait.

By contrast, the summary point for I falls in octant one. Since this score falls outside the range of the normative inner circle we conclude that her ideal self-concept is extreme or autocratic. Note here that the operational definition of self rejection is the degree of discrepancy between $S$ and $I$. That is, to the extent that the subject wants to be other than she is, she rejects herself. Discrepancy indices have been calculated for all possible S-I combinations on this diagnostic circle. Similarly, they have been calculated for our entire population. We will not discuss the computational basis of these discrepancy indices here. Suffice it to say that if the difference between 
$S$ and I exceed a discrepancy score of forty-four the subject is considered to exhibit significant levels of self rejection. The amounts and kind of self rejection have been tabulated for each subject and are also listed in Appendix C. To return to our example, we note that subject $A_{1}$ rejects herself to a considerable degree (91) and devalues her own passivity; that is, her dominance score is plus eighty-nine indicating that she desires to be more dominant than she is.

The ICL is a uniquely flexible device. Because any given octant score is a function of the summary point axes scores, the researcher need not confine his analysis to octant diagnosis. When engaged in large scale research with this instrument it is frequently desirable to combine descriptive octants or simply discard them altogether and refer only to the axes scores. In most of our presentation we have used a variant of the two alternatives and simply eliminated reference to octant diagnosis. Instead we use the four remaining quadrants that directly refer to the two major axes (see Figure 2). This is a simple refinement. Instead of interpreting the summary point by its octant location we now interpret it by the quadrant it falls in. Four self-concept types emerge which simply reflect a summary point by quadrant: 1) dominant and hostile; 2) passive and hostile; 3) passive and friendly and 4) dominant and friendly. This modification in no way affects the computation or validity of the data; it simply reduces its descriptive complexity from eight octants to four quadrants. Thus, our subject's self-concept no longer receives a diagnosis of 


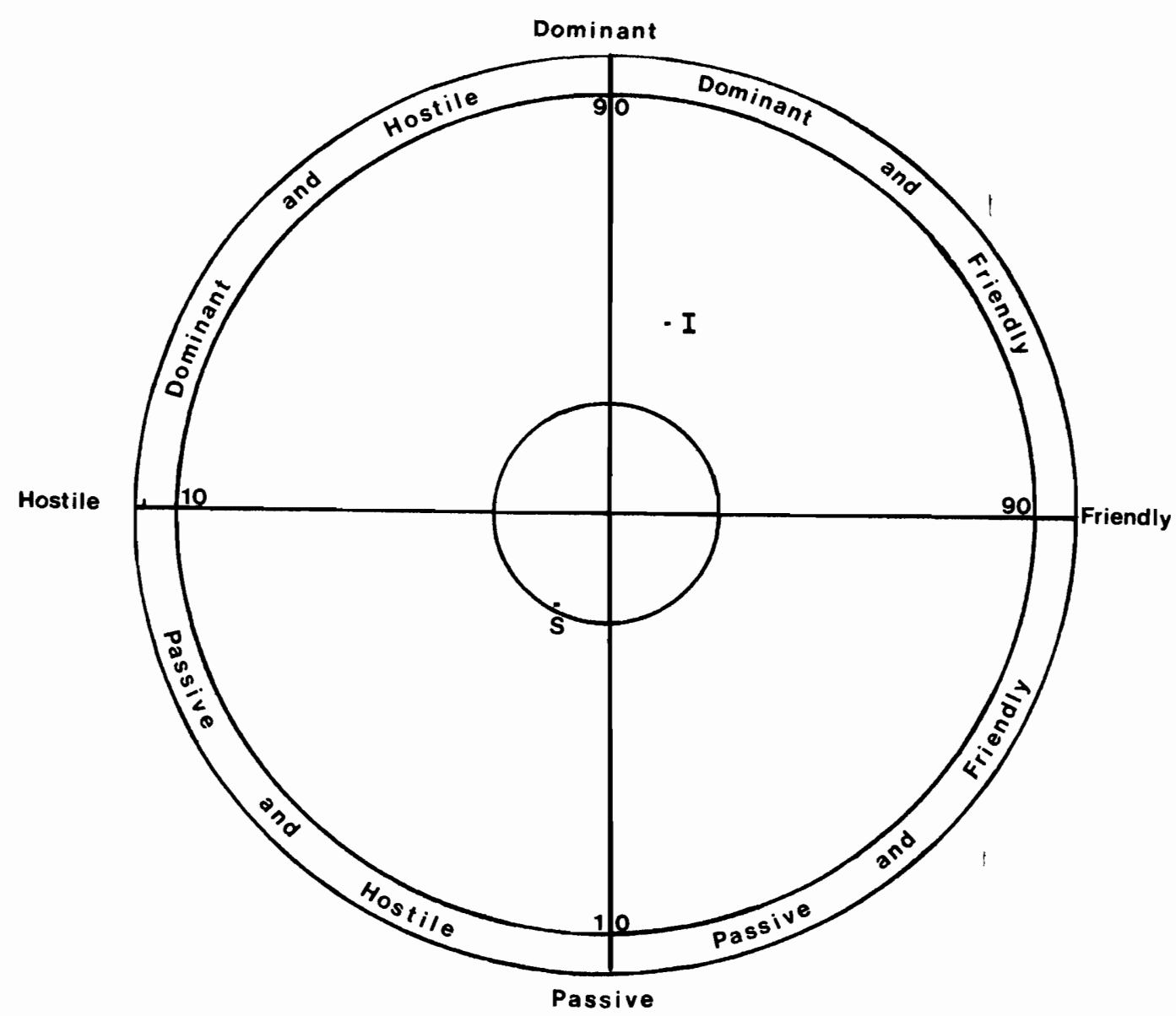

Figure 2. Summary point diagnosis of self and ideal self-concepts by major axes and descriptive quadrant

"modest;" she is instead passive and hostile. Similarly, she wants to be dominant and friendly as compared to autocratic.

The instmument provides an extensive compilation of performance norms for psychiatrically ill and non-psychiatrically ill (i.e. normals) populations. Any score derived from the ICL can be compared with these norms. However, these norms are based on adult, male and female populations and comparison of our adolescent sample is immediately subject to cautious generalization. We noted this difficulty early in the study and, at the invitation of 
the Kaiser Foundation, wrote to them specifically requesting performance norms for this adolescent population. We have not received a reply from them and can only assume that there are no norms available for this population. Any performance comparisons, therefore, are made with reference to existing adult norms.

Apart from the extensive compilation of performance norms contained in the ICL, which demonstrate that the inventory can discriminate types of self-concept among various populations, collateral research ${ }^{2}$ has provided validation for the assertion that the ICL does, indeed, measure two principle dimensions (axes) of self-concept. These dimensions have been successfully applied in the exploration of the role that the self-concept plays in mental illness, family interaction, and various perceptual processes. 3

Beyond its documented utility as a research device, the ICL is also used for clinical assessment of the individual case. This is the manner in which the instrument has been used at Villa Saint Rose. We hope to extend and concretize its use by administering the device to the entire population; norms thereby derived should provide important data by which other incoming residents can be evaluated.

The use of the ICL in this study is limited to the accumulation of two types of data, 1) the dominance and friendliness intensity scores of the self and ideal self concepts of the residents and 2) the extent of discrepancy between the self and ideal self expressed in degrees of self rejection. Thus we have 
obtained important information regarding: how each girl perceives herself. (self-concept), how she would like to perceive herself (ideal self) and the degree to which she is dissatisfied with her perception of self (self rejection).

\section{INTERPERSONAL PERCEPTION}

Because we established earlier the crucial importance of the "response of others" in shaping, maintaining, and changing the self-concept, we approached the exploration of the dynamics of interpersonal perception within the peer group through an analysis of the residents like and dislike choices distributed therein. Whether or not an adolescent is liked or disliked (the "response" of significant others) by her contemporaries is an important consideration since we know that their self-concepts are anchored within the peer group and depends upon her acceptance or rejection by these significant others. We assume that the same phenomenon exists within an institutional setting and is, in fact, much more intense since peer interaction is an unavoidable and indeed a requisite consequence of institutional existence. Any thoughtful observor of institutional processes can cite innumerable instances where acceptance or rejection by others, real or imagined, contributes significantly to the emotional fluxation of the resident: Rejection and isolation within a structured setting can drastically increase anxiety levels and thereby impede integration within the peer group. Precisely how the self-concept of the individual is influenced by this process is a significant question. 
As an exploratory design then, this study considers it crucial to understand, not only the self-concept profiles of the residents but also the nature of the interpersonal choice process in which they are engaged. We approach this second analytic task through a conceptual scheme known as "relational analysis" and a paridigm for organizing interpersonal choice data called "sociometric matrix analysis."

\section{Relational Analysis}

Tagiuri ${ }^{4}$ has noted that an understanding of interpersonal relationships depends upon the availability of information regarding two of its aspects: 1) the nature of the affective response (like and dislike choices given) of each person to the other and 2) the perception that each person has of the other persons response toward him. The analysis of any interpersonal relationship must consider these two components. Relational analysis represents a method of eliciting individual responses toward each other and collecting data on both the affective and perceptual components of the interpersonal relationship.

The Affective Component. Standard sociometric choice procedures provide simultaneously two types of data about any member of a group: 1) information about his affective response to others (whether he likes or dislikes them) and 2) information about others' affective response to him (whether others like or dislike him). Utilizing this paridigm to understand the interpersonal response system within this institution we asked each resident of Villa Saint Rose to designate (choose) those others whom she liked 
and disliked (see Appendix D). No limitations were placed on the number of such choices that the girl could make; she could choose as many or as few as she desired. Frequency data reflecting the number of like and dislike choices given and received by each resident was obtained in this manner. We conceived this data to represent the actual social situation of each girl insofar as it reflects the objective reality of who gives and receives varying numbers of choices at the time of testing.

The Perceptual Component. In addition to giving her affective response to others, each girl was asked to "guess" or "predict" which others would choose her as either liked or disliked (see Appendix E). Again no limitation was placed on the number of predictions a girl could make and frequency data was tabulated in the same manner as above. This data reflects the perceived social situation of the residents. That is, the number of guesses or predictions reflects the individuals perception of her actual social situation. What she perceives to be her actual social situation may diverge quite markedly from the existent reality. This, in fact, is the case and will be demonstrated quite clearly in the next chapter.

\section{Sociometric Matrix Analysis}

Throughout this study we were confronted with the collection and organization of prodigious amounts of quantitative data. This was particularly problematic with respect to the data derived from relational analysis. The combined components of the choice process required a tabulation of some 3200 choices, not including the 
necessity of discriminating between them and differentiating like from dislike choices.

These difficulties made it essential that we construct a data collection scheme that could intelligently organize large amounts of frequency data. This task was accomplished through the use of two sociometric matrixes, 5 one for data obtained from the actual social situation and the other for the perceived social situation of the girls. Both matrixes are structurally identical though the data are quite different (see Appendixes $F$ and $G$ ).

Each matrix requires that all girls be listed once as choosers (subjects) down the side of the page and again across the top of the page as chosen (objects). The reader will note that the girls names are not used. Instead a simple coding procedure was used where each girl received an alphabetical letter designating her group ( $\mathrm{A}=$ Sister Elizabeth, $\mathrm{B}=$ Sister Grace and $\mathrm{C}=$ Sister Monica) and a numeral designating her coded identity. This scheme resulted in the construction of two matrixes wherein frequency data could be tabulated and inspected visually for both components of the choice process. In effect the use of the sociometric matrix permitted us to order a potentially chaotic array of data and reduce both components of the choice process to two unified matrixes.

\section{INTERPERSONAI PERCEPTION AS A FUNCTION OF SETF-CONCEPT}

Although performance data on both the personality inventory and the interpersonal choice process were analyzed separately, the 
major task of this paper was to demonstrate, if possible, that the self-concept of the resident does affect the choice process and accounts for discrepancies between the two components of that process.

Using the two major axes of the ICL we found that four descriptive "types" of self-concept characterize the residential group. Girls saw themselves as either: 1) dominant and friendly; 2) dominant and hostile; 3) passive and friendly and 4) passive and hostile. These self-concept types were first correlated with the two components of the choice process separately. That is, we attempted to determine how closely a girl's self-concept is associ.. ated with her actual social situation and her perceived social situation.

Finally, and most importantly, the four self-concept types were applied in the interpretation of differences between the actual and perceived social situation. A major contribution of this study lies in demonstrating that disparities exist between these two components of the choice process--disparities that may be conceived as pathological and which can be viewed as a product of the type of self-concept that an individual manifests.

In all instances, examination of the various aspects of the choice process were correlated with length of stay. We felt that this one factor may predict the nature of the choice process equally or better than the self-concept profiles. 


\section{ADMINISTRATION OF THE DATA GATHERING INSTRUMENTS}

In one sitting, the entire residential population of Villa Saint Rose was administered a four part collection of instruments: 1) an ICL describing their self-concepts, 2) and ICL describing their ideal self-concepts, 3) a check list requesting the designation of like and dislike choices and 4) a check list requesting the designation of perceived like and dislike choices (the respective questionaires are located in Appendixes $A, B, D$ and $E$ ). Teachers administered the instruments in small groups and performed a most important function in clarifying and reiterating instructions. 
CHAPTER NOTES

1. Timothy Leary, Interpersonal Diagnosis of Personality (New York, 1957).

2. Scott Briar and James Bieri, "A Factor Analytic and Trait Inference Study of the Leary Interpersonal Checklist," Journal of Clinical Psychology, 19 (No. 2, 1963); Robert L. McDonald, "Leary's Overt Interpersonal Behavior: A Validation Attempt," Journal of Social Psychology, 74 (No. 2, 1968).

3. See for example: Simon Dinitz, A.R. Mangus and Benjamine Pasamanick, "Integration and Conflict in Self-Other Conceptions as Factors in Mental Illness," Sociometry, 22 (No. 3, 1959); James M. Terrill and Ruth E. Terrill, "A Method for Studying Family Communication," Family Process, 4 (No. 2, 1965); Harry S. Boyd and Vernon V. Sisney, "Immediate Self-Image Confrontation and Changes in Self-Concept," Journal of Consulting Psychology, 31 (No. 3, 1967); Oscar A. Parsons,

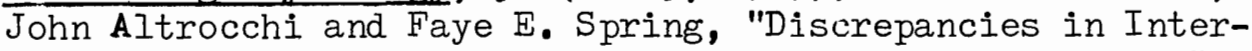
personal Perception, Adjustment, and Therapeutic Skills," Perceptual and Motor Skills, 18 (No. 2, 1964).

4. Renato Tagiuri, "Relational Analysis: An Extension of Sociometric Method with Emphasis upon Social. Perception," Sociometry, 15 (No. 1, 1952).

5. For a good discussion of the use of the sociometric matrix in large groups see, Matilda W. Riley, Sociological Research: A Case Approach (New York, 1963), pp. 1?6-181. 
CHAPTER IV

FINDINGS

Before discussing the findings, it would be well to note that apart from the data obtained through the use of the ICL and interpersonal choice questionaires, we did not consider other potential sources of information to be of significant value in our study. Immediate limitations were imposed on collateral data because of the nature of our exploratory design. To recapitulate briefly, our primary concerns in this study were: 1) to assess the nature of the self-concept and degree of self-rejection in this residential population; 2) to explore the nature of interpersonal pexception as manifest by certain sociometric choice processes and 3) to determine the extent to which types of self-concept could predict or distinguish between certain aspects of interpersonal perception. The accumulation and analysis of this data was indeed a ponderous task and one which precluded inclusion of other variables. The only additional variable that was utilized, and one that we strongly suspected would affect both the self-concept profiles and the processes of interpersonal perception, was the length of time a girl had been in residence. Although the average length of stay was 5.6 months, there was considerable variation about this mean (standard deviation (S.D.) 4.05 months). In most of the analyses to follow then, length of stay was considered to be a significant variable. 
All of the data to be discussed below is based on information gathered from the entire residential population at the time of testing $(N=40)$. We had anticipated a larger test population; however, a rash of runaway's occurred immediately prior to testing. Ages of these girls ranged from 14.2 to 17.9 years; with a mean age of 15.9 years (S.D. 1.06 years).

\section{SELF-CONCEPT, IDEAL SELF AND DEGREE OF SELF-REJECTION}

Summary points (refer to Chapter III) were calculated for both the self and ideal self-concepts of each of the forty girls in resi-. dence and then averaged to yield a mean performance score. In this manner we derived a measure of the "typical" self and ideal selfconcept of girls engaged in residential treatment at Villa Saint Rose.

Figure 3 indicates that the typical self-concept profile tends to be somewhat passive and hostile while the ideal self tends to be more dominant and friendly (we shall return to the significance of this discrepancy shortly). Note immediately that these summary points locate either within or closely to the inner circle. As we indicated in the previous chapter, the inner circle represents the normative performance limits for a non-psychiatrically ill, adult population. Since our residential sample is not equivalent (age difference) for comparative purposes we must excercise a degree of caution in generalizing from our data. We cannot conclude, for example, that these institutionalized adolescent girls exhibit nonpathological self or ideal self-concepts nor can we conclude that 


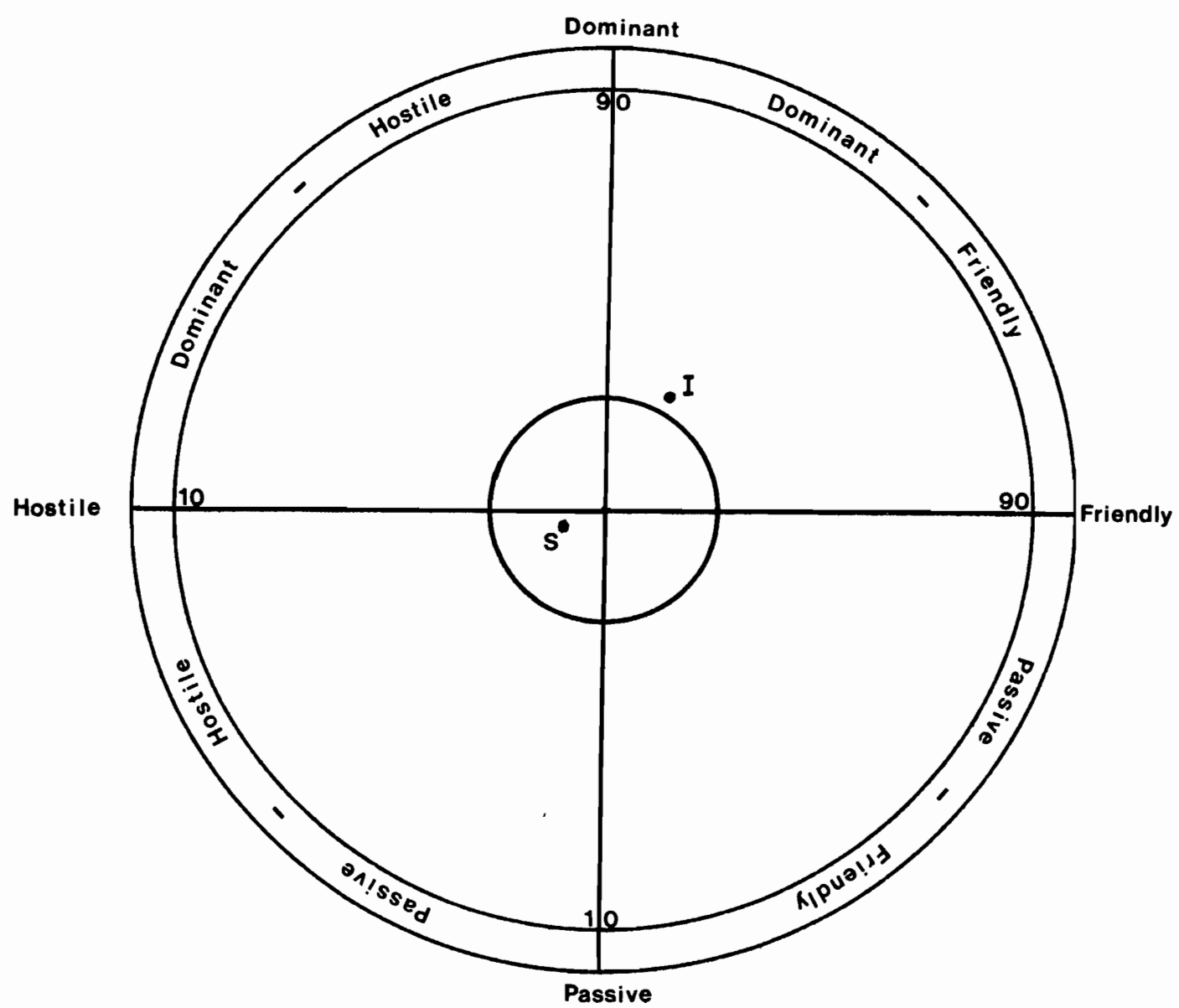

Figure 3. Mean surnmary point profiles of the residential population by self and ideal self-concepts.

they are essentially normal. We can conclude, however, that these self and ideal self profiles are representative of this adolescent female population engaged in treatment at this institution.

These limitations notwithstanding, we can now consider the pragmatic implications of this data. What can we expect, behaviorally, from these girls? Shostrom ${ }^{1}$ has developed a quite unique modification of the diagnostic circle and included the behavioral correlates of the self and ideal self-concepts. Figure 4 graphically illustrates the major "manipulative" orientations that 


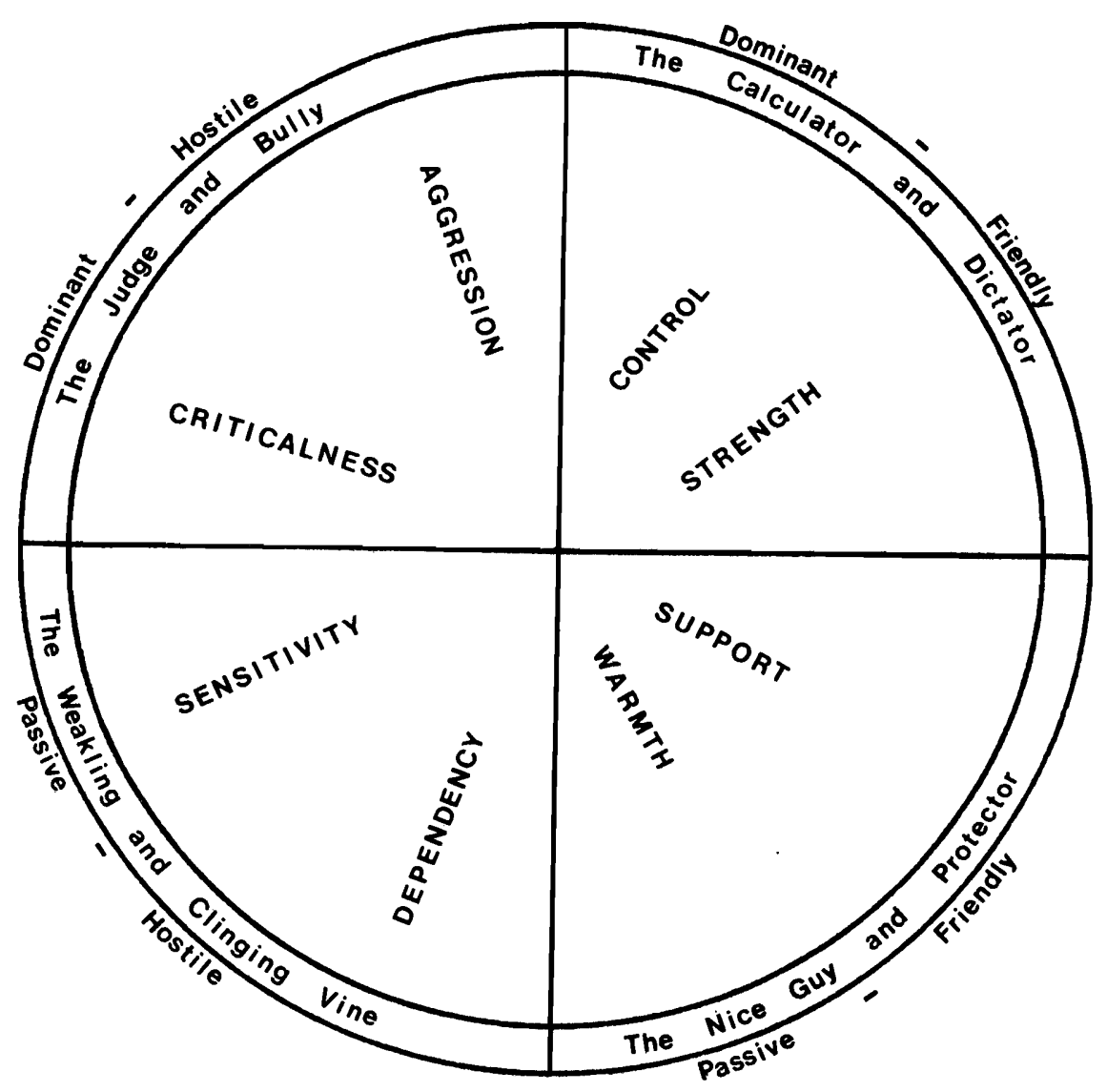

Figure 4. Manipulative orientations by four diagnostic types of self and ideal self-concepts.

coincide with the passive/hostile self-concept and the dominant/ friendly ideal self-concept.

Those girls who designate themselves as passive and hostile types assume a primary manipulative posture that reflects, ostensibly, sensitive and dependent behavior. To the extent that a girl exaggerates her sensitivity she may routinely enact the role of "The Weakling" in most interpersonal relationships. Her passivity may invite control and victimization by more dominant and aggressive peers. The weakling is known to all; she may mask her frail and 
impotent self-concept by enacting a number of dramatic scripts including "The Worrier," "The Giver-Upper," "The Confused One" and "The Withdrawer." By contrast, the passive and hostile girl who exploits and exaggerates her own dependency may act as if she wants to be led, fooled, or taken care of. She will typically let others do her work for her. Others may perceive her enactment of the dramatic role as "The Parasite," "The Crier," "The Perpetual Child," "The Attention Demander," and "The Helpless One."

The typical girl in Villa Saint Rose considers her ideal self to be the polar opposite of her passive and hostile self-conception. She also idealizes a manipulative orientation toward the world and others. She may want to exaggerate what little strength and contro]. she possesses and perhaps lead, advise, give, and sympathize more with others. If taken to extremes, her idealization of control may be reflected in the enacted role of the "calculator;" she may appear, at times, to be "The Seducer," "The Con-Artist," or "The Blackmailer." Her idealization of strength may also be excessive in which case she appears to others to be "dictatorial." She might attempt to dominate, order, and generally do anything that would control others. She may be known to others as "The Boss" and "Junior God."

The foregoing discussion was merely intended to be a descriptive formulation of the typical self and ideal self-concept as measured within this population. Not all girls could be described in these terms. This is particularly tmue with respect to the distribution of self-concept types. Table I indicates that there 
TABLE I

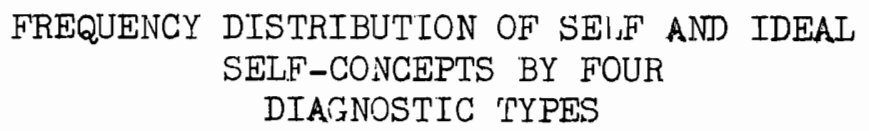

\begin{tabular}{|c|c|c|c|c|}
\hline \multirow{2}{*}{$\begin{array}{c}\text { Diagnostic } \\
\text { Types }\end{array}$} & \multicolumn{2}{|c|}{ SELF } & \multicolumn{2}{|c|}{ IDEAL } \\
\hline & $\mathrm{N}$ & $\%$ & $\mathrm{~N}$ & $\%$ \\
\hline $\begin{array}{l}\text { Dominant } \\
\text { Friendly }\end{array}$ & 9 & $22 \cdot 5$ & 32 & 80 \\
\hline $\begin{array}{l}\text { Dominant } \\
\text { Hostile }\end{array}$ & 8 & 20 & 6 & 15 \\
\hline $\begin{array}{l}\text { Passive } \\
\text { Hostile }\end{array}$ & 13 & 32.5 & 1 & 2.5 \\
\hline $\begin{array}{l}\text { Passive } \\
\text { Friendly }\end{array}$ & 10 & 25 & 1 & 2.5 \\
\hline Total & 40 & 100 & 40 & 100 \\
\hline
\end{tabular}

was much more variability in self-concept types than there was in the ideal type that these girls designated. While the modal selfconcept type locates in the passive and hostile quadrant, note that almost $70 \%$ of the population defined their self-concepts by either one of the other three diagnostic quadrants. By contrast, fully $80 \%$ of this population designated a fairly standard ideal type as dominant and friendly. Stated somewhat differently, regardless of the variation in self-concept most of these girls adopt an ideal self that is rather ridgidly defined (i.e. as dominant and friendily). To want to conform to this normative ideal is "O.K." There are, however, some personal consequences assumed, if one's self-concept varies significantly from the idealized norm: the girl rejects 
herself.

Self-rejection is operationally defined as the discrepancy between the self and ideal self-concepts. Analysis of individual discrepancies reveals that at least $60 \%$ of these girls reject themselves. Table 2 indicates that the amount of self-rejection is

TABLE II

MEAN SELF-REJECTION SCORE BY FOUR TYPES OF SELF-CONCEPT WITH COMPUTED

$T$ VALUES

\begin{tabular}{l|cccccc}
\hline \hline \multirow{2}{*}{$\begin{array}{c}\text { Self } \\
\text { Concept }\end{array}$} & Mean* & S.D. & $\mathrm{N}$ & $\mathrm{D}-\mathrm{H}$ & $\mathrm{P}-\mathrm{F}$ & $\mathrm{P}-\mathrm{H}$ \\
\hline $\begin{array}{l}\text { Dominant } \\
\text { Friendly }\end{array}$ & 33.11 & 17.82 & 9 & .926 & $3.776^{\mathrm{b}}$ & $7.64^{\mathrm{a}}$ \\
$\begin{array}{l}\text { Dominant } \\
\text { Hostile }\end{array}$ & 48.47 & 47.56 & 8 & - & 1.328 & $2.89^{\mathrm{b}}$ \\
$\begin{array}{l}\text { Passive } \\
\text { Friendly }\end{array}$ & 72.2 & 26.02 & 10 & - & - & $2.02^{\mathrm{c}}$ \\
$\begin{array}{l}\text { Passive } \\
\text { Hostile }\end{array}$ & 90.30 & 16.88 & 13 & - & - & - \\
\hline
\end{tabular}

* More than 44 defines high levels of self-rejection
a. P less than .001
b. P less than .01
c. P less than .05

related to the type of self-concept that a girl manifests. Those who perceived themselves to be passive and friendly and passive and hostile exhibit significantly higher indices of self-rejection than either of the two other self-concept types. Girls who see them- 
selves as passive and hostile dislike their self-concepts the most; girls who see themselves as dominant and friendly reject themselves the least and in fact accept themselves.

What do the self-rejectors dislike about themselves? Independent calculations of the kind of self-rejection manifested by these girls, reveal that in virtually all cases they devalue their own passivity; they would like to become much more dominant and less dependent than they now are.

Since we define self-rejection by degree of discrepancy between self and ideal self-concepts the normative ideal of the population (i.e. dominant and friendly) becomes the reference point by which one judges herself. To the extent that a girl's selfconcept fails to approximate the ideal norm we may expect to find increasing levels of self-rejection and the direction of desired change will be toward the actualization of the normative ideal Now, the significant questions to be raised regarding the causal basis of self-rejection are twofold. On one level the hypothesis could be advanced that high levels of self-rejection reflect defective elements of the self-concept and represent an extra-institutional phenomenon. Since we know, within our theoretical framework, that one's self-concept is the resultant of the responses of significant others, we might assume that high level self-rejectors were predisposed to have formed "rejecting" selfconcepts prior to engagement in residential treatment. From this perspective, the fact that $80 \%$ of the population exhibit a standard.. ized ideal may simply indicate that the ideal is a cultural stereo- 
type which a.l girls inculcate and carry into the institutional setting. Simply stated, this view suggests that the ideal self is not defective but self-concepts are, and that Villa Saint Rose has, through referral, "obtained" some of the more defective ones. The foregoing assumes that we have tapped real and defective self-concepts (high self-rejectors) and that the etiological basis lies outside the milieu of the residential setting. However, an equally plausible interpretation of self-rejection suggests that the milieu creates the problem. The fact that $80 \%$ of these girls idealize the virtues of dominance and friendliness may be less of an indication of the existence of a cultural stereotype than it is of an institutional stereotype; that is, an intra-institutional set of expectations, developed by peers and staff, with respect to "how one should be." If, indeed, such a set of normative expectations did exist within the residential milieu then one's self-concept would reflect the responses of significant others within the institution (i.e. staff and peers). The high selfrejectors may not be intrinsically self-rejecting but may develop these attitudes toward the self as they engage in focused, intense interaction with significant institutional others.

These are speculative hypotheses and we have no conclusive evidence substantiating or refuting either of them. They should sensitize us to the possibility that the milieu in which these girls are treated may have a significant impact upon whether or not a girl comes to accept or reject herself. Although we do not know the probable basis for the differ- 
ential types of self and ideal self-concepts nor the levels of self-rejection within this population, we do have some evidence that as a girl progresses through residential treatment changes occur in these variables. Table 3 gives the correlations between

TABLE III

PRODUCT-MOMENT CORRELATIONS BETWEEN

IENGTH OF STAY AND THE MAJOR

AXES OF SELF AND IDEAL

SELF-CONCEPTS

\begin{tabular}{c|cc}
\hline \hline Axis & SELF & IDEAI \\
\hline Dominance & .14 & .03 \\
Friendly & .09 & -.18 \\
\hline
\end{tabular}

length of institutional stay and the two major axis of the self and ideal self-concepts. These correlations are all very low and not statistically significant. However, one should note the direction of two of these correlations (Self-Dominance and IdealFriendly). Girls who have been in residence comparatively longer than others tend to exhibit an increase (Dominance +.14) in the intensity of the dominance dimension on self-concept. Older girls see themselves as less passive and more assertive than girls who have been in residence shorter periods of time. While some changes occur in the self, older girls also change aspects of their ideal self (Friendly $=-.18$ ). The longer a girl stays in residence the less she idealizes a self-concept that is friendly. These girls seem to want to become more hostile. One possible interpretation of these two correlations is based upon the phenomenon 
of group assimilation. Newly admitted, the girl may see herself as a passive, helpless creature, confronted by a large, and formidable group of strange peers. As a function of time (assimilation) the new girl gains confidence in the assertive capacity of the self (elevated dominance correlation), forms friendship bonds, and does not feel compelled to play out the passive dependent role in order to minimize conflict. At the same time, the older girl may realize that assimilation into the group had been a hard won battle; a battle in which it may "pay" to idealize a more hostile and less friendly self.

While the length of residential stay may also change some dimensions of the self and ideal self-concepts of these girls, it may also exercise some effect at decreasing levels of selfrejection. We obtained a correlation of -.12 between length of stay and degree of self-rejection. Although not significant we should again note the direction of change. There is a tendency towards increased levels of self acceptance as a girl increases her stay at Villa Saint Rose.

\section{INTERPERSONAL PERCEPTION}

\section{Population Performance}

Some of the findings presented above are only of peripheral interest in this study. Our first task was to explore the extent to which we could distinguish between different types of selfconcept within this residential setting. Data regarding the ideal 
self-concept and level of self-rejection were collated and interpreted within a framework that permitted a more precise understanding of a given self-concept profile. Again, our data indicates that four types of self-concept profiles characterize this adolescent population. The major task of this study was to demonstrate, if possible, that certain aspects of interpersonal perception could be explained by reference to this typology. Before presenting evidence indicating that this was indeed possible, we will examine the response system of the total residential population regarding interpersonal perception.

Recall that we defined interpersonal perception (refer to Chapter III) to be the resultant of two related processes: 1) how an individual feels about others and 2) how an individual perceives others feeling about her. The first dimension (affective choices given) was measured by asking each girl to designate whom she liked and disliked, while the second dimension (affective choices perceived as given by others) required her to guess or predict which others would say they liked or disliked her.

Table 4 depicts the total performance on both of these dimensions by considering the number of like and dislike choices given and perceived as given. Our calculations indicate that if each of the forty girls in residence at the time of testing had some definite feeling. (positive or negative) for every other girl in residence, then a population total of 1,560 choices given would result. This potential total would suggest that each girl was "linked" to every other girl by some type of affective bond. 
TABLE IV

NUMBER OF AFFECTIVE CHOICES GIVEN AND PERCEIVED

AS GIVEN BY THE RESIDENTIAL POPULATION

IN RESPONSE TO TWO SOCIOMETRIC

QUESTIONS $^{\mathrm{a}}$

\begin{tabular}{|c|c|c|c|c|c|c|c|c|}
\hline \multirow{2}{*}{$\begin{array}{c}\text { Kind } \\
\text { of } \\
\text { Affect }\end{array}$} & \multicolumn{4}{|c|}{$\begin{array}{l}\text { Number of Choices } \\
\text { Given }\end{array}$} & \multicolumn{4}{|c|}{$\begin{array}{c}\text { Number of Choices } \\
\text { Perceived }\end{array}$} \\
\hline & $\mathrm{N}$ & $\%$ & Mean & S.D. & $\bar{N}$ & $\%$ & Mean & $\overline{S . D .}$ \\
\hline Like & 895 & 57.4 & 22.4 & 5.9 & 759 & 48.7 & 19. & 7.8 \\
\hline Dislike & 285 & 18.3 & 7.1 & 4.8 & 280 & $17 \cdot 9$ & 7. & 6.6 \\
\hline None & 380 & 24.3 & - & - & 521 & 33.4 & - & - \\
\hline Total & 1560 & 100 & - & - & 1560 & 100 & - & - \\
\hline
\end{tabular}

a. Questions: Who do you like and dislike? Who do you think likes and dislikes you?

b. Maximum number of choices assumes each of forty (40) girls liking or disliking each of the other thirty-nine (39) girls $(40 \times 39=1560)$

Similarly, if every girl had some notion of how every other girl

felt about her (perception) the same total of 1,560 choices or predictions would result. The total 1,560 then, provided a convenient baseline from which the actual number of choices given and perceived as given could be compared.

With respect to the number of choices given we note that $73 \%$ of the total possible number of choices were actually distributed. This total indicates that, on the average, each girl had some definite feeling for approximately thirty of the other thirty-nine girls in residence (combined mean like and dislike responses). Although these girls do not say they like or dislike everyone there is a good deal of definite feeling expressed 
toward a large segment of the population. A preponderance of the affective choices given are positive (like $=57.4 \%$ ) indicating that these girls are not inclined to dislike many other girls (dislike $=18.3 \%)$.

Population performance regarding the girls predictions of others feelings for them were very similar to the findings above. These girls "see" a good deal of affect, both positive and negative being given to them by other girls. While they certainly cannot predict how everyone feels about them, they are capable of making a rather high number of predictions (66.6\% of total). Each girl, on the average, was able to predict the positive or negative feelings of approximately twenty-six other girls and most of this perceived affect was positive (like = $48.7 \%)$.

Interpretations of these findings revolve around two cental areas: 1) the quantity of affective response and 2) the quality of affective response. With respect to the quantity of affective choices given note that the two sociometric questions from which the data were derived did not require the girls to designate any specific number of choices. We wanted to assess the spontaneous, existing distribution of affect and realized that most of the girls would not have definite feelings for others nor be able to predict totally the feelings of others toward them. Our instructions notwithstanding, these girls still expressed rather high quantities of affective choices given and perceived a.s given. Furthermore, these quantities were not 
confined to choices made in the living group of the individual girl. One might logically expect these girls to be more certain about their affective feelings for others and anticipate with more certainty how others felt about them (i.e their "predictions") if these others were more intimately implicated with them in daily interaction; that is, if these others were members of the girls' living group. Independent calculations assessing the extent to which the quantity of choices were dependent on the girls' living group indicate that this simply was not the case. On the average, only $25 \%$ of a girls' total affective choices given were directed toward members of her living group. A slightly greater, though still relatively low percentage (40\%) of the perceived choices giver, were confined to a girls own living group.

These findings lead us to conclude that the large quantities of choices emitted on both dimensions of interpersonal perception are not primarily a result of a girls interaction within her own living group. Rather, we must conclude that interaction within the residential setting is sufficiently diffuse to permit a wide range of affective bonding (choices given) and the development of perceptual knowledge regarding the feelings of a great many others. If we assume the crucial importance of peer interaction as both a potential facilitator and/or inhibitor of treatment, and take our data as an index of that interaction, then it would seem that a girls living group exerts only partial control over the total range of her interactional possibilities. A great 
deal of interaction occurs beyond the rather artificial boundaries of the "living group."

The quality of interpersonal relationships within the residential setting is also reflected in our data. The comparatively large numbers of positive affect (like choices) given and perceived as giver indicate a certain degree of cohesiveness within the residential unit. By and large the residential population is optimistic toward relationships. Translating our data, most girls seem to be saying: "I like many girls here (choices given) and believe (perceived choices given) that they also like me."

Although our data does not explain the rather positive orientation in interpersonal perception, we suspect that it may be a function of two interrelated factors. First, the world of the average adolescent is constructed in a Pollyanna like manner; she tends to minimize rather than maximize individual differences and hence solidify a position of acceptance within her peer group of "significant others" whose positive regard she values. Secondly, the nature of institutionalization may serve to intensify the expression as well as perception of positive affect in interpersonal relationships. Minimizing interpersonal conflict within a residential setting is a unique adjustive mechanism for many girls. "Acceptance" and "rejection," already significant symbols around which the average adolescent predicates self esteem, become ever more important when: 1) her peer group of significant others is not self determined but instead consist of 
a group of strangers and 2) the structure of a confined institutional setting requires rather intense, focused modes of interaction. It would be a rare breed of adolescent who, when placed in a structured group setting, could tolerate the isolation that must necessarily follow if she dislikes many others nor could she "feel" accepted if her perceptual hypothesis conceived others as disliking her to any great degree. The girls have a "vested interest," as it were, in developing and maintaining relatively conflict free relationships.

\section{The Self-Concept and Interpersonal Perception}

The foregoing analysis yields a descriptive presentation of data resulting from the total population response to two sociometric choice questions. Here we noted certain residential trends in both the quantity and quality of affective choices given to others and perceived as given by others as they were distributed throughout the interactional network of the residential setting.

Some information accumulated on the nature of the choice process was neglected in this broad level of analysis. In effect we considered only the aggregate of individual responses directed to the group (i.e. who do you like-dislike?) and did not consider the groups response to the individual (i.e. number of choices received). This omission was actually an artifact of the choice process since the total number of choices given will equal the number received if we confine analysis to the population perse. 
We will not discuss this point further, except to indicate that when we begin to analyze indivjdual choices given and received no such equality exists; some girls give out more choices than they receive and others receive more than they give. The individual variations are "masked" in a population analysis.

These differences became even more apparent by ordering individuals by our four self-concept types and attempting to determine whether or not self-concept has any discernable effect on the two dimensions of the choice process. Recall that earlier (Chapter III) we characterized the choices given and received, and perceived as given and received as the "Actual Social Situation" and "Perceived Social Situation" respectively. We use this same paridigm in determining whether or not the nature or type of a girls self-concept determines her performance in interpersonal perception.

With respect to the actual social situation of the girls we define this dimension to be the number of: 1) like choices given; 2) dislike choices given; 3) like choices received and 4) dislike choices received. That is to say, the number of other girls that are liked and disliked by the individual and the number. of like and dislike choices received from others by the same individual is a measure of her performance and position relative to the existing (actual) affective network of relationships within the residential group.

Does the self-concept of a girl affect her actual social situation as herein defined? Table 5 depicts the average number 


\section{TABLE V}

MEAN NUMBER OF AFFECTIVE CHOICES GIVEN AND RECEIVED BY TYPE OF SELF-CONCEPT

\begin{tabular}{|c|c|c|c|c|c|c|c|c|}
\hline \multirow{3}{*}{$\begin{array}{l}\text { Type of } \\
\text { Self- } \\
\text { Concept }\end{array}$} & \multicolumn{4}{|c|}{ Number of Choices Given } & \multicolumn{4}{|c|}{ Number of Choices Received } \\
\hline & \multicolumn{2}{|c|}{ Like } & \multicolumn{2}{|c|}{ Dislike } & \multicolumn{2}{|c|}{ Like } & \multicolumn{2}{|c|}{ Dislike } \\
\hline & Mean & S.D. & Mean & S.D. & Mean & S.D. & Mean & S.D. \\
\hline $\begin{array}{l}\text { Dominant } \\
\text { Friendly }\end{array}$ & 23.11 & 6.27 & 5.11 & 3.75 & 22.89 & 3.68 & 7.33 & 5.07 \\
\hline $\begin{array}{l}\text { Dominant } \\
\text { Hostile }\end{array}$ & 21.88 & 5.27 & 10.63 & 4.74 & 22.13 & 10.37 & 7.25 & 5.67 \\
\hline $\begin{array}{l}\text { Passive } \\
\text { Friendly }\end{array}$ & 22.80 & $5 \cdot 94$ & 6.90 & 4.28 & 24.20 & 6.57 & 5.80 & 4.02 \\
\hline $\begin{array}{l}\text { Passive } \\
\text { Hostile }\end{array}$ & 21.85 & 6.61 & 6.54 & 5.19 & 20.69 & 6.47 & 8.23 & 3.14 \\
\hline
\end{tabular}


of affective choices eriven and received by girls with four types of self-concept. As an example of interpretation consider the performance indices of the dominant-friendly types. Girls with this type of self-concept say they like, on the average, twentythree other girls and dislike five. These same girls are liked (choices received), on the average, by twenty-two girls and disliked by seven.

The focus of interest here, concerns the significance of the mean differences among each of the four aspects of the choice process by self-concept type. Table 6 considers the significance of these mean differences as a function of the girls self-concept. Number of Like Choices Given. While the dominant and friendly types appear to say that they like more girls (23.11) than any of the other three self-concept types, this difference is not statistically significant. It would seem that, regardless of self-concept, most girls are similar in the degree to which they distribute their positive affective choices.

Number of Dislike Choices Given. The girls with dominanthostile self-concepts say they dislike approximately twice as many more girls $(10.63)$ than either of the three self-concept types. This difference is statistically significant. Each of the three other self-concept types distribute considerably less negative affect in their interpersonal environment than do the dominant and hostile types. It is interesting to note here that the relatively higher number of dislike choices given by these girls extends their total range of distributed affect. That is, 
TABLE VI

T VAIUES OF MEAN DIFFERENCES AMONG AFFECTIVE CHOICES GIVEN AND RECEIVED BY TYPES OF SEIF-CONCEPT

\begin{tabular}{|c|c|c|c|c|c|c|c|c|}
\hline \multirow{3}{*}{$\begin{array}{c}\text { Type of } \\
\text { Self-Concept } \\
\text { Relationship }\end{array}$} & \multicolumn{4}{|c|}{ Number of Choices Given } & \multicolumn{4}{|c|}{ Number of Choices Received } \\
\hline & \multicolumn{2}{|c|}{ Like } & \multicolumn{2}{|c|}{ Dislike } & \multicolumn{2}{|c|}{ Like } & \multicolumn{2}{|c|}{ Dislike } \\
\hline & $\mathrm{T}$ & $\mathrm{P}$ & $\mathrm{T}$ & $P$ & $\mathrm{~T}$ & $\mathrm{P}$ & $\mathrm{T}$ & $\mathrm{P}$ \\
\hline $\begin{array}{l}\text { Dominant-Friendly } \\
\text { Dominant-Hostile }\end{array}$ & 0.43 & NS & 2.68 & $P<.02$ & 0.20 & NS & 0.64 & NS \\
\hline $\begin{array}{l}\text { Dominant-Friendly } \\
\text { Passive-Friendly }\end{array}$ & 0.11 & NS & 0.96 & NS & 0.53 & NS & 0.35 & NS \\
\hline $\begin{array}{l}\text { Dominant-Friendly } \\
\text { Passive-Hostile }\end{array}$ & 0.44 & NS & 0.70 & NS & 0.92 & NS & 0.52 & NS \\
\hline $\begin{array}{l}\text { Dominant-Hostile } \\
\text { Passive-Firiendly }\end{array}$ & 0.34 & NS & 1.76 & $P<.10$ & 0.51 & NS & 0.64 & NS \\
\hline $\begin{array}{l}\text { Dominant-Hostile } \\
\text { Passive-Hostile }\end{array}$ & 0.01 & NS & 1.81 & $P<.10$ & 0.39 & NS & 0.51 & NS \\
\hline $\begin{array}{l}\text { Passive-Friendly } \\
\text { Passive-Hostile }\end{array}$ & 0.35 & NS & 0.18 & NS & 1.28 & NS & 1.64 & NS \\
\hline
\end{tabular}


although they tend to dislike many more girls than most of their peers, they do not like any less (like given $=21.88$ ). We would, therefore, caution against an interpretation of the relatively higher indices of dislike choices as an indication that the dominant and hostile girl "alienates" others. It may very well be, given the higher gross affect distributed (combined like and dislike choices) that these girls participate in interaction much more intensely than others and are more discriminating with respect to whom they give their "allegiance."

Number of Like Choices Received. The number of choices received may be taken as an index of the quantity and quality of the peer groups reaction (response) to a given individual. All self-concept types receive about the same quantity of "positive regard" (like choices) from their peer group of significant others. Although Table 5 seems to suggest that the passivefriendly girl is liked more $(24.20)$ and the passive-hostile girl liked less than others (20.69), none of these differences are statistically significant.

Number of Dislike Choices Received. Again, it appears that the passive-friendly and passive-hostile girl receives respectively less and more dislike responses from others than do other selfconcept types. These differences are not statistically significant. However, despite the failure to obtain significant differences here, two trends in group response seem noteworthy. First, the passive and friendly girl appears to be generally more liked and less disliked than any of the other three 
self-concept groups. Secondly, the passive and hostile girl is liked by fewer and disliked by more girls than any other group. It would seem then, that these two self-concept types invite an entirely different set of reactions from the residential population. The passive and friendly girl seems to evoke a comparatively more positive reaction (high number of like received and low number of dislike received) from her peers than does the passive and hostile girl, who tends to evoke the most intense negative reaction (low number of like received and high number of dislike received).

If we assume (as the interactionist theory of the self clearly does) that the nature of one's self-concept affects, and is affected by, the responses of others then it may well prove crucial to explore the basis for the residential group's differential evaluation of these two self-concert types. Our data does not provide anything except a superficial and speculative interpretation of these findings. However, more extensive research with these two self-concept types may indicate that they do in fact polarize group affect toward them (i.e. positive and negative) and either limit or facilitate their integration within the residential community.

We have seen that the nature of a girl's self-concept does exert a partial influence over certain aspects of their actual social situation. The second component of interpersonal perception explores the girl's perceptions of her actual social situation. We defined the "Perceived Social Situation" to be: 
1) the number of like choices perceived (i.e. "predicted") f'rom others; 2) the number of dislike choices perceived from others; 3) the number of perceptions of like received and 4) the number of perceptions of dislike received (see Table 7, Footnote b for explanation of the meaning of numbers 3 and 4 ). The addition of the perceptual component is a necessary adjunct to the complex processes of interpersonal perception, for the reality (actual social situation) of a girls interpersonal relationships may be at variance with her perceptions of that reality. We will examine the significance of this discrepancy shortly. First we will proceed with an analysis of the four aspects of the perceived social situation as they are determined by self-concept type.

Does the nature of a girl's self-concept influence her perceptions of peer response or the groups perception of her response? Table 7 depicts the average number of perceived choices given and received by four types of self-concept. As an example of interpretation consider the performance indices of the passive-hostile girl. On the average, these girls perceive sixteen other girls liking them and six others disliking them. On the average, eighteen other girls perceive the passive and hostile girl as liking them while six others perceive the passive and hostile girl as disliking them. In effect, the number of perceived choices received by each self-concept type reflects peer predictions of what they believe the actual response of the girl will be. Again, the focus of analysis lies in determining 


\section{TABLE VII}

MEAN NJMBER OF AFFECTIVE CHOICES PERCEIVED AS GIVEN AND RECEIVED BY TYPE OF SELF-CONCEPT

\begin{tabular}{|c|c|c|c|c|c|c|c|c|}
\hline \multirow{3}{*}{$\begin{array}{l}\text { Type of } \\
\text { Self- } \\
\text { Concept }\end{array}$} & \multicolumn{4}{|c|}{ Number of Choices Given ${ }^{a}$} & \multicolumn{4}{|c|}{ Number of Choices Received b } \\
\hline & \multicolumn{2}{|c|}{ Like } & \multicolumn{2}{|c|}{ Dislike } & \multicolumn{2}{|c|}{ Like } & \multicolumn{2}{|c|}{ Dislike } \\
\hline & Mean & $S . D$. & Mean & S.D. & Mean & $S . D$. & Mean & S.D. \\
\hline $\begin{array}{l}\text { Dominant- } \\
\text { Friendly }\end{array}$ & 22.11 & 6.62 & 3.66 & 3.35 & 19.22 & 4.54 & 7.44 & 3.43 \\
\hline $\begin{array}{l}\text { Dominant- } \\
\text { Hostile }\end{array}$ & 20.75 & 8.46 & 10.00 & 6.32 & 18.25 & $5 \cdot 59$ & 6.87 & 1.72 \\
\hline $\begin{array}{l}\text { Passive- } \\
\text { Friendly }\end{array}$ & 17.00 & 9.67 & 7.60 & 6.39 & 19.00 & 6.09 & 6.20 & 3.55 \\
\hline $\begin{array}{l}\text { Passive- } \\
\text { Hostile }\end{array}$ & 16.84 & 6.65 & 6.92 & 6.67 & 18.53 & $5 \cdot 39$ & 6.69 & 2.49 \\
\hline
\end{tabular}

a. Data refers to the number of the individual's predictions of others positive or negative feelings for her.

b. Data refers to the number of predictions received and represents others prediction's of how they think another will respond. 
the significance of the mean differences among each of the four aspects of the perceptual choice process by type of self-concept. Table 8 considers the significance of these differences as a function of self-concept type.

Number of Perceived Like Choices Given. Table 7 suggests that there was a great deal of variance in the number of perceptions of others a given self-concept type designated as liking them. It appears, for example, that the dominant and friendly girls perceive much more positive regard in their immediate network of peer relationships than any other of the remaining selfconcept types. The passive and hostile girls, by contrast, "see" comparatively little affection directed toward them by others (perceived like given $=16.84$ ) relative to the other self-concept groups. However, only two mean differences are statistically significant. We can conclude, with some degree of statistical reliability, that those girls who view themselves as dominant and friendly see much more affection in their residential environment than do the passive and hostile types, who see significantly less. The trend toward lower number of perceived like choices among the two "passive" groups should be noted. These findings suggest that the nature of a girl's self-concept is related to the perceptual hypothesis she forms regarding others positive feelings for her.

Number of Perceived Dislike Choices Given. All girls, by self-concept type, appear to vary considerably in the extent to which they perceive negative affect in their residential milieu. 
TABLE VIII

$T$ VALUES OF MEAN DIFFERENCES AMONG AFFECTIVE CHOICES PERCEIVED AS GIVEN AND RECEIVED BY

TYPES OF SELF-CONCEPT

\begin{tabular}{|c|c|c|c|c|c|c|c|c|}
\hline \multirow{3}{*}{$\begin{array}{c}\text { Type of } \\
\text { Self-Concept } \\
\text { Relationship }\end{array}$} & \multicolumn{4}{|c|}{ Number of Choices Given } & \multicolumn{4}{|c|}{ Number of Choices Received } \\
\hline & \multicolumn{2}{|c|}{ Like } & \multicolumn{2}{|c|}{ Dislike } & \multicolumn{2}{|c|}{ Like } & \multicolumn{2}{|c|}{ Dislike } \\
\hline & $\mathrm{T}$ & $P$ & $\mathrm{~T}$ & $\mathrm{P}$ & $\mathrm{T}$ & $P$ & $\mathrm{~T}$ & $\mathrm{P}$ \\
\hline $\begin{array}{l}\text { Dominant-Friendly } \\
\text { Dominant-Hostile }\end{array}$ & 0.37 & NS & 2.63 & $P<.02$ & 0.40 & NS & 0.43 & NS \\
\hline $\begin{array}{l}\text { Dominant-Friendly } \\
\text { Passive-Friendly }\end{array}$ & 1.33 & NS & 1.65 & NS & 0.09 & NS & 0.77 & NS \\
\hline $\begin{array}{l}\text { Dominant-Friendly } \\
\text { Passive-Hostile }\end{array}$ & 1.84 & $P_{<.10}$ & $1 \cdot 32$ & NS & 0.31 & NS & 0.47 & NS \\
\hline $\begin{array}{l}\text { Dominant-Hostile } \\
\text { Passive-Friendly }\end{array}$ & 0.86 & NS & 0.80 & NS & 0.27 & NS & 0.29 & NS \\
\hline $\begin{array}{l}\text { Dominant-Hostile } \\
\text { Passive-Hostile }\end{array}$ & 1.20 & NS & 1.05 & NS & 0.11 & NS & 0.18 & NS \\
\hline $\begin{array}{l}\text { Passive-Friendly } \\
\text { Passive-Hostile }\end{array}$ & 0.05 & NS & 0.25 & NS & 0.20 & NS & 0.39 & NS \\
\hline
\end{tabular}


However, not all the mean differences are significant. The dominant and hostile girl perceives significantly more negative affect (perceived dislike given $=10.00$ ) being directed to them by others than do the dominant and friendly types, who see significantly less (perceived dislike given $=3.66$ ). It is interesting to note again the relatively higher dislike indices for the dominant and hostile girl. We saw earlier that these girls also tended to say they disliked more girls than any of the other three self-concept types. The same caution also applies to the interpretation of their performance on the perceptual component as was the case earlier. We might, for example, hastily conclude that the dominant and hostile girl is predisposed to "see" only the negative reaction of her peers. Again, this is simply not the case. While it is true that the dominant and hostile girl tends to perceive more negative affect than other self-concept types she does not, concurrently, perceive less positive affect. The net affect of their performance on the perceptual dimension is to extend, more than other girls, the total range of their perceptions. Whether or not the dominant and hostile types perceptions are "reality based" (i.e. are an accurate perception of others feelings) will be considered shortly. For the moment, simply note that these girls are more inclined to state, evidently with some degree of confidence, who they believe does or does not like them.

Number of Perceived Like and Dislike Choices Received. The nature of a girls' self-concept does not appear to bear any signif- 
icant relationship to how the group predicts another will

respond. Regardless of self-concept, most girls receive between eighteen and nineteen predictions of a like response from the residential group. That is, most girls are "thought of" as liking between eighteen and nineteen other girls irrespective of whether or not they in fact do. Similarly, most girls are thought of as disliking between six and seven other girls in the residential community irrespective of whether or not they in fact do.

In a further attempt to understand the basis of interpersonal perception within this residential population we did not confine our analysis to self-concept types. Each of the four aspects of interpersonal choice on both components of interpersonal perception were correlated with length of time a girl had been in residence.

Table 9 yields the correlation coefficients derived from

TABLE IX

PRODUCT-MOMENT CORRELATIONS BETWEEN LENGTH OF INSTITUTIONAL STAY AND TWO COMPONENTS OF INTERPERSONAI PERCEPTION

\begin{tabular}{|c|c|c|c|c|}
\hline \multirow{2}{*}{$\begin{array}{l}\text { Component of } \\
\text { Interpersonal } \\
\text { Perception }\end{array}$} & \multicolumn{2}{|c|}{ Like Choices } & \multicolumn{2}{|c|}{ Dislike Choices } \\
\hline & Given & Received & Given & Received \\
\hline $\begin{array}{c}\text { Actual } \\
\text { Social } \\
\text { Situation }\end{array}$ & -.26 & .25 & .19 & .14 \\
\hline $\begin{array}{l}\text { Perceived } \\
\text { Social } \\
\text { Situation }\end{array}$ & .24 & .23 & .04 & .07 \\
\hline
\end{tabular}


the measured relationship between length of stay and the number of like and dislike choices, given and received, on both the actual and perceptual components of interpersonal perception. Note first that all correlations are low and not statiscally significant. However, we should be cognizant of the general direction of the correlated relationship which seems to indicate some important differences between the younger and older girls in residence.

With respect to the actual system of interpersonal relationships, the longer a girl is in the treatment program the less she is inclined to like others $(r=-.26)$ and more she is inclined to dislike others $(r=+.19)$. At the same time, the "older girl" tends to experience an increase in the degree to which she is both liked $(r=+.25)$ and disliked $(r=+.14)$ by others. We would suggest a common sense interpretation of these general trends based on solidification of a power base within the residential community. We see an increased reliance on a few significant interpersonal relationships which suggest a general tendency towards clique formation as a function of length of stay. The simultaneous increase in both like and dislike choices received would seem to indicate a polarization of group response to the older girl.

There is also a general tendency for the length of stay to exert a partial effect on a girl's perceptions of her actual social situation. The older girl perceives more girls liking her $(r=+.24)$ than does the girl who has been in residence a 
comparatively shorter period of time. At the same time the older girl tends to be seen as more friendly $(r=+.23)$ by her peers who predict that she will like them. Length of stay seems to have absolutely no measurable impact upon a girls perceptions of the number of girls who dislikes her $(r=+.04)$ nor the number of girls who predict that a given girl will dislike them more than others $(r=+.07)$.

\section{Pathological Implications of Certain Self-Concept Types}

We have, until now, omitted reference to the discrepancy between a girl's actual social situation and her perception of that social situation. Although each of these components are intimately, and reciprocally related to the process of interpersonal perception, we have considered them as separate dimensions for purposes of intensive analysis. Each of these two components has been analyzed as a function of self-concept. Now, however, we will relate the self-concept types to the degree of discrepancy between these two components.

Recall that one major application of the interactionist theory of the self is its utility in articulating the relationship between interpersonal perception and pathology. We noted earlier that this most significant relationship was subsumed under the "accurate role-taking model" wherein the ability to accurately predict the response of significant others is deemed crucial to the adequate adjustment of the individual. Our data provides a unique opportunity to explore the degree of pathology charac- 
teristic of this residential population and is predicated upon the accuracy of role-taking functions of the individual girl. More importantly, our utilization of an objectively scored personality inventory has permitted us to relate the degree of pathology to self-concept type.

Since accurate role-taking has been operationally defined as the "successful prediction of another's response" we utilize two sources of information already reflected in our data: 1) the number of peers that an individual girl perceives or "predicts" will respond to her in a given way (i.e. like or dislikes her) and 2) the number of girls who actually respond to her (choices received) in the predicted manner. The larger the discrepancy between (1) and (2) the more severely impaired are the accurate role-taking functions of the girl, and by definition, the more pathology exists.

Table 10 yeilds data which tests the role-taking accuracy of the residential population and relates the discrepancy indices to the type of self-concept that an individual girl manifests. A large segment of the residential population, with the exception of the dominant and friendly girls, are comparatively inaccurate in predicting the amount of positive affect (Iike choices received) being directed toward them. The nature of the role-taking inaccuracy clearly lies in the direction of underestimating the positive regard that others feel for them. This deficit is significantly pronounced in the passive-friendly and passive-hostile groups who exhibit marked, and we would say 
TABLE X

ROLE-TAKING ACCURACY: MEAN DIFFERENCES BETWEEN THE PREDICTED AND ACTUAL NUMBER OF AFFECTIVE RESPONSES RECEIVED FROM OTHERS BY TYPE OF SELF-CONCEPT

\begin{tabular}{|c|c|c|c|c|}
\hline \multirow{2}{*}{$\begin{array}{c}\text { Type of } \\
\text { Self- } \\
\text { Concept }\end{array}$} & \multicolumn{2}{|c|}{ Like Choices } & \multicolumn{2}{|c|}{ Dislike Choices } \\
\hline & $\begin{array}{l}\text { Number } \\
\text { Predicted vs }\end{array}$ & $\begin{array}{l}\text { Number } \\
\text { Received }\end{array}$ & $\begin{array}{c}\text { Number } \\
\text { Predicted vs }\end{array}$ & $\begin{array}{c}\text { Number } \\
\text { Received }\end{array}$ \\
\hline $\begin{array}{l}\text { Dominant- } \\
\text { Friendly }\end{array}$ & 22.11 & 22.89 & 3.66 & $7 \cdot 33^{a}$ \\
\hline $\begin{array}{l}\text { Dominant- } \\
\text { Hostile }\end{array}$ & 20.75 & 22.13 & 10.00 & 7.25 \\
\hline $\begin{array}{l}\text { Passive- } \\
\text { Friendly }\end{array}$ & 17.00 & $24 \cdot 20^{\mathrm{a}}$ & 7.60 & 5.80 \\
\hline $\begin{array}{l}\text { Passive- } \\
\text { Hostile }\end{array}$ & 16.84 & $20.64 a$ & 6.92 & 8.23 \\
\hline
\end{tabular}

$a=T$ value of mean difference exceeds .05

severe, impairment in their role taking capacities. Considered together, these two groups comprised almost $60 \%$ of the residential population at the time of testing.

In contrast to the misperception of positive affect, most of the residential population is rather accurate in predicting the amount of negative affect (dislike choices received) directed toward them by the larger residential group. Only the dominant and friendly group exhibit any impairment in role-taking accuracy, and this group accounts for less than $25 \%$ of the residential population. These girls underestimate the amount of negative affect that others direct toward them. Let us examine more closely the extent of perceptual deficits reflected by the four 
self-concept types.

Dominant and Friendly Girls. These girls would say: "I believe that I am well liked and rarely disliked." The dominant and friendly girl estimates quite accurately the amount of positive regard directed toward them. These same girls are grossly inaccurate in estimating the negative affect being directed toward them. They accurately predict less than $50 \%$ of the total amount of the dislike choices that they in fact receive from others. For some reason, these girls appear to be "selectively sensitive" to others feelings for them. They either misperceive and.or simply deny the negative aspects of their interpersonal relationships with their peers. To speculate therapeutically, we note that modification of behavior and attitudes depends on the ability to attend to positive as well as negative feedback systems. If this is indeed the case, we might logically expect the dominant and friendly girl to be most resistant to therapeutic intervention, particularly if that intervention carries with it any implication that another dislikes or otherwise finds her behavior and/or attitudes to be offensive.

Dominant and Hostile Girls. These girls would seem to say that "I believe I am well liked by others and also know that I am disliked a great deal." Statistically, our data indicates no significant impairment in role-taking function. Our earlier findings indicating that these girls give out more dislike choices and perceive more dislike in their residential environment takes on a different kind of significance when we consider 
their comparatively accurate performance in role-taking. That is to say, regardless of the amount of negative affect given and received by these girls, they are the most "reality oriented" of the entire population. They "know" they do not like others and also "know" that others do not like them. They exhibit little, if any, perceptual distortion. Although we have no evidence to support or deny this hypothesis, it may well be that the dominant and hostile girl is the most responsive to therapeutic intervention. Their apparently greater accuracy and, by implication, sensitivity to the responses of others may correspond to a well developed ability to evaluate the total range of external. stimuli impinging upon them. Contrary to what one might expect from the diagnostic label, "dominant and hostile," these girls may exhibit the most well-developed ego functions of the entire population. In any case, as defined by the criteria of our accurate roletaking model, the dominant and hostile girl exhibits minimal pathological adjustment.

\section{Passive and Friendly and Passive and Hostile Girls. Each} of these two self-concept types reveal an identical impairment in the nature and quality of role-taking impairment. These girls seem to be saying, "I believe that (relative to the other two self-concept types) I am not well liked by others and am perhaps somewhat more disliked than many of my peers." These girls exhibit grossly impaired role-taking functions which are diametrically opposed to those of their dominant and friendly peers. These girls underestimate, to a significant degree, the positive 
feelings of others which are directed toward them. The passive and friendly girl typically fails to perceive $30 \%$ of the existing positive feelings of others. The passive and hostile girl, although slightly more perceptive, still fails to perceive almost $20 \%$ of the existing positive feelings of others. In contrast to their relatively poor performance in predicting the positive feelings of others, both of these self-concept types accurately (no significant differences) perceives the amount of negative affect being directed toward them. The expectation for therapeutic change might be directly opposite that expected for the dominant and friendly girl. Where these latter self-concept types appeared hyposensitive to the negative reactions of others, the passive-friendly and passive-hostile types are hyposensitive to the positive reactions of others. These girls, might be expected to routjnely distort the intentions of others and forever accumulate "evidence" that validates their life script: "I am basically no good; how could anyone care for me." Basic trust issues are likely to become severe impediments to any successful therapeutic relationship. These girls may in fact present the best therapeutic prognosis if intervention could successfully redirect their perceptual proclivity to underestimate their own self worth. 


\section{CHAPTER NOTES}

1. Everett L。Shostrom, Man, the Manipulator (New York, 1967), see Chapter II. 
CHAPTER V

\section{SUMMARY AND IMPLICATIONS}

Four different self and ideal seli-concept types were found to characterize the adolescent female population at Villa Saint Rose. Girls described these two personality variables is either: 1) dominant and friendly; 2) dominant and hostile; 3) passive and friendly or 4 ) passive and hostile. Of these four descriptive types the most frequently designated self-concept of the population was passive and hostile; the most frequently designated ideal self-concept was dominant and friendly.

The distribution of self-concept types was much more variable than the distribution of ideal self-concept types. Fully $80 \%$ of the residential population described their ideal as dominant and friendly while less than $25 \%$ described their self-concept in the same way.

Self-rejection was found to be related to the degree to which the self-concept diverged from the normative ideal of the dominant and friendly typology. Utilizing this criterion, more than $60 \%$ of the residential population rejected or dislike themselves. The majority of individual girls who reject themselves described their self-concepts as either passive and friendly or passive and hostile.

Self-concepts, ideal self-concepts, and degree of self- 
rejection were not significantly related to the length of time a girl had been in residence. However, some trerds indicating change in the self system as a function of time were noted. The most important of these trerds, in our view, was the relatively lower indices of self-rejection characterizing girls who had been in residence for some time. If one of the therapeutic values in residential treatment lies in the resolution of conflict within the individual's self system then there would seem to be some partial support that this resolution does occur in some cases.

Beyond these material findings regarding the personality system of the residents, a number of implications for treatment utilization of this data also emerged. First, and perhaps most importantly, we have succeeded, at least tenatively, in delineating four different and unique self-concept types within this residential setting. This fact leads us to conclude that the Interpersonal Check List is a sufficiently sensitive measuring device to warrant its continued use in this setting. What is most urgently needed in future research with this instrument is a more thorough demonstration of its predictive capacity than we have accomplished in this exploratory study. We perceive this task as one of primarily correlating observed therapeutic success and failure with certain defined self-concept types. If a more precise criterion of success and failure could be defined and related to these four self-concept types, we could envision such data being utilized to: 1) screen at intake those girls who 
were defined to be poor and good therapeutic risks in this program and 2) either reject the poorer risks or structure different strategic interventive tactics to deal with them.

Secondly, through the use of the Interpersonal Check List we were able to uncover the existence of a standard normative ideal (dominant and friendly) that characterizes this residential population. Whether this ideal is a developmental and hence preinstitutional phenomenon or actually reflective of a set of intra-institutional expectations remains a crucial and immediate research question. In order to answer this question a much more rigorous testing procedure must be designed that would measure ICL performance prior to contact with this agency and once again during residence.

Finally, the fact that this study uncovered measurable levels of self-rejection in a substantial segment of the residential population should not escape critical examination by treatment staff. Those engaged in residential treatment of delinquent youth are frequently required to attend to and deal with the symptomatic behavior that initially brought these children into contact with the judicial and correctional systems. Runaway, theft, drug use, promiscuity, impulsivity, etc. are all examples of the socially unacceptable behavior which the residential system is charged with treating. Less apparent, it seems, are the defective self systems of these children which, in our study, are manifest as a conflict between what she is (selfconcept) and what she would like to become (ideal self). Is 
residential treatment no less charged with the therapeutic task of resolving the internal struggle as well as changing dysfunctional behavior?

Our data on self-rejection would require an even more urgent consideration by treatment staff if it could be demonstrated that a non-institutionalized sample did not exhibit the same levels of self-rejection. We would suggest that future research with this personality inventory be at least partially directed towards the measurement of a non-institutionalized control group regarding level of self-rejection as well as performance on self and ideal self-concepts.

We consider the above data to reflect a significant step forward in understanding the personality systems of the residents at Villa Saint Rose: We also found that this personality system, specifically the self-concept, exercises some selective influence over certain aspects of the girls interpersonal peer relationships within this setting. Each of the four self-concept types was assessed for its impact in determining aspects of the girls "actual" system of interpersonal relationships and their "perception" of the same system of relationships. We include a. summary of the significant findings in this area.

Girls who describe themselves as dominant and friendly do not differ significantly from their peers in terms of the number of girls they actually like and dislike or the number of girls who actually like and dislike them. They do, however, tend to perceive more girls liking them than most of their peers do. 
If the residential peer group is designated as the significant environment of the indivjdual girl then it seems clear that the dominant and friendly gir]. is somehow perceptually inclined to view this ervironment as more positive, conflict free, and nurturing than most of her peers. The important point to note about the dominan' ard friendly girl is that the nature of her perceptual processes is such that they will only permit a selective and biased assessment of her immediate environnent. She will typically correctly assess the amount of positive feeling that exists for her in this environment but fails to correctly assess the amount of negative feeling that also exists for her. They underestimate the amount of hostility that their peers direct toward them.

The dominant and friendly girl either genuinely fails to "see" the negative elements of her interpersonal world or if she does see them, chooses to deny their existence. Specifically what, if any, adjustment problems this perceptual selectivity engenders is not clear. We suggest, however, that adequate personal and interpersonal adjustment depends on a functional feedback system that is characterjzed by the awareness of the positive as well as the negative elements of a relationship. Resistance to therapeutic change may be related to the disruption of this feedback system.

The passive and friendly and passive and hostile girl are uniquely differentiated from their peers in that they tend to polarize the actual response of the peer group toward them. In 
gereral, the passive and friendly girl is liked more and disliked less while the passive and hostile girl is disliked more and liked less.

These self-concept types share two identical impairments in their self systems. First, of the four self-concept types, the above two are the only ones which manifest severe levels of selfrejection. Secondly, they exhibit identical-modes of perceptual distortion in their interpersonal relationships. In both cases, these girls selectively attend to the negative feeling in their peer environment, accurately perceive this, but altogether fail to accurately perceive the existing amount of positive feeling that also is directed toward them. In contrast to their dominant and friendly peers who underestimate the negative feelings of others, these girls underestimate the positive feelings of others.

In our estimation, the critical finding here parallels that for the dominant and friendly girl. Their feedback systems are also distorted by perceptual processes that screer. out the positive aspects of their environment. Furthermore, we believe that the identical impairment in perceptual functioning and the concomittant high levelss of self-rejection are not unrelated. Specifically how these two factors are related remains a significant question for future research. Is it the fact that these girls see only the negative reality of their interpersonal world that leads to self-rejection or is it the fact that they reject themselves that leads to the perceptual distortion? 
The dominant and hostile girl differs significantly from the other three self-concept types in terms of both her actual. and perceived system of interpersonal relationships. These girls direct more hostility towards their peer environment and perceive more hostility being directed toward them than most other girls. In contrast to each of the other three self-concept types who exhibit some perceptual distortion, the dominant and hostile girl is most accurate in assessing the amount of both positive and negative feeling existing for her. By the criterion of accurate role-taking capacity, these girls are better adjusted personally and interpersonally than most of her peers are. While it is true that the dominant and hostile girl directs and perceives more hostility in her residential environment the net effect of this process is to extend, to a greater degree than others, the total range of interaction with others.

These findings compel us to challenge any superficial interpretation of a girl's adjustment potential, if that interpretation is based on a biased reaction to a diagnostic labeling of her self-concept. For example "dominant" and "hostile" connotes a sense of power bordering on sadism, impulsiveness, and a ruthless orientation to interpersonal relationships. We would hypothesize however, that the expression of hostility towards others is a functional concomittant of interpersonal adjustment if (as is true of the dominant and hostile types) there is not also a simultaneous decrease in the expression of positive feelings for others. That the dominant and hostile girl 
is able to develop a more extensive system of peer relationships (both positive and negative) and accurately assess them may be an indication that this self-concept type is the most functional one of them a.ll.

Apart from the specific future research inquiries suggested thus far, our major recommendation for additional research is primarily concerned with validating the efficiency of the Interpersonal Check List. For purposes of analysis this exploratory study assumed the reliability and validity of this instrument. We suggest, that the continued use of the Interpersonal Check List be supported by a much more rigorous reliability and validity study than we have undertaken here.

The primary focus of a future study would require the following: 1) administration of the instrument to a noninstitutionalized control group as well as a residential sample; 2) administration of the instrument to girls prior to placement and 3) re-testing at two month intervals for the duration of a girls stay. This design would answer several crucial questions. First, do girls involved in residential treatment differ significantly from a non-institutionalized "normal" group with respect to performance on the instrument? Secondly, do measurements of self, ideal self, and self-rejection represent relatively stable components of a girl's self system or are they merely situationally determined and subject to wide variation over time? Third, can we reliably compare every newly admitted girls' performance to an established norm? In this last case, in order to establish a 
comparison system we need many more measures of different girls than we have gathered. If the Interpersonal Check Iist is to have any capacity for prediction then each of these questions must be addressed. 


\section{A SELECTED BIBLIOGRAPHY}

Allport, Gordon W. "The Ego in Contemporary Psychology." Psychological Review, 50 (No. 5, 1943), pp. 451-478.

Backman, C.W. "Liking, Selective Interaction, and Misperception in Congruent Interpersonal Relations." Sociometry, 25

(December, 1962), pp. 321-335.

and Secord, P.F. "The Effect of Perceived Liking on Interpersonal Attraction." Human Relations, 12 (No. 4, 1959), pp. 289-392.

Bergin, A. "The Effect of Dissonant Persuasive Communication upon Changes in a Self-Referring Attitude." Journal of Personality, 30 (No. 3, 1962), pp. 423-438.

Bertocci, P.A. "The Psychological Self, the Ego, and Personality." Psychological Review, 52 (No. 2, 1945), pp. 91-99.

Blumer, Herbert. "Society as Symbolic Interaction." Symbolic Interaction. Edited by Jerome G. Manis and Bernard N. Meltzer. Boston: Allyn and Bacon, Inc., 1972, pp. 145153.

- Symbolic Interactionism: Perspective and Method. Englewood Cliffs: Prentice-Hall, Inc., 1969.

Boyd, Harry S., and Sisney, Vernon V. "Immediate Self-Image Confrontation and Changes in Self-Concept." Journal of Consulting Psychology, 31 (No. 3, 1967), pp. $291-294$.

Briar, Scott; and Bieri, James. "A Factor Analytic and Trait Inference Study of the Leary Interpersonal Check List." Journal of Clinical Psychology, 19 (No.2, 1963), pp. 193198.

Chein, I. "The Awareness of Self and Structure of the Ego." Psychological Review, 51 (No. 5, 1944), pp. 304-314.

Clark, John P; and Wenninger, Eugene P. "Socioeconomic Class and Area as Correlates of Illegal Behavior Among Juveniles." American Sociological Review, 27 (December, 1962), pp. 826834. 
Cloward, Richard A; and Ohlin, Lloyd E. Delinguency and Opportunjty: A Theory of Delinquent Gangs. New York: The Free Press, 1960.

Cohen, Albert K. Delinquent Boys. New York: The Free Press, 1955.

- Delinquent Boys: The Culture of the Gang. Illinois: The Free Press, 1956.

, and Short, James F. Jr. "A Survey of Delinquency Theories." Faces of Delinquency. Edited by John P. Reed and Fuad Baali. New Jersey: Prentice-Hall, Inc., 1972, pp. 215-228.

Coleman, James S. The Adolescent Society. New York: The Free Press, 1961.

Cottrell, Leonard S. "Forward." Cottage Six by Howard W. Polsky. New York: John Wiley and Sons Inc., 1962.

Couch, Carl. "Self-Attitude and Degree of Agreement with Immediate Others." American Journal of Sociology, 63 (March, 1958), pp. 491-496.

Desmonde, William H. "The Position of George Herbert Mead." Psychoanalysis and the Future. Edited by B. Nelson. New York: National Psychological Association for Psychoanalysis, Inc., 1957, pp. 31-50.

Didato, Salvatore V. "Some Recent Trends in Juvenile Delinquency." Mental Hygiene, 53 (No. 4, 1969), pp. 545-549.

Dinitz, Simon; Scarpitti, Frank R; and Reckless, Walter C. "Delinquency Vulnerability: A Cross Group and Longitudinal Analysis." American Sociological Review, 27 (No. 4, 1962), pp. 515-517.

; Reckless, Walter C.; and Kay, Barbara.' "A Self Gradient Among Potential Delinquents." Journal of Criminal Law, Criminology and Police Science, 49 (No. 3, 1958), pp. 225-232.

; Mangus, A.R.' and Pasamanick, Benjamine. "Integration and Conflict in Self-Other Conceptions as Factors in Mental Illness." Sociometry, 22 (No. 3, 1959), pp. 44-55.

Dittes, G.E. "Attractiveness of Group as a Function of SelfEsteem and Acceptance by Group." Journal of Abnormal and Social Psychology, 59 (No. 3, 1959), pp. 77-82. 
Dorn, Dean S. "Self-Concept, Alienation and Anxiety in a Contraculture and Subculture." Journal of Criminal Law, Criminology and Police Science, 59 (No. 4, 1968), pp. 531535.

Dunham, Warren H. "The Juvenile Court: Contradictory Orientations in Processing Offenders." Readings in Juvenile Delinquency. Edited by Ruth Cavan. Philadelphia: Lippincott, 1964.

- "The Ecology of the Functional Psychosis in Chicago." American Sociological Review, 2(No. 4, 1937), pp. 467479.

Ellis, Evelyn. "Social Psychological Correlates of Upward Social Mobility Among Unmarried Career Women." American Sociological Review, 19 (No. 5, 1952), pp. 558-563.

Empey, Lamar T. "Contemporary Programs for Convicted Juvenile Offenders: Problems of Theory, Practice and Research." Crime and Violence: A Staff Report on the Causes and Prevention of Violence. Washington D.C.: U.S. Government Printing Office, 1969.

Enright, John B.; and Jaeckle, Walter R. "Psychiatric Symptoms and Diagnosis in Two Subcultures." International Journal of Social Psychiatry, 9 (No. 1, 1963), pp. 12-17.

Faris, Robert E. Social Disorganization. New York: The Ronald Press, 1948.

Haas, H.I.; and Maehr, M. "Two Experiments on the Concept of Self and the Reacting of Others." Journal of Personality and Social Psychology, 1 (No. 1, 1965), pp. 100-105.

Hakeem, Michael. "A Critique of the Psychiatric Approach to the Prevention of Juvenile Delinquency." Social Problems, 5 (No. 3, 1958), pp. 194-205.

Hare, A.P.; Borgatta, Edgar F.; and Bales, R. F. Small Groups. New York: Alfred A. Knopf, 1965.

Harvey, O.J.; Kelley, H.H.; Shapiro, M.M. "Reactions to Unfavorable Evaluations of the Self made by Other Persons." Journal of Personality, 25 (No. 4, 1957), pp. 393-411.

Haskell, Martin R: "Toward a Reference Group Theory of Juvenile Delinquency," Social Problems, 8 (Winter, 1961), pp. 220230. 
Hilgard, E.I. "Human Motives and the Concept of Self." American Psychologist, 4 (No. 9, 1949), pp. 374-382.

Hollingshead, Auglust B.; and Redlich, Frederick C. "Social Stratification and Psychiatric Disorders." American Sociological Review, 18 (No. 2, 1953), pp. 163-169.

Horrocks, John E. The Psychology of Adolescence. Boston: Houghton Mifflin, 1951.

Hyman, Herbert. "The Psychology of Status." Archives of Psychology, 269 (No. 3, 1942), pp. 235-242.

Jennings, Helen $\mathrm{H}$. "Individual Differences in the Social Atom." Sociometry, 4 (No. 2, 1941), pp. 225-234.

Jones, Harold E. Development in Adolescence. New York: Appelton-Century, 1943.

Joplin, Glenn H. "Self-Concept and the Highfields Program." Correctional Psychologist, 3 (No. 5, 1968), pp. 4-5.

Kaplan, Bert; Reed, Robert B.; and Wyman, Richard. "A Comparison of the Incidence of Hospitalized and Non-Hospitalized Cases of Psychosis in Two Communities." American Sociological Review, 21 (No. 4, 1956), pp. 472-479.

Kennedy, J.I.; and Lasswell, H.D. "A Cross-Cultural Test of Self-Image." Human Organization, 17 (No. 1, 1958), pp. 4143.

Kinch, John W. "Experiments on Factors Related to Self-Concept Change." Journal of Social Psychology, 74 (April, 1968), pp. $251-258$.

- "A Formalized Theory of the Self-Concept." American Journal of Sociology, 68 (No. 4, 1963), pp. 481-486.

Klapp, Orrin E. Collective Search for Identity. New York: Holt, Rinehart and Winston, Inc., 1969, pp. 57-62.

Klein, Malcolm W. "On the Group Context of Delinquency." Sociology and Social Research, 54 (October, 1969), pp. 6371.

Knopka, Gisela. "The Rehabilitation of the Delinquent Girl." Adolescence, 2 (No. 5, 1967), pp. 69-82.

- The Adolescent Girl in Conflict. New Jersey: Prentice-Hall, 1966. 
Knudten, Richard D. "Social-Psychological Causes of Crime." Crime in a Complex Society. Edited by Richard D. Knudten. Illinois: Dorsey Press, 1970, pp. 279-304.

Kuhn, Manford H. "Self-Attitudes by Age, Sex, and Professional Training." Sociological Quarterly, 1 (No. 2, 1960), pp. 39-55.

; and McPartland, Thomas S. "An Empirical Investigation of Self-Attitudes." American Sociological Review, 19 (No. 1, 1954), pp. 68-76.

Leary, Timothy. Interpersonal Diagnosis of Personality. New York: Ronald Press, 1957.

Lindesmith, Alfred R.; and Strauss, Anselm I. Readings in Social Psychology. New York: Holt, Rinehart and Winston Inc., 1969.

Lundberg, George A.; and Lawsing, Margaret. "The Sociography of Some Community Relations." American Sociological Review, 2(No. 3, 1937), pp. 318-335.

Maehr, M.; Mensing, J.; and Nafager, S. "Concept of Self and the Reactions of Others." Sociometry, 25 (No. 4, 1962), pp. 353-35?.

Manis, Jerome G.; and Meltzer, Bernard N. Symbolic Interact:on. Boston: Allyn and Bacon, Inc., 1972.

McDonald, Robert I. "Leary's Overt Interpersonal Behavior: A Validation Attempt." Journal of Social Psychology, 74 (No. 2, 1968), pp. 259-264.

McHugh, Peter. Defining the Situation: The Organization of Meaning in Social Interaction. Indianapolis: BobbsMerrill Go. Inc., 1968.

Mead, George Herbert. Mind, Self and Society. Chicago: The University of Chicago Press, 1934.

Meltzer, Bernard N. "Mead's Social Psychology." Symbolic Interaction. Edited by Jerome G. Manis and Bernard N. Meltzer. Boston: Allyn and Bacon, Inc., 1972, pp. 4-22.

Merton, Robert K.; and Kitt, A. "Contributions to the Theory of Reference Group Behavior." Studies in the Scope and Method of the American Soldier. Edited by Robert K. Merton and Paul F. Lazarsfeld. Illinois: The Free Press, 1950, pp. 42-53. 
Miyamoto, S. Frank; and Dornbush, Sanford M. "A Test of the Interactionist Hypothesis of Self-Conception." American Journal of Sociology, 61 (No. 5, 1956), pp. 399- 403.

Monahan, Thomas P. "Family Status and the Delinquent Child: A Reappraisal and Some New Findings." Social Forces, " 65 (No. 3, 1957), pp. 54-63.

Moreno, Jacob I. Who Shall Survive? A New Approach to the : Problem of Human Interrelationships. Washington, D.C.8 Nervous and Mental Diseases Publishing Co., 1934, Monograph, No. 58.

Muller, Herbert J. Freedom in the Western World: From the Dark Ages to the Rise of Democracy. New York: Harper and Row, 1963.

Murphy, H.B.; Wittkower, E.D.; Fried, J.; and Ellenberger, H. "A Cross-Cultural Survey of Schizophrenic Symptomatology." International Journal of Social Psychiatry. 9 (No. 4, 1963), pp. 237-249.

Nye, Ivan F.; Short, James F. Jr.; and Olson, Virgin J. "Socioeconomic Status and Delinquent Behavior." American Journal of Sociology, 63 (January, 1958), pp. 381-389.

Page, James D. Psychopathology: The Science of Understanding Deviance. New York: Aldine, Atherton, 1971.

Parsons, Oscar A.; Altrocchi, John; and Spring, Faye E. "Discrepancies in Interpersonal Perception, Adjustment, and Therapeutic Skills." Perceptual and Motor Skills, 18 (No. 2, 1964), pp. 659-702.

Peretti, Peter O. "Identification and Reidentification A Change in the Self-Concept." International Journal of Child Psychiatry, 37 (No. 11, 1971), pp. 314-316.

Piaget, Jean. The Child's Conception of Physical Causality. New Jersey: Littlefield, Adams and Company, 1960.

- The Language and Thought of the Child. New York: Humanities Press, Inc., 1952.

- The Child's Conception of the World. New York: Humanities Press, Inc., 1951. - The Moral Judgment of the Child. New York: The Free Press, 1948.

Quarantelli, E.I.; and Cooper, Joseph. "Self-Conceptions ind 
Others: A Further Test of Median Hypothesis." Sociological Quarterly, ? (No. 3, 1966), pp. 281-297.

Reckless, Walter C.; Dinitz, Simon; and Murray, Eller. "SelfConcept as an Insulator Against Delinquency." American Sociological Review, 21 (No, 6, 1956), pp. 744-746.

Redl, Fritz; and Wineman, David. Children Who Hate. New York: The Free Press, 1951.

- "The Concept of a Therapeutic Milieu." American Journa.1. of Orthopsychiatry, 29 (No. 4, 1959), pp. 721-736.

Reeder, Leo G.; Donohue. George; and Biblarz, Arturo. "Conceptions of Self and Others." American Journal of Sociology, 66 (September, 1960), pp. 153-159.

Reese, H.W. "Relationships Between Self-Acceptance and Sociometric Choices." Journal of Abnormal and Social Psychology, 62 (No.2, 196, ), pp. 472-474.

Reiss, Albert J. Jr.; ard Rhodes, Albert I. "Status Deprivation and Delinquent Behavior." The Sociological Quarterly, 4 (Spring, 1963), pp. 135-149.

; and Rhodes, Albert I. "The Distribution of Juvenile Delinquency in the Social Class Stmucture." American Sociological Review, 26 (October, 1961), pp. $\overline{720-732 .}$

Richard, Wayne C.; Mates, Catherine G.; and Whitten, Laura. "Personality Traits and Attitudes of Adolescent Girls with Behavior Disorders." Correctivie Psychiatry and Journal of Social Therapy, 15 (No. 2, 1969), pp. 34-44.

Riley, Matilda W. Sociological Research: A Case Approach. New York: Harcourt, Brace and World, 1963.

Roberts, Bertram H.; and Myers, Jerome K. "Religion, National Origin, Immigration and Mental Illness." American Journal of Psychiatry, 110 (No. 5, 1954), pp. 759-764.

Rosenberg, Morris. "Psychological Selectivity in Self-Esteem Formation." Attitudes, Ego-Involvement and Change. Edited by Carolyn $W$. Sherif and Muzarf Sherif. New York: John Wiley, 1967, pp. 26-50.

Rosengren, William R. "The Self in the Emotionaily Disturbed." American Journal of Sociology, 66 (March, 1961), pp. 454.462 . 
Rubin, Jerome. "Change in Self-Concept During Institutional Confinement." Dissertation Abstracts International. Ann Arbor Michigan: University Microfilms, No. 71-13594.

Scarpitti, Frank R.; Murray, Ellen.; Dinitz, Simon; and Reckless, Walter C. "The Good Boys in a High Delinquency Areas Four Years Later." American Sociological Review, 25 (No. $2,1960), \mathrm{pp} \cdot 555-55 \overline{8}$.

Schonfeld, William A. "The Twentieth Century Adolescent: Adolescent Turmoil and the Search for Identity." American Journal of Psychoanalysis, 31 (No. 1, 1971), pp. 41-55.

Schwartz, Michael. "A Note on the Self-Concept as an Insulator Against Delinquency." American Sociological Review, 30 (December, 1963), pp. 922-926.

Shaw, Clifford R.; and McKay, Henry D. "Social Factors in Juvenile Delinquency." Report on the Causes of Crime. Washington D.C.: U.S. Government Printing Office, 1931, No. 3, Vol. II.

Sherif, Muzafer. Group Relations at the Crossroads. New York: Harper and Row, 1953.

, and Sherif, Carolyn W. "Social Settings and Reference Groups." Reference Groups. Edited by Muzafer Sherif and Carolyn W. Sherif'. New York: Harper and Row, 1964. , and Sherif, Carolyn W. "Group Processes and Collective Interaction in Delinquent Activities." Journal of Research in Crime and Delinquency, 4 (January, 1967).

, and Cantril, H. "The Psychology of Ego Involvements." New York: Wiley, 1947.

Sherwood, John J. "Self-Identity and Referent Others." Sociometry, 28 (March, 1965), pp. 68-71.

Shibutari, Tamotsu. Human Nature and Collective Behavior: Papers in Honor of Herbert Blumer. Englewood Cliffs: Prentice Hall, Inc., 1970. 1961.

Society and Personality. New Jersey: Prentice Hall,

- "Reference Groups as Perspectives." American Journal of Sociology, 60 (No. 2, 1955), pp. 562-569.

Shostrom, Everett L. Man the Manipulator. New York: Abingdon Press, 1967. 
Smith, M. Brewster. "The Pheromenological Approach in Personality Theory: Some Critical Remarks." Journal of Abnormal and Social Psychology, 45 (No. 3, 1950), pp. 516522.

Stone, Gregory P.; and Farberman, Harvey A. Social Psychology Through Symbolic Interaction. Waltham: Ginn-Blaisdell, 1970 .

Stryker, Sheldon. "Symboljc Interaction as an Approach to Family Research." Symbolic Interaction. Boston: Allyn and Bacon, Inc., 1972, pp. 435-446.

- "Conditions of Accurate Role-Taking: A Test of Mead's Theory." Human Behavior and Social Processes. Edited by Arnold Rose. Boston: Houghton Mifflin, 1962, pp. 41-62.

- "Role-Taking Accuracy and Adjustment." Sociometry, 20 (December, 1957), pp. 286-296.

Sutherland, Edwin H. Principles of Criminology. New York: J.B. Lippincott Co., 1955.

Taguiri, Renato. "Relational Analysis: An Extension of Sociometric Method with Emphasis upon Social Perception." Sociometry, 15 (No. 1, 1952), pp. 91-104.

Tangri, Sandra S.; Schwartz, Michael. "Delinquency Research and the Self-Concept Variable." Journal of Criminal Law, Criminology and Police Science, 59 (No. 4, 1968), pp. $531-$ 535.

Terrill, James M.; and Terrill, Ruth E. "A Method for Studying Family Communication." Family Process, 4 (No. 2, 1965), pp. 259-290.

Thrasher, Frederick M. The Gang: A Study of 1,313 Gangs in Chicago. Chicago: University of Chicago Press, 1963.

Videbeck, Richard. "Self-Conceptions and the Reaction of Others." Sociometry, 23 (December, 1960), pp. 351-359.

White, Robert W. The Abnormal Personality. New Yorks Ronald Press, 1948.

Wylie, Ruth C. The Self-Concept. Nebraska: University of Nebraska Press, 1961.

Youth and Delinquency. (Summary Report on Regional Hearings and Statewide Conference). New York: Temporary State Commission on Youth and Delinquency, 1956. 
A P P E N D I X A

I NTERPERSONAL CHECK LIST: SELF.CONCEPT

Check every item that describes YOURSELF

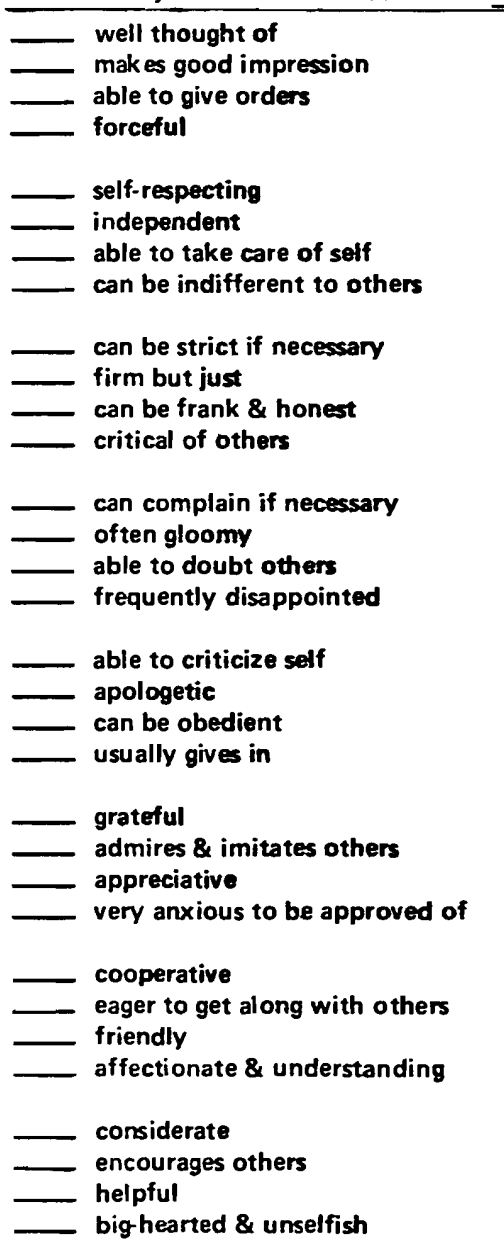

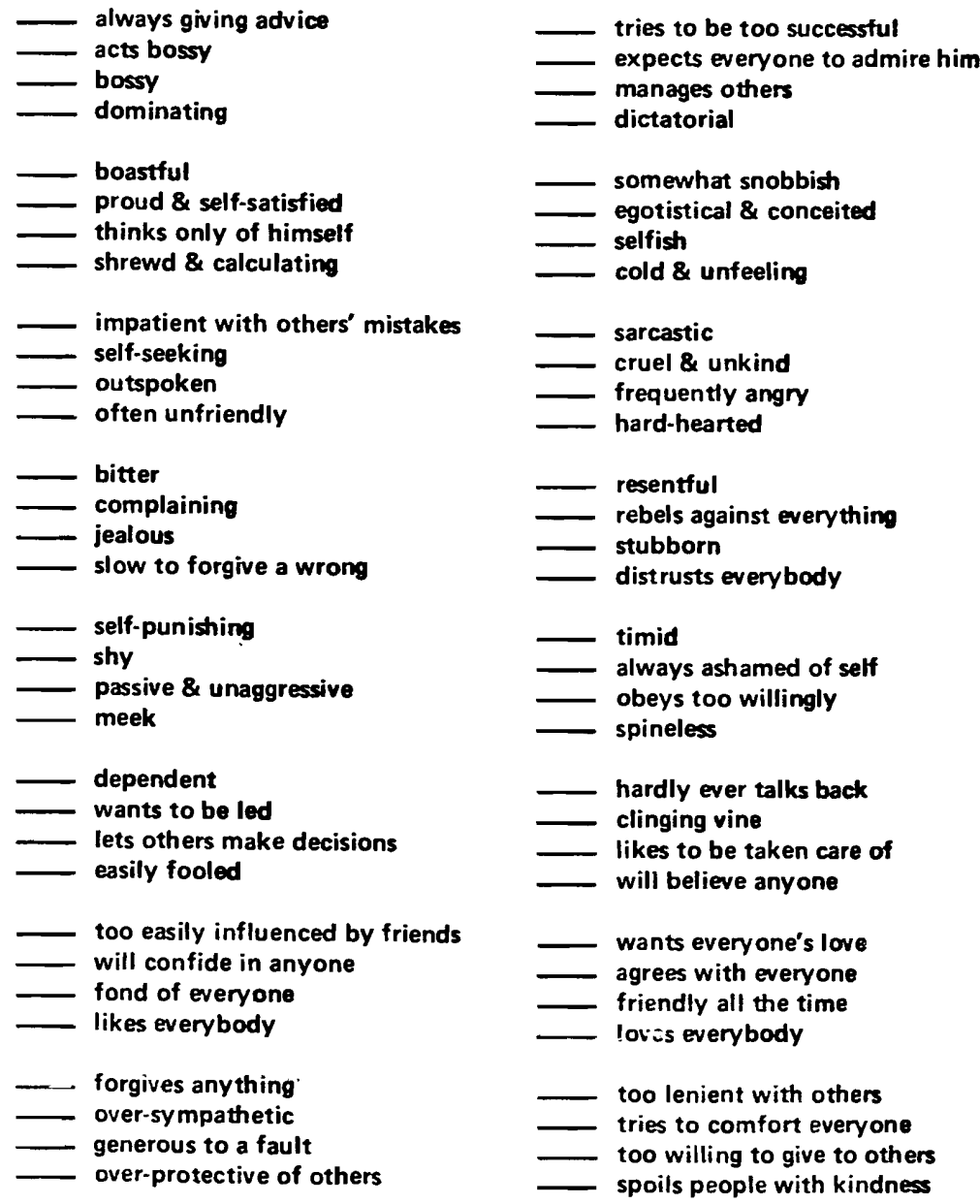


APPENDIX B

INTERPERSONAL CHECK LIST: IDEAL SELF.CONCEPT

Check every item that describes THE WAY YOU WOULD LIKE TO BE

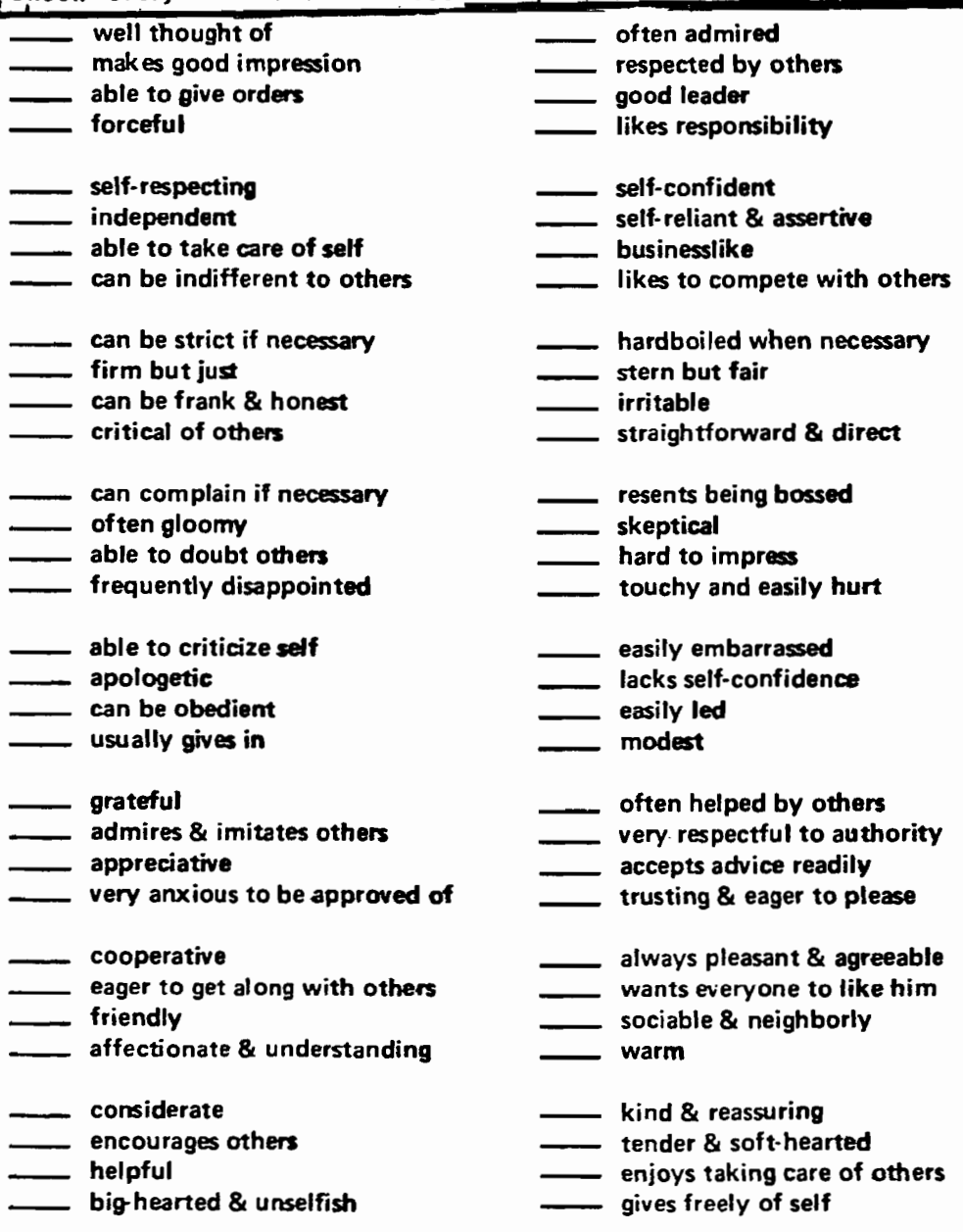

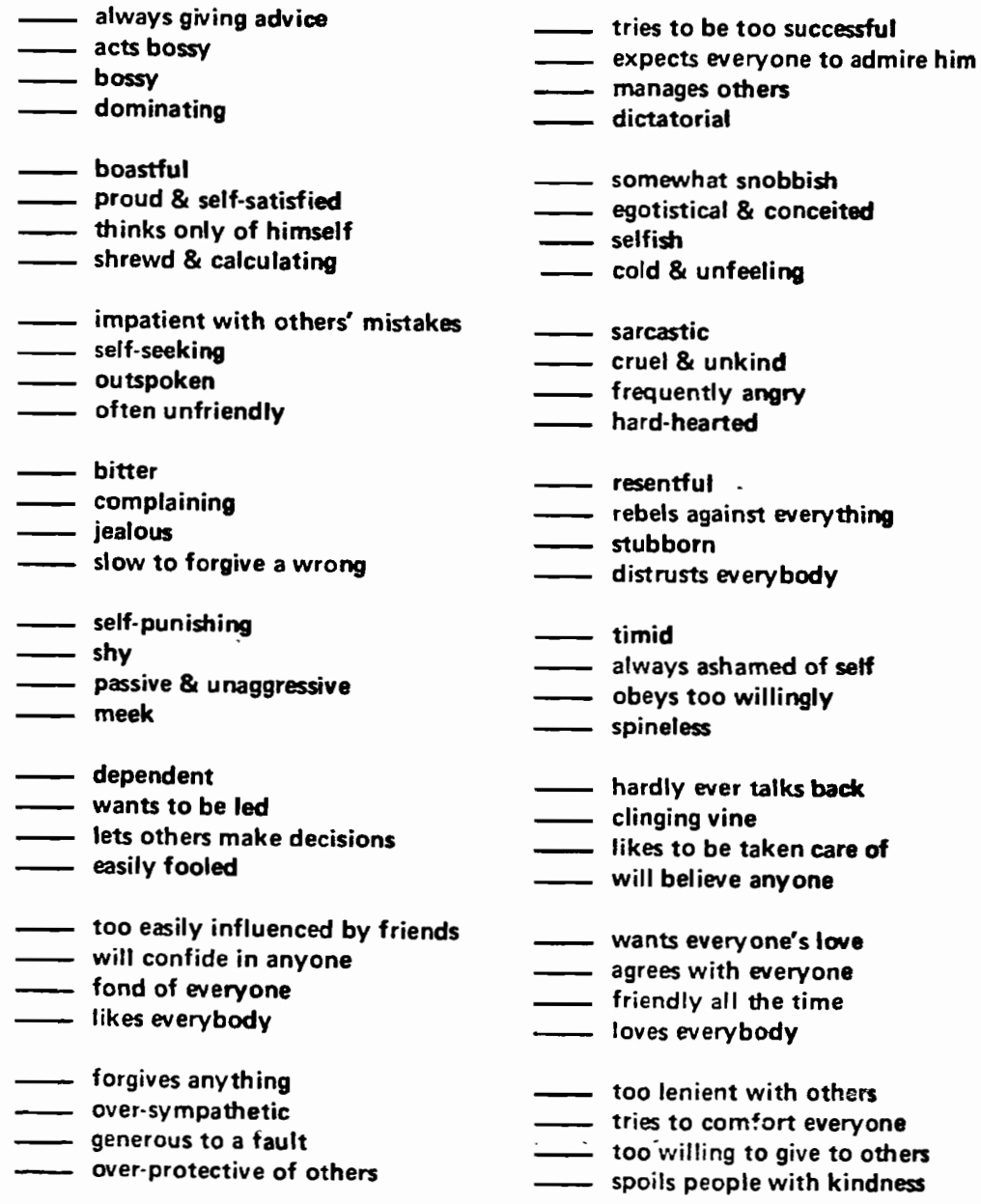


APPENDIX C

POPULATION PERFORMANCE SCORES FOR THE SEIF-CONCEPT, IDEAL SELF-CONCEPT, AND DEGREE OF SELF-REJECTION

\begin{tabular}{|c|c|c|c|c|c|c|c|c|c|c|c|c|c|c|}
\hline \multirow{3}{*}{$\begin{array}{c}\text { SUBJJECT } \\
\text { CODE }\end{array}$} & \multicolumn{4}{|c|}{ RAW SCORE } & \multicolumn{2}{|c|}{ STA N D A R D } & \multicolumn{4}{|c|}{$\begin{array}{c}\text { DI A G NOS O TI C } \\
O C \text { C A NT }\end{array}$} & \multicolumn{3}{|c|}{ SELF-REJECTION } & \multirow{3}{*}{$\mathrm{R} / \mathrm{A}$ * } \\
\hline & \multicolumn{2}{|c|}{ SELF } & \multicolumn{2}{|c|}{ I DEAL } & \multicolumn{2}{|c|}{ SELF } & \multicolumn{2}{|c|}{ I DEAL } & \multirow{2}{*}{ SELF } & \multirow{2}{*}{ PDEAE } & \multicolumn{2}{|c|}{$\begin{array}{r}\text { KIND OF } \\
\text { DISCREPANCY }\end{array}$} & \multirow{2}{*}{ AMOUNT } & \\
\hline & Dominant & Friendly & Dominant & Friendly & Dominant & Friendly & Domipant & Friendly & & & Dominant & Friendly & & \\
\hline$A_{1}$ & -10.8 & -3.2 & 8.5 & 6.5 & 40 & 45 & 54 & 55 & 5 & 1 & 89 & $1 ?$ & 91 & K \\
\hline$A_{2}$ & 0.4 & 1,6 & 5.5 & 9.2 & 54 & 50 & 61 & 59 & 1 & 8 & -1 & +41 & 41 & A \\
\hline$A_{3}$ & $-5 \cdot 1$ & 3.7 & 2.4 & 13.6 & 47 & 52 & 57 & 63 & 6 & 8 & 60 & 28 & 66 & $\mathrm{R}$ \\
\hline$A_{4}$ & -5.5 & 14.7 & 12.3 & 4.3 & 47 & 65 & 69 & 53 & 7 & 1 & 67 & -45 & 81 & $\mathrm{R}$ \\
\hline$A_{5}$ & -14.4 & 3.8 & 3.4 & 15.4 & 35 & 52 & 58 & 65 & 5 & 8 & 88 & 58 & 105 & $\mathrm{k}$ \\
\hline A6 6 & -4.1 & 5.5 & 0 & 4.4 & 48 & 54 & 54 & 53 & 7 & 8 & 38 & 14 & 41 & A \\
\hline An & -15.2 & 2.8 & 9.1 & 10.9 & 34 & 51 & 65 & 60 & 5 & 1 & 112 & 22 & 114 & $\mathrm{R}$ \\
\hline$A_{8}$ & 3.6 & -16.8 & 4.9 & 11.9 & 58 & 29 & 60 & 62 & 3 & 8 & 21 & 103 & 105 & $\mathrm{k}$ \\
\hline Ag & -12.0 & 5.4 & 7.2 & 15.2 & 38 & 54 & 63 & 65 & 6 & 8 & 79 & 15 & 81 & $\mathrm{R}$ \\
\hline A10 & 2.8 & -8.0 & 2.8 & -8.0 & $5 ?$ & 39 & 57 & 39 & 3 & 3 & 0 & 0 & כo & A \\
\hline $\mathrm{B}_{1}$ & $i .5$ & $-4=3$ & 9.2 & -2.4 & 63 & 43 & 55 & 45 & 2 & 2 & 0 & 0 & 0 & A \\
\hline $\mathrm{B}_{2}$ & $-1 . ?$ & 3.7 & 7.4 & 6.8 & 51 & 52 & 63 & 56 & 8 & 1 & 37 & -17 & 41 & A \\
\hline
\end{tabular}


APPENDIX C (cont.)

\begin{tabular}{|c|c|c|c|c|c|c|c|c|c|c|c|c|c|c|}
\hline \multirow{3}{*}{$\begin{array}{l}\text { SUBJECT } \\
\text { CODE }\end{array}$} & \multicolumn{4}{|c|}{ RAW SCORE } & \multicolumn{4}{|c|}{ STANDARD SCORE } & \multicolumn{6}{|c|}{$\begin{array}{c}D I A G N O S T I C \\
O C T A N T \\
O C A N\end{array}$} \\
\hline & \multicolumn{2}{|c|}{ SELF } & \multicolumn{2}{|c|}{ I DEAL } & \multicolumn{2}{|c|}{ SELF } & \multicolumn{2}{|c|}{ I DEAL } & \multirow{2}{*}{ SELF } & \multirow{2}{*}{$D E A$} & \multirow{2}{*}{$\frac{\text { DISCRE }}{\text { Dominant }}$} & \multirow[b]{2}{*}{ Friendly } & \multirow{2}{*}{ AMOUNT } & \multirow{2}{*}{$R / A$} \\
\hline & Dominant & Friendly & Dominant & Friendly & Dominant & Friendly & Dominant & Friend!y & & & & & & \\
\hline$B_{3}$ & -7.5 & 0.5 & 4.1 & 2.1 & 44 & 49 & 59 & 51 & 5 & 1 & 66 & 12 & 58 & $\mathrm{R}$ \\
\hline $\mathrm{B}_{i}$ & -11.1 & --4.1 & 8.0 & 5.2 & 40 & 44 & 64 & 54 & 5 & 1 & 112 & 22 & 114 & $\mathrm{R}$ \\
\hline$B_{5}$ & 0.1 & 1.7 & 10.2 & 2.8 & 54 & 50 & 67 & 51 & 1 & 1 & 23 & 5 & 23 & A \\
\hline B6 & 1.5 & $7 \cdot 9$ & 5.2 & 17.8 & 56 & $5 ?$ & 60 & 68 & 8 & 8 & 13 & 19 & 23 & A. \\
\hline $\mathrm{Br}_{7}$ & $-7 \cdot 1$ & 2.1 & 5.1 & 0.7 & 45 & $5 !$ & 60 & 49 & 5 & 1 & 66 & 12 & 68 & $R$ \\
\hline B8 & -9.2 & 2.6 & 8.2 & 15.0 & 42 & 51 & 64 & 65 & 5 & 8 & 65 & 53 & 84 & $\mathrm{R}$ \\
\hline $\mathrm{B}_{9}$ & -13.3 & -5.5 & 8.2 & 14.6 & 37 & 42 & 64 & 65 & 5 & 8 & 88 & 58 & 105 & R \\
\hline$B_{10}$ & 8.8 & -0.2 & 10.7 & 13.1 & 65 & 48 & 80 & 63 & 1 & 1 & 0 & 0 & 0 & A \\
\hline$B_{11}$ & -7.7 & -14.3 & 11.0 & 8.4 & 44 & 32 & 68 & 58 & 4 & 1 & 88 & 58 & 105 & R \\
\hline$B_{12}$ & 1.0 & 2.6 & 9.0 & 18.8 & 55 & 51 & 65 & 69 & 1 & 8 & -1 & 41 & 41 & A \\
\hline$E_{13}$ & 15.5 & -3.9 & 10.7 & 10.5 & 73 & 44 & $6 ?$ & 60 & 2 & 1 & 9 & 43 & 44 & A \\
\hline$B_{14}$ & -8.9 & 3.1 & 8.9 & 9.3 & 42 & 52 & $65^{\circ}$ & 59 & 6 & 1 & 103 & -21 & 105 & R \\
\hline$B_{15}$ & -7.4 & 4.8 & 1.9 & 3.1 & 44 & 54 & 55 & 52 & 6 & 1 & 84 & -8 & 84 & $\mathrm{R}$ \\
\hline
\end{tabular}


APPENDIX $\mathrm{O}$ (cont.)

\begin{tabular}{|c|c|c|c|c|c|c|c|c|c|c|c|c|c|c|}
\hline \multicolumn{5}{|c|}{ RAW SCORE } & \multicolumn{2}{|c|}{ STANDARD } & sco & & \multicolumn{2}{|c|}{$\begin{array}{c}\text { DI AG G N S STIC } \\
\text { OCTANT }\end{array}$} & \multicolumn{3}{|c|}{ SELF-REJECTION } & \multirow{3}{*}{$R / A$} \\
\hline \multirow{2}{*}{$\begin{array}{c}\text { SUBJECT } \\
\text { COLE }\end{array}$} & \multicolumn{2}{|c|}{ SELF } & \multicolumn{2}{|c|}{ I DEAL } & \multicolumn{2}{|c|}{ SELF } & \multicolumn{2}{|c|}{ IDEAL } & \multirow{2}{*}{ SELF } & \multirow{2}{*}{ I DEAL } & \multicolumn{2}{|c|}{$\begin{array}{l}\text { KIND OF } \\
\text { DISCREPANCY }\end{array}$} & \multirow{2}{*}{ AMOUNT } & \\
\hline & Dominant & Friẹndly & Dominant & Friendly & Dominant & Friendly & Dominant & Friendly & & & Dominant & Friendly & & \\
\hline$C_{1}$ & -3.4 & $-11 \cdot 4$ & -1.1 & 12.3 & 49 & 35 & 52 & 62 & 3 & $?$ & -22 & 112 & 114 & $\mathrm{R}$ \\
\hline $\mathrm{C}_{2}$ & 6.9 & 0.1 & 5.0 & -6.2 & 62 & 48 & 60 & 41 & 1 & 2 & -9 & -43 & 44 & A \\
\hline$C_{3}$ & $-1 \cdot 7$ & 2.7 & -5.5 & .3 & 51 & $5 !$ & 47 & 49 & 8 & 5 & -52 & -34 & 62 & $\mathrm{R}$ \\
\hline $\mathrm{C}_{4}$ & -6.8 & 2.2 & 2.5 & 5.1 & 45 & 51 & 57 & 54 & 5 & 1 & 66 & 12 & 68 & $\mathrm{R}$ \\
\hline $\mathrm{C}_{5}$ & .5 & 2.1 & 10.7 & 7.5 & 54 & 51 & 67 & 57 & 1 & 1 & 23 & 5 & 23 & A \\
\hline $\mathrm{c}_{6}$ & -3.4 & 2.4 & 4.8 & 0 & 49 & 51 & 60 & 48 & 6 & 2 & 56 & -38 & 68 & $\mathrm{R}$ \\
\hline $\mathrm{C}_{7}$ & -2.4 & -3.4 & 5.1 & 10.5 & 51 & 44 & 60 & 60 & 3 & 8 & 26 & 80 & 84 & K \\
\hline$c_{8}$ & 7.0 & -9.0 & 7.5 & -0.3 & 63 & 38 & 63 & 48 & 2 & 1 & 9 & 43 & 44 & A \\
\hline $\mathrm{C}_{9}$ & $-10 \cdot 3$ & -5.5 & 2.1 & 4.7 & 41 & 42 & 56 & 53 & 4 & 1 & 65 & 53 & 84 & 3 \\
\hline$c_{10}$ & -2.7 & 2.3 & 0.1 & 10.7 & 50 & 51 & 54 & 60 & 7 & 8 & 38 & 14 & 41 & A \\
\hline$c_{11}$ & -1.0 & 0 & 0 & 0 & 52 & 48 & 54 & 48 & 2 & 2 & 0 & 0 & 0 & A \\
\hline$c_{12}$ & -6.2 & -3.2 & 8.2 & 0.6 & 46 & 45 & 64 & 49 & 4. & 1 & 75 & 39 & 34 & $\mathrm{~K}$ \\
\hline$c_{13}$ & -12.0 & 6.0 & 6.2 & -2.4 & 38 & 55 & 62 & 45 & 6 & 2 & 94 & -64 & 114 & $\mathrm{R}$ \\
\hline
\end{tabular}


APPENDIX C (cont.)

\begin{tabular}{|c|c|c|c|c|c|c|c|c|c|c|c|c|c|c|}
\hline & \multicolumn{4}{|c|}{ RAW SCORE } & \multicolumn{2}{|c|}{ STANDAR } & sco & & \multicolumn{2}{|c|}{$\begin{array}{c}\text { D I A G NOS T I C } \\
\text { OCTANT }\end{array}$} & \multicolumn{3}{|c|}{ SELF-REJECTION } & \multirow{3}{*}{ R/A } \\
\hline \multirow{2}{*}{$\begin{array}{c}\text { SUBJECT } \\
\text { CODE }\end{array}$} & \multicolumn{2}{|c|}{ SELF } & \multicolumn{2}{|c|}{ I DEAL } & \multicolumn{2}{|c|}{ SE LF } & \multicolumn{2}{|c|}{ I DEAL } & \multirow{2}{*}{ SELF } & \multirow{2}{*}{ IDEAL } & $\begin{aligned} K I N D \\
0 I S C B\end{aligned}$ & $\begin{array}{l}O F \\
=P A N C Y\end{array}$ & \multirow{2}{*}{ AMOUNT } & \\
\hline & Dominant & Friendly & Dominant & Friendly & Dominant & Friendly & Dominant & Friendly & & & Dominant & Friendly & & \\
\hline $\mathrm{C}_{14}$ & -1.9 & $? .5$ & 6.8 & 10.6 & 51 & $5 ?$ & 62 & 60 & 7 & 8 & 38 & 14 & 41 & A \\
\hline$c_{15}$ & -9.3 & 0.1 & 4.8 & 9.2 & 42 & 48 & 60 & 59 & 5 & 8 & 65 & 53 & 84 & $\mathrm{R}$ \\
\hline
\end{tabular}

* $(R)=$ Self-Rejection

(A) = Self-Acceptance 


\section{A SOCIOMETRIC CHOICE QUESTIONAIRE FOR THE AFFECTIVE. COMPJNEN'T OF INTERPERSONAL PERCEP'TION}

Here is a list of all the girls at Villa Saint Rose today.* Each girl is listed under the living group to which she is assigned. Beginning with your living group, look over each name listed on this page. Which of these girls do you like or dislike? Please maxk $L$ if you like the girl and $D$ if you dislike her in the space provided to the left of the girl's name. If you do not know the girl well enough or are unsure of your feelings for her leave the name blank. You may name as many like or dislike choices as you wish.

\section{Sr. Elizabeth}

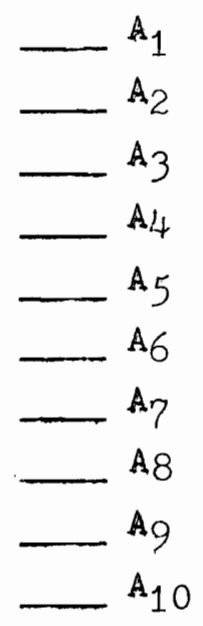

Sr. Grace

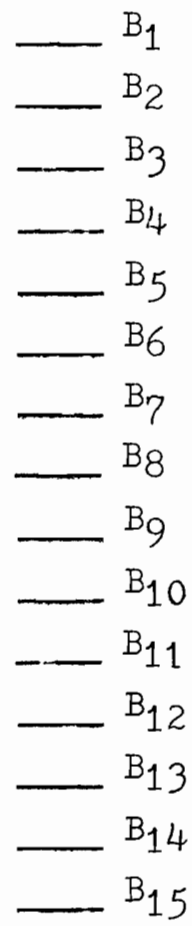

Sr. Monica

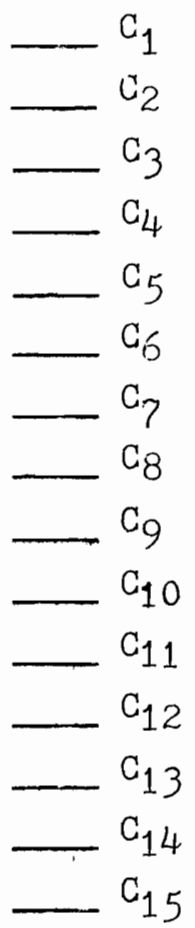

*The names of these girls have been omitted as a matter of. confidentiality. 


\section{A SOCIJMETRIC CHOICE QUESTIONAIRE FOR THE PERCEPTUAL COMPONENT OF IN'TERPERSONAL PERCEPTION}

Here is the same list of girls.* Please mark, in exactly the same way, all those girls whom you think like or dislike you. This means that you are to "GUESS " or predict which of these girls will say how they feel about you. Please mark I if you think the girl likes you and $D$ if you think the girl dislikes you in the space provided to the left of the girl's name. If you do not know the girl well enough or are unsure of her feelings for you leave the name blank. You may make is may guesses as you wish.

Sr. Elizabeth

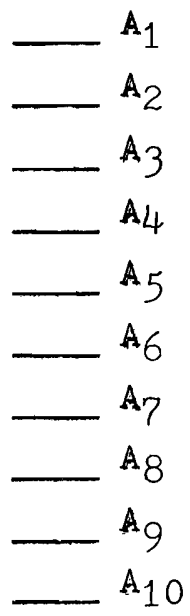

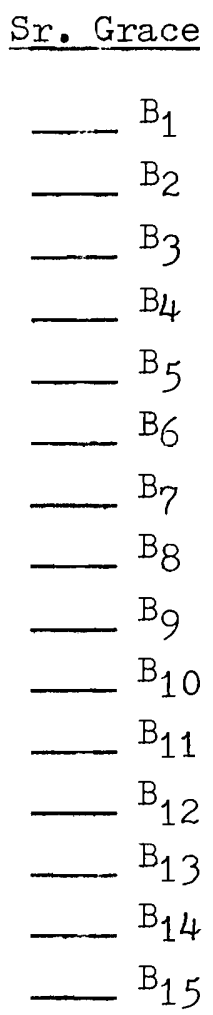

Sr. Monica

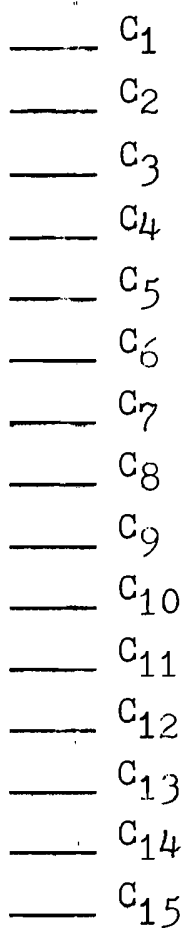

*The names of these girls have been omitted as a matter of confidentiality. 
A SOGIOMETRIC MATRIX ANAIYSIS OF THE ACTUAL SOCIAI SITUATION OF THE RESIDENTIAI POPULATION

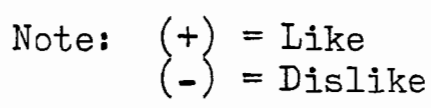

$A_{1} A_{2} A_{3} A_{4} A_{5} A_{6} A_{7} A_{8} A_{9} A_{10} B_{1} B_{2} B_{3} B_{4} B_{5} B_{6} B_{7} B_{8} B_{9} B_{0} B_{11} B_{12} B_{13} B_{14} B_{15} C_{1} C_{2} C_{3} C_{4} C_{5} C_{6} C_{7} C_{8} C_{9} C_{10} C_{11} C_{12} C_{13} C_{14} C_{15}$ $A_{1} 1+1+++++-1+1+1-1+1+1+1+1-1+1+1+1-101+-1-1+1++1-1+1+-1-1-1+1-1$ $\mathrm{A}_{2}+\mathrm{C}++++-+++++-++++-+-2+-+-2-++-++++-+++++++$ $\mathrm{A}_{3}+-\mathrm{C}+\mathrm{+}+\mathrm{+}+\mathrm{+}+-+++++-+++1+++-+++++++++++$

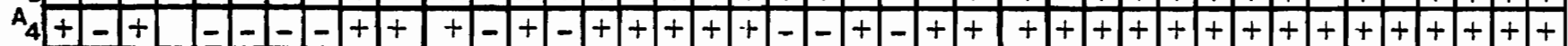

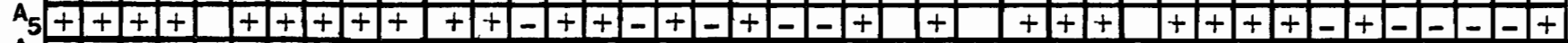

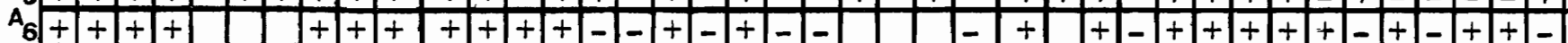

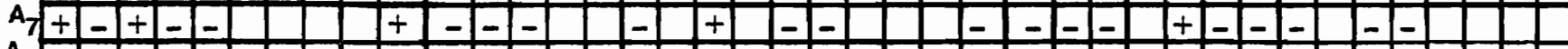

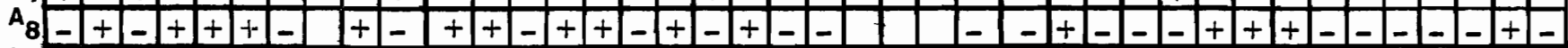

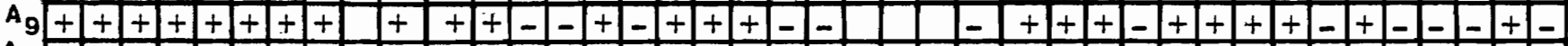

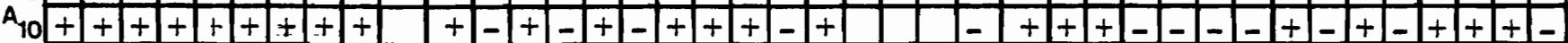

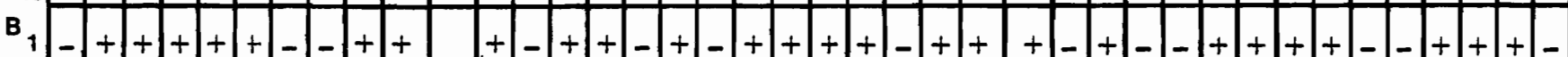

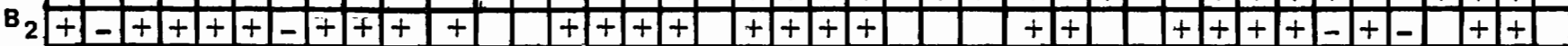

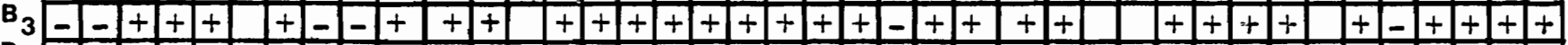

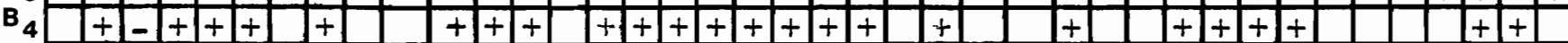

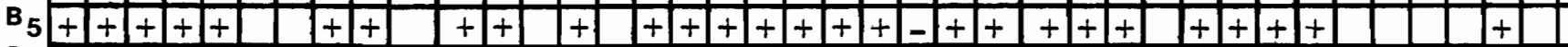

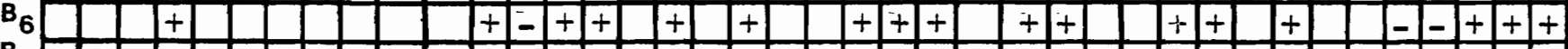

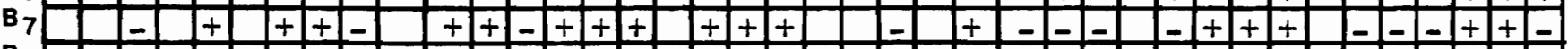

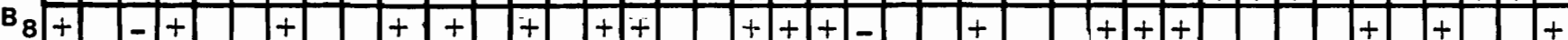

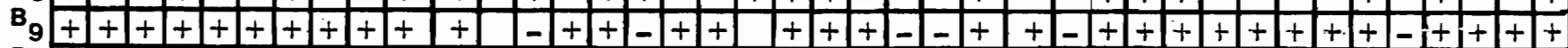

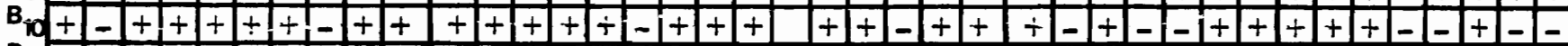

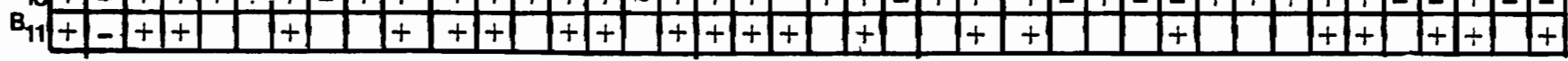




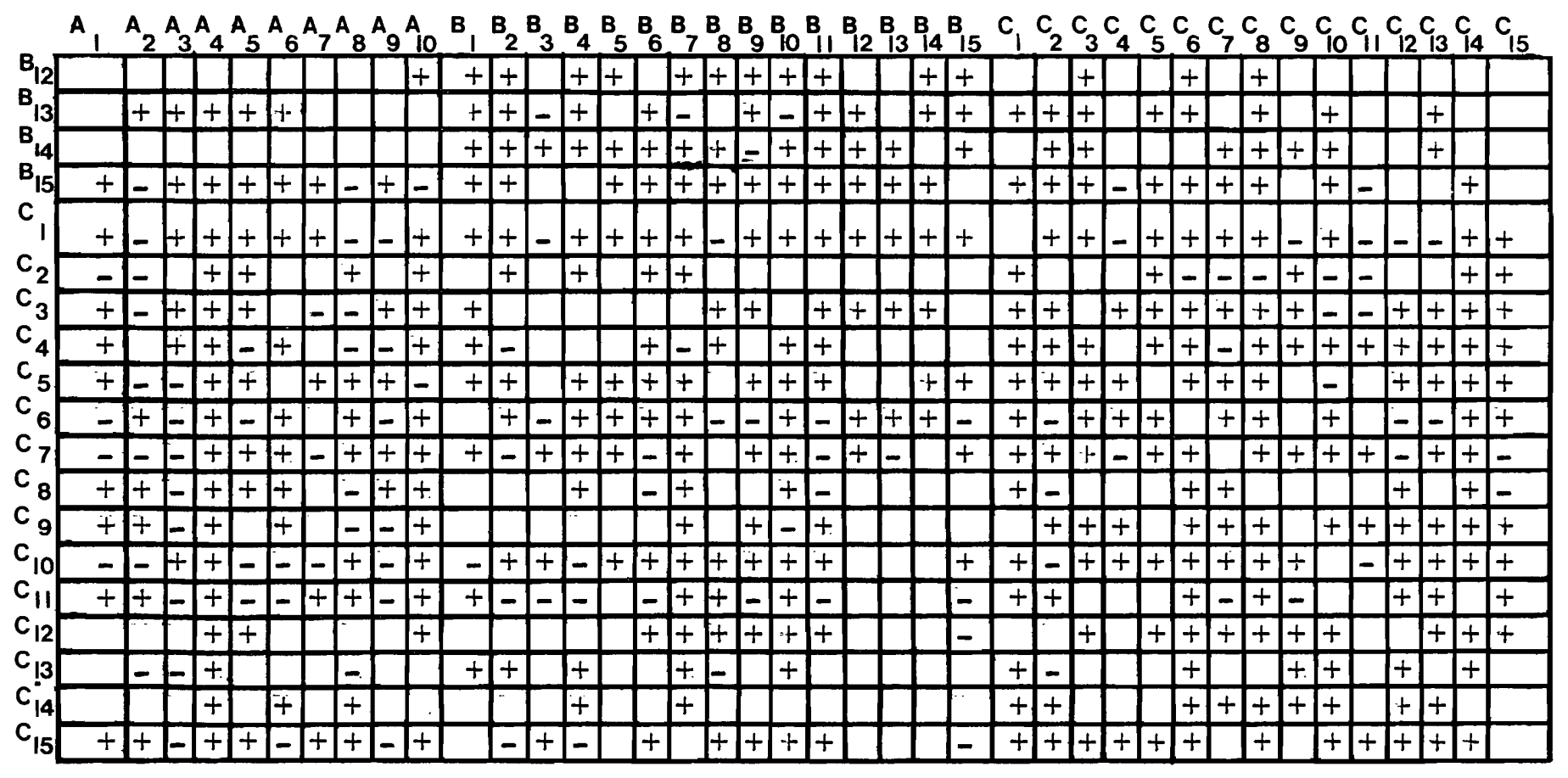




\title{
A SOCIOMETRIC MATRIX ANAIYSIS OF THE PERCEIVED SOCIAL
} SITUATION OF THE RESIDENTIAI POPULATION

\begin{abstract}
Note: $(+)=$ Iike
$(-)=$ Dislike
\end{abstract}

$A_{1} A_{2} A_{3} A_{4} A_{5} A_{6} A_{7} A_{8} A_{9} A_{10} B_{1} B_{2} B_{3} B_{4} B_{5} B_{6} B_{7} B_{8} B_{9} B_{10} B_{11} B_{12} B_{13} B_{14} B_{15} C_{1} C_{2} C_{3} C_{4} C_{5} C_{6} C_{7} C_{8} C_{9} C_{10} C_{11} C_{12} C_{13} C_{14} C_{15}$

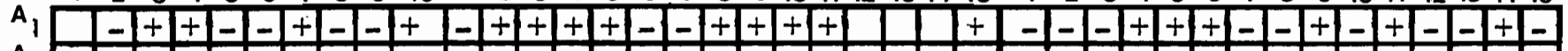

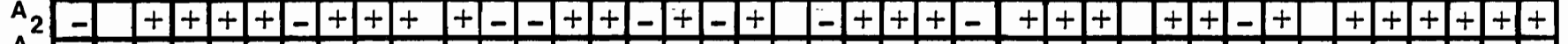

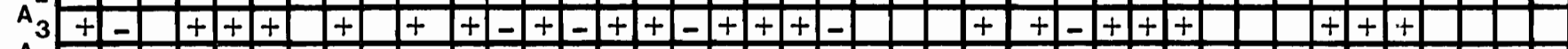

$\mathrm{A}_{4}++++++-+++++++++++++-+_{+}+++++++++++++++++++++$

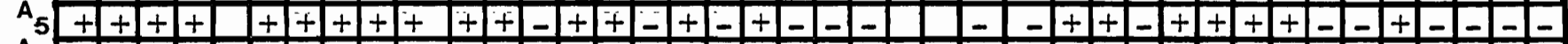

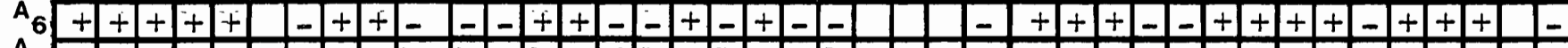

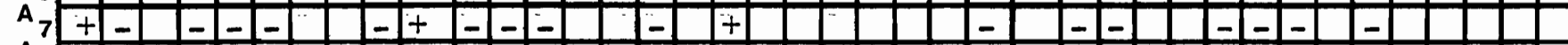

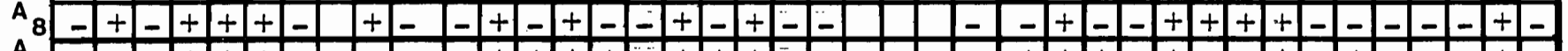

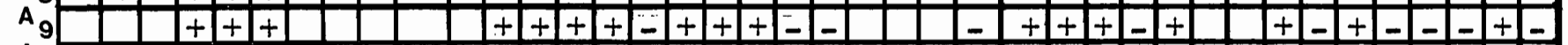

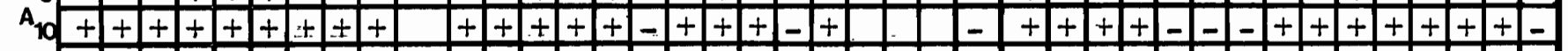

$\mathbf{B}_{1}++++++--+++2+-2++-++++++-++++2+++++++++++++$

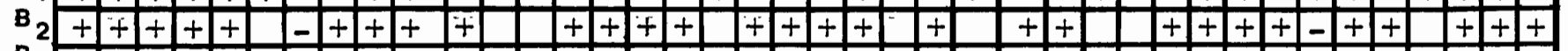

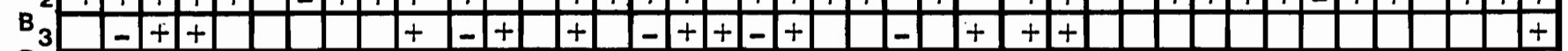

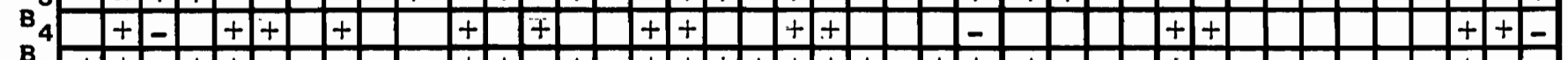

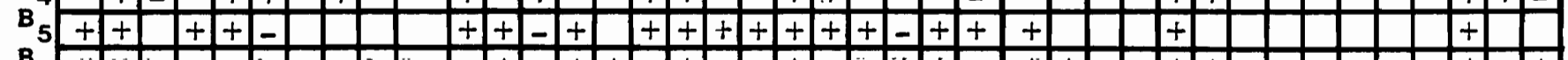

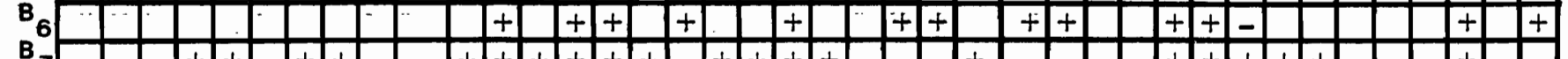

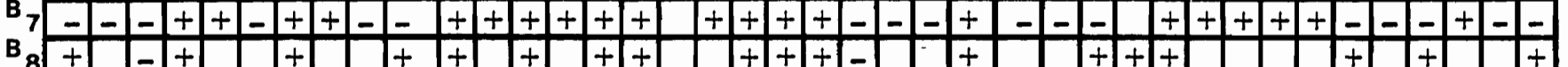

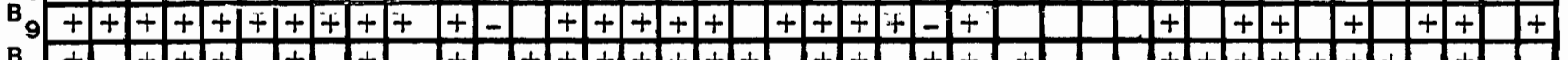

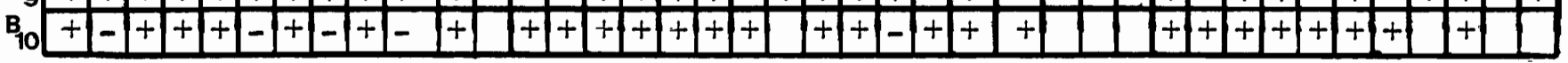




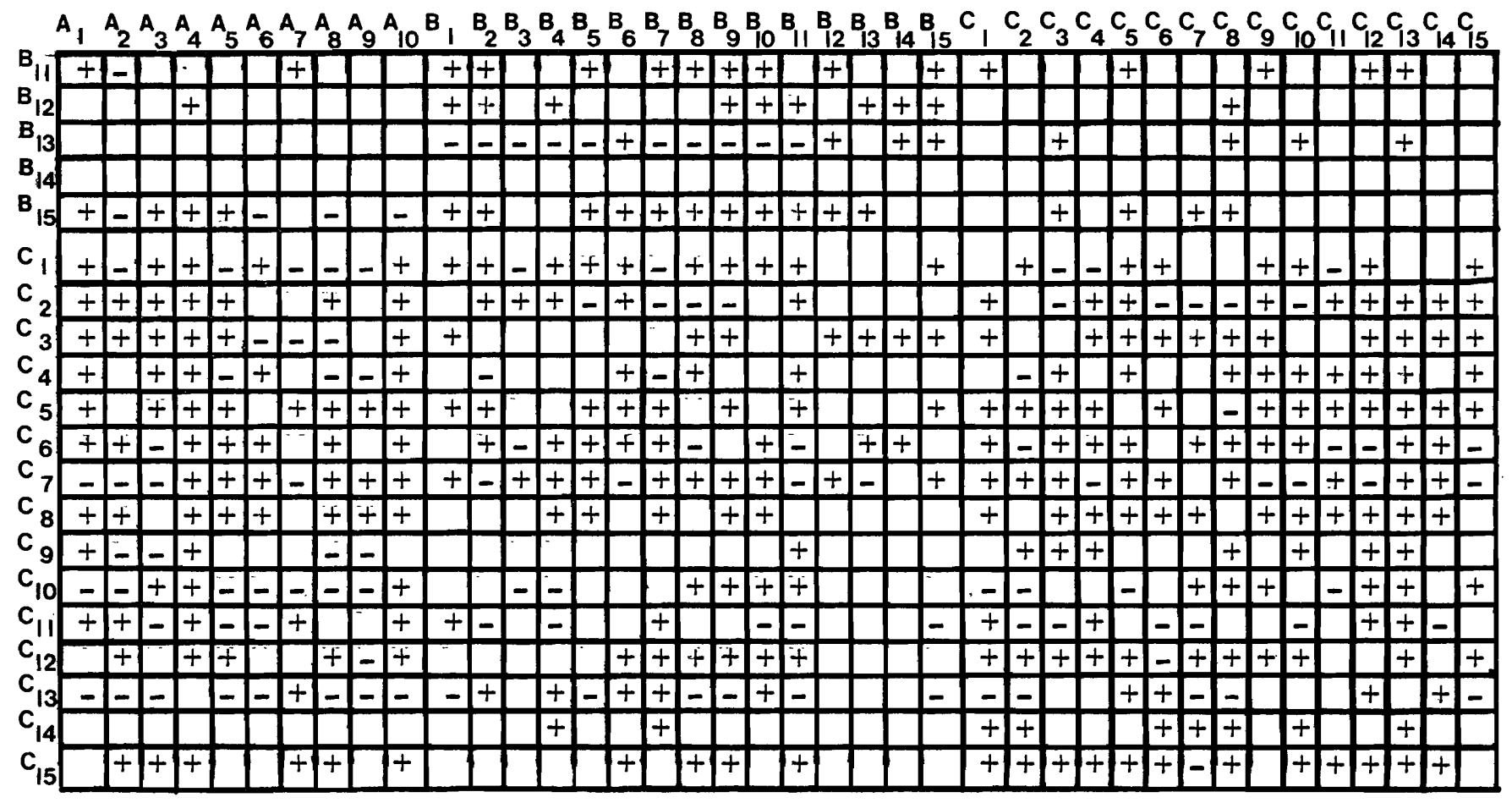

